IZA DP No. 10197

The Anatomy of Behavioral Responses to Social Assistance When Informal Employment Is High

Marcelo Bergolo

Guillermo Cruces

September 2016 


\title{
The Anatomy of Behavioral Responses to Social Assistance When Informal Employment Is High
}

\author{
Marcelo Bergolo \\ IECON-UDELAR, \\ CEDLAS-FCE-UNLP and IZA
}

Guillermo Cruces

CEDLAS-FCE-UNLP, CONICET and IZA

\section{Discussion Paper No. 10197 \\ September 2016}

\author{
IZA \\ P.O. Box 7240 \\ 53072 Bonn \\ Germany \\ Phone: +49-228-3894-0 \\ Fax: +49-228-3894-180 \\ E-mail: iza@iza.org
}

\begin{abstract}
Any opinions expressed here are those of the author(s) and not those of IZA. Research published in this series may include views on policy, but the institute itself takes no institutional policy positions. The IZA research network is committed to the IZA Guiding Principles of Research Integrity.

The Institute for the Study of Labor (IZA) in Bonn is a local and virtual international research center and a place of communication between science, politics and business. IZA is an independent nonprofit organization supported by Deutsche Post Foundation. The center is associated with the University of Bonn and offers a stimulating research environment through its international network, workshops and conferences, data service, project support, research visits and doctoral program. IZA engages in (i) original and internationally competitive research in all fields of labor economics, (ii) development of policy concepts, and (iii) dissemination of research results and concepts to the interested public.
\end{abstract}

IZA Discussion Papers often represent preliminary work and are circulated to encourage discussion. Citation of such a paper should account for its provisional character. A revised version may be available directly from the author. 


\section{ABSTRACT}

\section{The Anatomy of Behavioral Responses to Social Assistance When Informal Employment Is High*}

The disincentive effects of social assistance programs on registered employment are a first order policy concern in developing countries. Means tests determine eligibility with respect to some income threshold, and governments can only verify earnings from registered employment. The loss of benefit at some level of formal earnings is an implicit tax that results in a strong disincentive for formal employment. We study an income-tested program in Uruguay and extend previous literature by developing an anatomy of the behavioral responses to this program. Our identification strategy is based on a sharp discontinuity in the program's eligibility rule and uses information from the program's records, social security administration data, and a follow-up survey. First, we establish that beneficiaries respond to the program's incentives by reducing their levels of registered employment by about 8 percentage points. Second, we find the program induces a larger reduction of formal employment for individuals with a medium probability to be a registered employee, suggesting some form of segmentation - those with a low propensity to work formally do not respond to the financial incentives of the program. Third, we find evidence that the fall in registered employment is due to a larger extent to an increase in unregistered employment, and to a lesser extent to a shift towards non-employment. Fourth, we find an elasticity of participation in registered employment of about 1.7, implying a deadweight loss from the behavioral responses to the program of about 3.2\% of total registered labor income.

JEL Classification: H31, I38, J22, O17

Keywords: $\quad$ welfare policy, labor supply, registered employment, labor informality

Corresponding author:

Marcelo Bérgolo

Department of Economics

Universidad de La República

1375 Joaquín Requena

Montevideo 11200

Uruguay

E-mail: mbergolo@iecon.ccee.edu.uy

\footnotetext{
* We would like to thank Leonardo Gasparini, Marco Manacorda and Andrea Vigorito for their valuable input at different stages of this project. We are also grateful to Mariano Bosch, David Card, Emily Conover, Paul Gertler, Corrado Giulietti, Hilary Hoynes, Clément Imbert, Hugo Jales, Stefan Staubli, Darío Tortarolo, Andrea Weber and Josef Zweimüller for comments on earlier drafts and presentations, as well as seminar participants at the $9^{\text {th }}$ IZA/World Bank Conference on Employment and Development (June 2014), the European Association of Labour Economists $26^{\text {th }}$ Annual Conference (September 2014), ORT University seminar (October 2014), IECON seminar (July 2015), the IZA/CEPR $17^{\text {th }}$ European Summer Symposium in Labour Economics (September 2015), the 2015 Northeast Universities Development Consortium (NEUDC) Conference (November 2015), and the SEU Annual Conference (December 2015). G. Cruces would like to thank the generosity of CEGA at U.C. Berkeley, where part of this work was carried out while visiting in January 2015. Matías Giaccobasso provided excellent research assistance. A previous version of this paper circulated under the title "Work Incentives and Welfare Programs. Evidence on Real and Reporting Effects in Uruguay."
} 


\section{Introduction}

The incentive effects of social assistance programs on labor supply have been at the center of the debate on economic policy in developed countries. In developing and middle income countries, besides the effects of these programs on labor supply, the potential disincentives to registered (or formal) employment is an additional concern because labor market informality is a major policy issue, for at least four reasons. First, the underground sector in developing economies represents on average a third of the official economy (Schneider, Buehn, and Montenegro, 2010) Second, access to social insurance for workers and their families is typically tied to formal jobs (Levy, 2008; Levy and Schady, 2013). Third, unregistered employment entails lower reporting of income and thus lower payroll and income tax collection. Fourth, a larger informal sector could lead to a variety of market distortions and efficiency losses, and can limit productivity growth and economic development (La Porta and Shleifer, 2014; Meghir, Narita, and Robin, 2015).

Empirical research on developed countries includes a sizable literature on the welfare impact of these labor supply incentive effects, their underlying mechanisms, their magnitude, and the groups of the population most affected by them. These studies have generated a series of anatomies of the incentive effects of social assistance programs on labor supply. The anatomies have, in turn, provided key inputs used in the design of welfare reforms to minimize efficiency losses (Scholz and Levin, 2001). A growing body of empirical literature has examined these effects in developing and middle income countries, motivated in part by the widespread implementation of social assistance programs over the last two decades. ${ }^{1}$ The debate in these countries, and in particular in Latin America (Levy, 2008; Levy and Schady, 2013), has focused primarily on disincentives to registered employment. These disincentives are unintended consequences of the programs and are largely related to the difficulties of targeting in contexts of high labor informality and poor enforcement of tax and labor regulations. ${ }^{2}$ To determine eligibility for social assistance programs, policymakers often rely on earnings from registered employment, which are reported on a periodic basis to tax and social security authorities. Since governments can only verify earnings from registered employment, the income test in means-tested programs implies that benefits are withdrawn above a certain threshold of formal income, which generates a discrete fall in households' disposable income at the cutoff level. This implicit taxation at the threshold - a notch in beneficiaries' budget constraints - creates a strong disincentive for registered

\footnotetext{
${ }^{1}$ In the literature on welfare systems in developing countries, these types of programs are known as conditional cash-transfer programs (CCTs). See Fiszbein and Schady (2009) for a review of social assistance programs in Latin America and the Caribbean, and for an evaluation of their impact on family consumption patterns, education, child labor and health, among other outcomes.

${ }^{2}$ Gasparini and Tornarolli (2009) estimate that approximately 56 percent of wage earners in Latin America are informal workers - i.e., there are no payroll taxes and social security contributions associated to these jobs, and thus workers do not receive social insurance benefits such as health and old-age pension coverage.
} 
employment, since individuals can keep the benefit (or gain eligibility) by lowering their verifiable earnings from registered employment, either by reducing hours worked in formal employment (intensive margin response) or by exiting from registered employment (extensive margin response).

There is already ample evidence of social assistance programs inducing reductions in registered employment (see Bosch and Manacorda 2012 for an comprehensive review). Most existing studies, however, document negative impacts on formal work from different programs but do not characterize these effects and the programs' welfare implications in full. We attempt to fill this gap in the existing literature by developing an anatomy of the effects of a social assistance program in the context of widespread labor market informality. We characterize the extensive margin behavioral responses of recipients of an income-tested program in Uruguay, the Asignaciones Familiares-Plan de Equidad (hereafter, AFAM). ${ }^{3}$ We construct the anatomy of the program's effects along four dimensions. First, we establish whether beneficiaries respond to the program's incentives by reducing their levels of registered employment, as predicted by the theory.

Second, we establish empirically which groups of individuals are the most responsive to these incentives, and most importantly, we illustrate the heterogeneity of responses by studying how the effects vary across the distribution of individuals' propensities to be employed formally. Previous studies have focused on mean effects, or on heterogeneous effects according to socio-economic and demographic characteristics, but a fuller picture - and a key input for policy design - requires the analysis of the distribution of effects beyond the mean impact.

Third, we analyze the margins along which individuals respond to the program's financial incentives. Finding an impact on formal employment is an important result because it sheds light on the relevant margins of response in developing countries, but it is also necessary to decompose this main effect in terms of the impact on labor supply and informality. The cash benefit might induce a reduction in labor supply when individuals drop out of the labor force. Alternatively, individuals might keep working, but they might do so as informal workers to reduce verifiable income (i.e., earnings from registered employment) and avoid the loss of the benefit.

Finally, we quantify the responses to the program's financial incentives by computing the elasticity of labor force participation as a function of the implicit tax on registered employment induced by the program. While the impact of the informality effects on tax collection can be informative (see for instance Bergolo and Cruces, 2014), measurement of the relevant elasticities is crucial for a full welfare analysis that quantifies the efficiency

\footnotetext{
${ }^{3}$ While AFAM's design implies a potential effect on the intensive margin of labor supply, we concentrate on the extensive margin of response. Unlike Kleven and Waseem (2013) or Kline and Tartari (2016), we are unable to measure (local) labor supply effects at the intensive margin since our data does not cover hours worked nor earnings (see Section 4).
} 
costs of social assistance programs. We estimate the elasticity of participation in registered employment and use it as an input to compute the efficiency losses from the program, and the potential welfare gains from changes in its design.

Our empirical approach exploits a specific feature of the AFAM program's eligibility rules. Households that apply to the program must first pass an income test based on household members' earnings from registered employment as reported to tax and social security authorities. When household income is below a certain threshold, the household is subject to a proxy means test and assigned a score from a detailed set of socio-economic and demographic characteristics. The score is based on the household's predicted poverty levels as a function of the given information. The household is deemed eligible for the program only if its score is above a predetermined threshold. Authorities followed this regulation very closely, creating a sharp discontinuity in the likelihood of participation at the cutoff point. Because the eligibility score is based on a non-linear combination of a large set of household characteristics collected before participation in the program, and neither the algorithm nor the level of the threshold were disclosed by the authorities, applicants were unable to manipulate the assignment rule to gain entry into the program. This sharp discontinuity in the AFAM assignment rule provides a credible identification strategy to analyze the applicants' behavioral responses to the program's financial incentives. We rely on a regression discontinuity design which amounts to a local randomized experiment that compares labor market outcomes for adults in applicant households just above (i.e., the treatment group) and just below (i.e., the comparison group) the program eligibility threshold (Hahn et al., 2001; Lee and Lemieux, 2010).

Our empirical analysis relies on three matched sets of information linked through unique individual identifiers. The AFAM administrative records contain baseline socio-economic and demographic information from the program's application process. We have information for all individuals in households that applied to the program (whether they gained entry or not) during the period January 2008 to September 2010. We use national identification numbers to match the adults in the applicant households to their registered employment work histories, constructed from data provided by Uruguay's social security administration (SSA), which is responsible for collecting and recording payroll taxes and social security contributions from registered employment. This method provides a rich longitudinal database that covers all spells of registered employment for individuals in the program for the period January 2005 to December 2012. As is usually the case with social security administrative records in developing countries, this data only covers formal (or registered) employment spells; thus, it is not possible to determine whether indinviduals not engaged in formal employment are not working or engaged in informal (or unregistered) employment based on this data alone. We overcome this limitation by matching the administrative records with a detailed follow-up survey of eligible and ineligible households that applied to AFAM, which 
was designed and implemented specifically for the evaluation of the impact of the program. This combined data provides detailed information on registered employment, informal work and non-employment for each household member in eligible and ineligible households.

The results can be summarized as follows. First, as predicted by the theory, beneficiaries respond to the program's incentives. We find a reduction of registered employment for adults in eligible households of about 8 percentage points, a fall of 15 percent compared to adults in households below the eligibility score. This reduction is larger for household heads, for women, for adults in single-headed households, and for younger individuals.

Second, we find a marked heterogeneity in these effects. We establish each individual's propensity to work as a registered employee as a function of her observable baseline characteristics and pre-application registered employment histories. We find that the program has a stronger negative effect for individuals with a medium probability to be a registered employee, a smaller negative and significant effect for those with a higher probability, and an even smaller but not significant effect for those with a low probability. These results suggest some form of segmentation among potential beneficiaries, in which those with a low probability to work formally do not respond much to the financial incentives of the program because they have limited opportunities to work as registered employees to begin with, independent of AFAM eligibility. The opposite is true for those with a high propensity to work formally: they are not affected by the program's disincentive for registered employment, probably because they will work formally regardless. The group with the middle propensity to be formally employed seems to be the one closer to the margin of choice between formal and informal employment, and thus individuals in this group are those who react the most to the new incentives.

Third, the evidence from the matched follow-up household survey data is very informative about the relevant margins of adjustment. Our results indicate that the observed reduction in registered employment induced by the program can be attributed to a larger extent (about two thirds) to an increase in unregistered employment, and to a lesser extent (about one third) to a shift towards non-employment. These results are compatible with the presence of both an income effect and a shift towards informal employment induced by the means test, with the latter effect accounting for a larger share of the response.

The fourth and final dimension of our anatomy of behavioral responses to AFAM required the quantification of the program's effects in terms of elasticities. Our results indicate an average elasticity of participation in registered employment with respect to the net-ofparticipation in registered employment tax rate of 1.689. This implies that a reduction of 1 percent in the net-of-tax share of income that individuals are permitted to keep reduces registered employment by about 1.7 percent. Consistent with the estimated effects of the program for the different subgroups, the elasticity is substantially higher (about 2.6) for those with a medium propensity to work as a registered employee, compared to an elasticity 
of 1.67 for those with a low propensity to work formally and an elasticity of 0.76 for those in the group with a high propensity to work formally. These results reflect the fact that the middle group is the most responsive to changes in the tax and transfer schedule. Since the informality margin accounts for two thirds of the effect, a back of the envelope calculation indicates a participation elasticity of about 0.56 , in line with the results in the literature for developed countries, with about 1.14 corresponding to the formal-informal margin of adjustment. Using this elasticity and the implicit tax rates, we find that the behavioral responses to AFAM imply a deadweight loss (or efficiency cost) of about 3.2 percent of total labor income. As a benchmark, Eissa, Kleven, and Claus Kreiner (2006) find that the welfare gains from extensive margin changes induced by the Earned Income Tax Credit and the 1986 tax reform in the United States range from 3.27 percent to 7.64 percent of wage income. The efficiency cost from AFAM for the representative agent thus seems significant but not exceedingly large.

Our paper is primarily related to a large body of literature on the effects of social assistance programs on labor market behavior. A large body of research for developed economies has studied how individuals respond to welfare policies, in particular, on the labor supply margin (see for instance the surveys in Moffitt, 2003, Ben-Shalom et al., 2011). The responses along additional margins, such as registered and unregistered employment, have received less attention in the literature on developed countries, although there is some evidence that programs that subsidize work based on declared earnings, such as the EITC in the United States, induce low income individuals to shift hours from informal to registered employment (Gunter 2013), in particular among the self-employed (LaLumia, 2009). As discussed above, a series of studies based on credible identification strategies have analyzed the labor market responses to conditional cash transfer programs in developing countries, specifically in regards to labor supply (Alzua et al., 2012, Banerjee et al., 2015, Imbert and Papp, 2015), registered employment (Amarante et al., 2011), and choices between formal and informal work (Garganta and Gasparini, 2015). We provide additional evidence to confirm that individuals in developing countries respond to the tax and transfer schedule in their labor market behavior (Behrman, 1999, Levy, 2008, Meghir, Narita, and Robin, 2015), thus contributing to studies of policy interventions that use quasi-experimental designs to infer the extent to which individuals move across formal and informal sectors (Bosch and Campos-Vazquez, 2014). We add to this literature by separating the effects along the employment and formal/informal margins. Araujo et al. (2016)'s study of the Bono Solidario in Ecuador also relies on matched administrative and household survey data and disentangles these margins, finding that most of the effect is due to movements from formal to informal work, although these results are based on data for women only. Our evidence is suggestive that both margins are at play, at least when considering the population of low income adults in Uruguay. Our analysis also adds to the literature in terms of the heterogeneity of effects. 
While we find, as others have (e.g., Amarante et al., 2011, Araujo et al., 2016), that women react more to the program's incentives, we extend the analysis to subgroups of the population according to their propensity to work as formal employees. Our results uncover significant heterogeneity along this dimension. These findings are relevant to the design of these types of programs. For instance, specific incentives or conditionalities that are costly to monitor (such as minimum working hours requirements) may only be worthwhile for those who might be expected to react to the program's incentives. Finally, our study also contributes an innovation to the existing literature on developing countries by computing the elasticity of participation implied by the program's financial incentives and deducing the welfare effects of the behavioral responses to the policy.

This study is also related to a growing literature that uncovers the distribution of responses to social assistance programs. The importance of documenting impacts beyond the mean has been illustrated by Bitler, Gelbach, and Hoynes (2006), Eissa, Kleven, and Kreiner (2008) and Bargain and Doorley (2011), among others. As stressed by Eissa, Kleven, and Kreiner (2008), welfare analysis varies substantially when it allows for heterogeneous elasticities for different groups, and as we discussed in the previous paragraph, the design of programs in developing countries can also be optimized by taking this heterogeneity into account.

Our results add to a body of evidence on the participation elasticity of low-income groups. First, we provide novel results based on credible and well-identified quasi-experimental evidence, which is still relatively scarce (Chetty et al., 2013), especially for developing and low income countries. Second, our analysis is the first for a developing country (that we are aware of) that computes the elasticity of participation in registered employment, a key margin of adjustment. As discussed above, based on very different populations and very different tax and transfer systems and reforms, our estimate of the average participation elasticity is within the range of previous results in the literature for developed countries (see for instance the review by Eissa, Kleven, and Claus Kreiner, 2006).

Finally, our results illustrate how a full analysis of the anatomy of responses to a social assistance program can inform the policy debate about the design of optimal redistributive programs in developing countries, just as the analysis of similar programs in developed countries provided valuable inputs for welfare reform (Saez, 2002, Laroque, 2005). The first generation of conditional cash transfer programs targeted at very poor rural areas was shown not to have sizable effects on recipients' labor market outcomes (Alzua, Cruces, and Ripani, 2012; Banerjee et al., 2015), but these programs are being scaled-up and their coverage broadened to urban areas, where their compatibility with registered work becomes a first order policy concern. There is thus an even stronger case for establishing anatomies of this type, as they can serve as an input for the design for the next generation of programs in developing countries. 
The paper proceeds as follows. Section 2 describes the context of Uruguay's social protection system, the AFAM program and its rules and characteristics. Section 3 discusses the expected effects from AFAM on the participants' labor market outcomes. Section 4 describes the data sources and the construction of the datasets we employ in our empirical analysis. Section 5 discusses the empirical approach and the details of the regression discontinuity design which is the basis of our identification strategy. Section 6 presents the main results on registered employment responses to the program, Section 7 establishes its distributional effects in terms of participants' propensities to work formally, and Section 8 decomposes the main effects in informality and non-employment responses. Finally, Section 9 computes the elasticity of participation in registered employment, and the efficiency costs of the program's disincentives. Conclusions follow.

\section{Background: The AFAM Program and its Charac- teristics}

\subsection{Social Insurance and Social Assistance Programs in Uruguay}

Uruguay has one of the oldest and most developed social protection systems in Latin America. This system follows a contributive, European Bismark-type model, where access to most welfare and social insurance programs is linked to registered employment and financed through payroll taxes and contributions from both employers and employees. Registered (or formal) employees are those working in firms which reported them to the Social Security Administration (henceforth, SSA) and for which they paid the relevant taxes and contributions. Registered (or formal) employees are those working for employers that have reported them to the Social Security Administration (henceforth, SSA) and for whom relevant taxes and contributions are paid. Formal status makes these workers eligible for social insurance benefits such as health and unemployment insurance, sickness and disability benefits, maternity leave, family allowances, and old age pensions.

As in many middle-income countries, enforcement of labor market regulations is far from universal. There is widespread non-compliance with social insurance regulations and evasion of payroll taxes is quite pervasive. This means that a substantial fraction of employees are not registered with the SSA and thus not covered by social insurance benefits. Unregistered (or informal) workers in Uruguay represented about a quarter of the total of salaried employees in the decade of 2000 (Gasparini and Tornarolli, 2009), and about 55 percent among AFAM beneficiaries in 2008, when the program was implemented (calculated using microdata from Uruguay's national household survey). In addition, about a quarter of AFAM beneficiaries aged 18-64 years old were out of the labor force in 2008, thereby without coverage of social 
insurance benefits.

A severe economic crisis hit Uruguay in 2002-2003. Unregistered workers lacked access to the risk-coping mechanisms provided by the SSA, and they were especially hit by this crisis. As a response to this increase in the economic vulnerability of the population, the government launched a series of reforms to the social protection system to expand the coverage of social assistance programs. ${ }^{4}$ In particular, the government launched a temporary social assistance program called Plan de Atención Nacional a la Emergencia Social (PANES) in 2005. This program, which targeted the poorest 10 percent of households in Uruguay, provided a cash transfer conditional on a series of health and education controls for children in beneficiary households. ${ }^{5}$ This emergency program was replaced in January 2008 by a new system of family allowances (Law 18.227), the AFAM program, as part of a broader progressive tax and transfer system reform.AFAM, targeted at poor households with children, became the most important social assistance program in Uruguay in terms of both coverage and magnitude of the cash benefits provided.

AFAM was implemented as a means-tested conditional cash transfer (CCT) program targeted to households in vulnerable socioeconomic conditions with either pregnant women or children under 18 years old. The program's monetary transfers are conditional to health checks (both for pregnant women and children) and school attendance for children in beneficiary households. At the beginning of 2008, AFAM covered 275,000 children. In 2014, the program reached nearly 370,000 children, about 42 percent of all children under the age of 18 in Uruguay. The budget for the cash transfer component of program in 2013 was just over 0.35 percent of the GDP. In terms of its relative coverage and its budget as a proportion of GDP, AFAM was among the largest programs of its type in Latin America. ${ }^{6}$

\subsection{Eligibility Process: Assignment Rule and Enrollment}

To participate in the program, households were required to complete an application form in which they provided an array of socio-economic information, including household characteristics (address, housing conditions, dwelling type, characteristics and quality, ownership, access to water and sanitation, etc.), and detailed information about household members, such as their national identification number, education levels, labor force participation, and income levels.

\footnotetext{
${ }^{4}$ Those reforms were in line with a number of policies implemented during the decade of 2000 by many countries in Latin America with the purpose of expanding social protection and non-contributive programs (Fiszbein and Schady, 2009).

${ }^{5}$ See Manacorda, Miguel, and Vigorito (2011) for more details on the goals, components and implementation of PANES.

${ }^{6}$ For instance, Brazil's Bolsa Familia reached almost 24 percent of the country's population, and had a budget of 0.4 percent of GDP in 2006, whereas Mexico's Progresa/Oportunidades covered 20 percent of the population with a budget of 0.4 percent of the GDP in the same year (Bastagli, 2009).
} 
After completing the application form, program eligibility was determined in two steps. First, the household was subject to an income test: the per-capita income of the household had to be below a predetermined threshold. Crucially, the household's income level was computed by combining the self-reported information on the application form and SSA administrative records (matched through each household member's national identification number), which include the individual's earnings from registered employment as reported to the tax and social insurance authorities by employers, and from other transfer programs. The SSA recorded the applicants' household income as the highest between the self-declared income in the application form and the household's total income as reflected in the administrative records. In 2014, the threshold was set at a monthly level of UYU 4,517 (around USD 196, using June 2014's exchange rate) for households with up to two members (about 50 percent of the monthly national minimum wage), and UYU 5,570 (about USD 242) for households with more than two members.

Conditional on passing the income test, households entered the second step for eligibility, a proxy means test. This test relied on an eligibility score calculated by program officials and based on the large set of socioeconomic characteristics provided by the household in the application form. The score's algorithm was devised in consultation with social policy experts and academics, and its details were never disclosed to the public. ${ }^{7}$ Households with income below the threshold of the income test and with an eligibility score above a predetermined level were admitted to the program.

AFAM's eligibility rules have a very important implication for our analysis. The presence of a cutoff level and the strict enforcement of the program's rules by authorities generates a strong discontinuity in program participation rates at the cutoff point. Figure 1 plots the proportion of applicant households, both those deemed eligible or ineligible through the application process, that were enrolled into the program at any given point in time since its implementation in 2008, as a function of the eligibility score (see Section 4 for a description of the samples). We standardized the eligibility score for the figures presented in this paper: the eligibility cutoff is centered at zero, so that eligible households have positive scores and ineligible households have negative scores. The figure clearly shows a sharp discontinuity in the probability of participation in AFAM, which is about 96 percentage points higher

\footnotetext{
${ }^{7}$ The eligibility score was devised by researchers at the Universidad de la Republica (UDELAR) in Montevideo, Uruguay (see Amarante and Vigorito, 2011). The algorithm is based on the coefficients of a probit model in which the dependent variable is equal to one if households were below the first quintile of per capita income, and zero for those above the first quintile but below the median of per capita income. The original model was estimated by means of a fully saturated function of household variables drawn from the ECH national household survey. The resulting coefficient estimates were used to predict the score for each applicant household based on data from the application form, and the eligibility thresholds were different for residents of Montevideo, the country's capital, and the rest of the country, to reflect differences in living costs. The computation of the score and the monitoring of household income and conditionalities was a responsibility of Uruguay's Social Security Administration, the Banco de Previsión Social (BPS), and the Ministry of Social Development (Ministerio de Desarrollo Social, henceforth MIDES).
} 
for those households with a score just above the eligibility threshold than for those just below it. This plausible exogenous variation in the assignment into the program due to its eligibility rule is the basis of our identification strategy. Our empirical analysis is based on the comparison of the behavior and outcomes of individuals in eligible households - i.e., those with an eligibility score above the threshold - and individuals in ineligible households - i.e., those who applied with a score below the cutoff point - as discussed in detail in Section 5.1 below.

\subsection{Level and Duration of the AFAM Monetary Benefits}

Households selected to participate in the program are entitled to a monthly cash transfer. The level of the transfer depends (non linearly) on the number of children under the age of 18 , and on the number of children attending secondary school. ${ }^{8}$ The transfer is larger for those in secondary school so as to encourage older children to attend and complete their schooling.

The total benefit granted to a household can be calculated as follows:

$$
A F A M= \begin{cases}0 & \text { if } Y^{F}>T \\ \beta \times(\text { Kids0to17 })^{0.6}+\delta \times(\text { HighSchoolKids })^{0.6} & \text { if } Y^{F} \leq T\end{cases}
$$

where Kids0to17 represents the number of children below 18 years old, HighSchooKids is the number of children that attend secondary school, $\beta$ and $\delta$ are the transfers levels, and $\mathrm{T}$ the income test's threshold. These amounts are adjusted periodically according to the evolution of the official Consumer Price Index. For instance, in 2014 the transfers were set at $\beta=\mathrm{UYU} 1,096$ (USD 48) and $\delta=\mathrm{UYU} 470$ (USD 20). The average income transfer for a beneficiary household with two children in 2014 was UYU 2,374 (USD 103), about 25 percent of the monthly national minimum wage.

While households participate in the program, they receive the full transfer according to the program's rules as long as their monthly income (from all sources) is lower than the predetermined income eligibility threshold. If a household's income exceeds this threshold, it becomes ineligible for the program and loses the entire AFAM benefit. In practice, however, the income test is only applied every two months and is based only on verifiable sources of income, i.e., labor income from registered employment, retirement pensions or other government transfers recorded in the SSA administrative records. Our analysis of the program's administrative records for the 2008-2010 period indicates that only about 0.5 percent of beneficiaries left the program for this reason. Households were also disqualified and made to exit the program when they failed to meet the mandatory health and school attendance checks for children. According to AFAM administrative records, less than 0.1 percent of the bene-

\footnotetext{
${ }^{8}$ There is also an extra component for disabled children.
} 
ficiaries left the program for this reason during the 2008-2010 period. ${ }^{9}$ Finally, households also exited the program when all of their children reached 18 years old.

\section{Expected Effects of AFAM on Labor Market Behav- ior}

Economic theory predicts that a means-tested transfer program such as AFAM could affect the labor market behavior of potential beneficiaries along two extensive margins of choice (Bosch and Manacorda, 2012). We first discuss how it may change the decisions of workingage eligible individuals in terms of whether to enter or exit the labor market, i.e. the labor force participation margin. ${ }^{10}$ It may also affect the decision to work as a formal or as an informal employee for both those who were employed and those who were not employed, i.e. the formal-informal employment margin.

\subsection{AFAM and the Labor Force Participation Margin}

AFAM's benefits and eligibility rules introduce strong financial incentives for individuals to reduce their labor force participation, as in the case of traditional welfare programs (see for instance, Moffitt, 2002). First, the income test entails an implicit tax on labor earnings, thus reducing labor supply through a substitution effect. The transfer also increases households' non labor income, inducing a negative income effect. Both effects reinforce the program's disincentive for labor force participation.

Besides these standard economic theory arguments based on the program's rules and benefits, the program's conditionalities might also induce changes in the labor force participation of adults. On the one hand, the requirement that children attend school might free up time that adults in the household previously spent on childcare. On the other hand, if conditionalities are effective in curbing child labor, the net effect of transfers on households' incomes is reduced, which might mitigate the program's potential disincentive for adult labor supply (Alzua et al., 2012).

\footnotetext{
${ }^{9}$ The school attendance condition was enforced beginning in the year 2013. To enforce this regulation, the government cross-checked the AFAM's beneficiary lists against school attendance records. Unfortunately, we do not have access to the program's administrative records for the period after 2010 and thus cannot evaluate the extent to which this enforcement measure affected AFAM participation among beneficiaries.

${ }^{10}$ In fact, AFAM's design implies that it might also affect the intensive margin of labor supply. Individuals in eligible households have a strong incentive to not exceed the income test's threshold level, since earnings from registered labor above this level would result in loss of the benefit (for beneficiaries) and in ineligibility (for non-beneficiaries considering applying to the program). This implies a discrete fall in households' incomes at the threshold, which generates a notch in their budget constraint (Kleven, 2016). At this notch, households could increase their disposable income by reducing hours worked as formal workers and thus reducing verifiable earnings from registered employment. Unfortunately, we are unable to measure labor supply at the intensive margin because our data does not cover working hours or earnings (see Section 4).
} 
The combination of these three channels implies that the overall effect of AFAM on adults' labor force participation is ambiguous from a theoretical point of view. However, we expect the negative response in labor force participation from the financial disincentive to be of first-order importance relative the more ambiguous incentives introduced by the conditionalities. First, as discussed above, it is not clear to what extent the government really enforced these conditionalities, at least during the period that we study. In fact, evidence from our follow-up survey suggests that about 40 percent of the beneficiaries were unaware of conditionalities being attached to the program (Bergolo et al., 2016). Manacorda, Miguel, and Vigorito (2011) also note that the conditionalities were de facto not enforced in the case of PANES, the program that preceded AFAM, because of the lack of coordination between public institutions. Second, school attendance is nearly universal for primary school children in Uruguay, and thus the child labor argument would only apply to teenagers and not to all children in the household. In fact, Amarante, Ferrando, and Vigorito (2013) did not find any evidence that PANES affected school attendance or child labor for children aged 14 to 17 .

\subsection{AFAM and the Formal-Informal Employment Margin}

As argued by Bosch and Campos-Vazquez (2014), there are two extreme theoretical approaches to model the presence of informal work in an economy. The traditional view, based on Harris and Todaro (1970), posits that informal workers are those rationed-out from scarce (and "good") formal jobs. Informality is thus considered to be a form of queuing that represents unemployment in disguise; in this model all workers prefer to be employed as formal workers - informality is not voluntary nor the result of an optimal choice from the worker. An alternative view, the sorting approach, advances that workers may choose to engage in informal employment because they place less value on the social insurance benefits tied to registered or formal jobs. They seek to avoid the related payroll taxes and contributions because, in the context of weak enforcement of tax and labor regulations, informal employment results in better pay, among other benefits (Maloney, 1999, 2004, Levy, 2008).

The first approach implies that all workers prefer formal jobs, while in the second perspective there is a continuum of individual preferences as well as a marginal worker who is indifferent between the option of formal or equivalent informal employment. In the context of segmented labor market models, a program such as AFAM would not have a discernible effect on the formality-informality margin, although it would increase welfare for informal

workers. In the context of sorting models, however, AFAM's benefits and eligibility rules alter the cost-benefit equation of formal work at the margin.

The available evidence indicates that programs of this type do have an impact on the formal-informal employment margin, which implies that at least part of the labor market 
corresponds to some form of sorting. The extent of these effects, however, is an empirical question. The answer depends on the context of each program, for instance, on the mass of workers at the margin of choice between formality and informality, on the program's generosity, and on the tax rates on registered earnings implied by the eligibility conditions (see Albrecht, Navarro, and Vroman, 2009; Bosch and Esteban-Pretel, 2012, Bosch and Campos-Vazquez, 2014). In the case of AFAM, the incentives might be substantial: the transfer is large relative to the earnings of typical beneficiaries, the program introduces a high implicit marginal tax rate for earnings from registered employment at the income test threshold, and the program's potential beneficiaries belong to groups that are more likely to engage in informal work. Moreover, it has been argued that there are two tiers of informality in the labor market (Fields, 2009), and we could thus expect differential effects among individuals with different propensities to work formally. This differential analysis constitutes a key feature of an anatomy of labor market responses to social assistance programs.

\subsection{Testable Implications of the Theory}

The purpose of the analysis that follows is to test a set of predictions about the effect of AFAM on registered employment in order to create an anatomy of these behavioral responses. The combination of the negative income effect of the transfer and the substitution effect induced by the income test based on registered labor earnings yields the prediction that (1) the total share of eligible adults in the population in registered employment should decrease as a consequence of the program. Moreover, the eligibility criteria, based on formal earnings, mostly affects the decisions made by individuals at the margin between formal and informal employment. As a result, (2) the total effect on registered employment should be higher among individuals with higher propensities to be employed as formal workers relative to potential beneficiaries with lower propensities to be employed as formal workers.

The incentives introduced by the program might alter decisions at different margins of behavior - individuals may drop out of the labor force (pure income effect), while others might transition from registered to unregistered jobs (formal/informal substitution effect). While we do not have information to fully test these transitions, we can still establish whether (3) the share of non-employed population increases and (4) the proportion of unregistered workers increases, which can illustrate the effects at these two margins of labor supply. ${ }^{11}$

A further component of an anatomy of behavioral responses is the quantification of these responses. We hypothesize that (5) the generosity of the income transfer and the large implicit tax incentives on formal earnings are substantial enough to induce a sizable response

\footnotetext{
${ }^{11}$ The prediction for informal employment is a priori ambiguous because of the transfer-induced negative income effect on infra-marginal workers and the positive formal-informal substitution effect due to the implicit marginal tax on registered employment. Consequently, a positive effect on unregistered employment indicates some adjustment on the formal-informal margin (Bosch and Manacorda, 2012).
} 
on registered employment, and that (6) the implicit elasticities will vary according to the propensity to be employed as formal workers, as discussed in (2), or among subgroups of individuals defined by their socioeconomic characteristics.

\section{Data Sources and Sample Construction}

Our analysis is based on a series of administrative and household survey datasets matched by means of a unique individual identifier. This section describes the original data sources, their characteristics and their timeframes. It also documents the matching process, the resulting datasets that we use for our empirical work, and the outcomes of interest.

\subsection{Baseline Program Application Records}

The AFAM administrative records correspond to a detailed questionnaire on the socioeconomic and demographic characteristics of all individuals in households that applied to the program. This rich baseline data contains information for both successful (i.e., eligible) and unsuccessful (i.e., ineligible) applicant households. Our database covers the period January 2008 to September 2010.

The detailed application form was conceived to produce a targeting score, and thus included a host of information on the households' living conditions. It was filled-in by BPS staff and a member of the applicant household. Its design was based on the typical questions found on household and labor force surveys. The individual and household characteristics elicited by this process include demographics, schooling, labor force participation and income, housing conditions and durable assets ownership, and region of residence, among others. The records also include the date of application and, most importantly, the exact value of the household's eligibility score computed by the authorities and the national identification number of each member of the household. Identity cards ("Cédula de Identidad") are issued at birth and renewed periodically for all citizens of Uruguay. An individual's national identification number corresponds to their card's unique number. It is uniquely linked to tax and social security records, and it is widely used to prove identity in public offices and for private commercial services.

\subsection{Social Security Administration Records}

The Social Security Administration (SSA) records the monetary contributions made by employers and employees to social insurance services every month. A formal employee is one that is "registered" with the SSA, and thus covered by the social security and social insurance benefits provided by SSA: old age pensions, health insurance, unemployment benefits, 
maternity and child allowances, among others.

We have access to SSA records for program applicants for the period from January 2005 to December 2012. This type of data has two main advantages. First, it records all episodes of registered employment (for both employees and self-employed workers, and in both the private and public sectors). We can thus construct a longitudinal database of registered employment histories by month that covers the entire period under study and, most importantly, substantial periods before and after the period covered by the program application records. We use national identification numbers to match all adult members of applicant households to their registered employment histories and their baseline application records. The second advantage of this data is that it provides information on the entire universe of adults in applicant households, which results in a large dataset that allows for a high degree of precision in our estimates.

Finally, in terms of limitations, our SSA administrative data does not include information on hours worked per day (or days per month) nor on earnings from registered work, which means that we cannot determine the impact of AFAM on the intensive margin of labor supply.

\subsection{Follow-Up Survey of Applicants to the Program}

An additional limitation of administrative databases for the study of labor market outcomes in developing countries is that, by definition, these sources do not have any information about unregistered or informal employment. Individuals typically appear in these databases as working as registered workers for which social insurance contributions and payroll taxes are paid, since the main purpose of these databases is to determine eligibility for social insurance benefits. In some cases, as in our data for Uruguay, individuals may also appear as beneficiaries of social assistance programs - typically child-related cash transfers or unemployment insurance. Individuals that do not appear in the database may thus be either inactive, unemployed (and not receiving unemployment insurance payments), or working as unregistered or informal employees. While these are good data sources to determine registered employment status, they do not provide a complete panorama of labor market outcomes since we cannot distinguish between inactivity, unemployment and unregistered work.

To complement the administrative data source along these lines, MIDES commissioned a group of researchers based at IECON ${ }^{12}$ to develop and implement a follow-up household survey specifically designed to study the effects of AFAM on household welfare and on indi-

\footnotetext{
${ }^{12}$ This survey was designed by researchers at the Instituto de Economía (IECON) of the UDELAR, in collaboration with MIDES and researchers at the Institute of Statistics and in the Department of Sociology at UDELAR (Amarante and Vigorito, 2011). In order to limit strategic responses, surveyed households were not informed about the precise purpose of the survey.
} 
vidual labor market responses. The survey was designed with the evaluation's identification strategy in mind. Since eligibility to the program was determined by a score based on socioeconomic characteristics that resulted in a sharp discontinuity at the cut-off point, the survey's sampling frame was based on a random sample of eligible and ineligible households that were close to the cut-off point, according to AFAM application records. Therefore, the survey sample was constructed to exploit the quasi-random variation generated by the eligibility rule. These application records and the corresponding household survey were matched using each individual's unique national identification number.

The follow-up survey was collected from September 2011 to February 2013. Overall, 40 percent $(1,441)$ of the stratified random sample of 3,565 households were interviewed, with a slightly higher proportion of non-response among ineligible households (44 percent) relative to eligible households (39 percent). Despite the high-level of non-response, there is no robust evidence of correlation between non-response and eligibility status. For an analysis of this issue, see Bergolo and Galvan (2016).

The survey's questionnaire was basically a shortened version of the Encuesta Continua de Hogares (the household survey carried out periodically by Uruguay's national statistical agency). It covered a host of information on household living conditions and individual labor market outcomes. More specifically, it allows us to establish the mutually exclusive labor market outcomes at the date of the interview - i.e., registered and unregistered employment, unemployment and non-participation - for each individual in the sample.

\subsection{Matched Datasets for the Empirical Analysis}

From these data sources, we construct two related but distinct datasets for our empirical analysis. For our first dataset, we match the program application records with SSA's registered employment work histories. We thus have complete registered work trajectories for the period January-2005-December 2012 for all adult individuals in households that applied to the program between January 2008 and September 2010. We adjust this data to the fact that application to AFAM occurs at different moments through the period we study (Appendix Figure A.1 depicts this distribution over time). Our analysis focuses on post-application employment outcomes - specifically, we study the period between 1 and up to 54 months after the application date. ${ }^{13}$ We also exploit the longitudinal dimension of the data and construct detailed pre-application registered employment trajectories for all adults in our sample for the 36 months immediately preceding application. ${ }^{14}$ Similarly to an event study,

\footnotetext{
${ }^{13}$ We use information up to 54 months after application to the program because only a small number of individuals are observed for 60 months, the maximum post-application window in our setup.

${ }^{14}$ We have more than 36 months of pre-application data for individuals who applied later in our observation window. We preferred to standardize the pre-application window to the minimum common denominator of 36 months (i.e., January 2005-January 2008 for the earliest applicants to the program).
} 
we re-center the work histories at the time of application to the program for individuals in both eligible and ineligible households.

The population of interest consists of heads of households or spouses of heads of households aged 18 to 57 at the time of the AFAM application during the period January 2008 to September 2010. These age limits restrict our sample to the economically active population over our whole period of study. ${ }^{15}$ In addition to the age restriction, we exclude a small proportion of individuals for whom the available data does not allow us to establish eligibility or treatment status (6.07 percent of the population of adults in applicant households). Finally, we exclude individuals whose household eligibility score is misreported in the AFAM application records (0.48 percent out of the population). These restrictions yield a population of 241,092 individuals aged 18-57 at the time of application to AFAM. Since our identification strategy is based on the sharp discontinuity of the eligibility at the cut-off point in a regression discontinuity setting, we restrict our analysis to a sample of the population of applicants in households in a specific range of $(-0.1 ;+0.1)$ of the eligibility score. ${ }^{16}$ From the population of 241,092 adults in all applicant samples, we use a sample (henceforth, the main sample) of about 10 percent of the total - 24,563 observations (18,790 eligible and 5,773 ineligible).

The second dataset (henceforth, the follow-up sample) covers the adult individuals in households interviewed for the follow-up survey during the period September 2011- February 2013. As described above, these households were also drawn from those close to the eligibility cut-off in the AFAM application records. ${ }^{17}$ There are 2,544 adults (18-57) interviewed in the follow-up survey (1,736 eligible individuals and 808 ineligibles). We match these individuals and their households with the information in the program application records and with their registered employment work histories from the SSA administrative records.

Because of how these samples were selected, we should expect individuals in the main sample to be similar to those in the follow-up sample, since both groups were drawn from a relatively small interval of the eligibility score around its cut-off point. However, we can also expect these two groups to differ from the full population of applicants: because they were close to the cut-off, these individuals represent the more well-off (as proxied by the eligibility score). This is verified in Table 1, which presents summary statistics of selected socio-economic characteristics of adult (18-57) individuals in all applicant households

\footnotetext{
${ }^{15}$ The lower bound for the age reflects the fact that individuals under 18 would not have benefited from the program as eligible children (e.g., they were not required to be enrolled in school). The restriction at 57 years old is due to the fact that workers in Uruguay are eligible for retirement benefits at 60 . For the last period of our work histories data, none of the workers were older than 59 .

${ }^{16}$ The range of the standardized eligibility score for the population of all applicant households is $(-0.268 ;+0.712)$, where positive values represent eligible (and thus less well-off) households and negative values correspond to non-eligible households.

${ }^{17}$ The optimal bandwidth for the survey was set at the eligibility score interval of $[-0.0426 ;+0.0727]$. This implies that the households selected were those with predicted probabilities of falling below the target income level within 7.27 percentage points and minus 4.26 percentage points of the cutoff point.
} 
(column 1), of those from the main sample (column 2) and from individuals in the follow-up sample (column 3). There do not seem to be substantial systematic differences between the characteristics in columns 2 and 3. However, households and individuals in our two selected groups differ from those in the full population in some key characteristics. For instance, in our two samples there is a substantially smaller proportion of female heads $(77.08$ percent in the main sample and 79.71 percent in the follow-up sample, compared to 72.89 percent in the full population), the education level is higher (30 percent and 26.69 percent compared to 50.76 with only primary school) there are less children in the households (1.42 and 1.40 compared to 2.09), and there are far less former beneficiaries of the PANES emergency cash transfer program, which targeted the extreme poor (42.43 percent and 10.37 percent compared to 9.51 percent). In Section 6.4, we assess to what extent the baseline RD estimates are generalizable to the full population of adults in AFAM applicant households.

\subsection{Outcomes of Interest}

The outcomes that we consider are defined as follows. The key outcome is registered employment as recorded in SSA administrative data. Specifically, registered employment in our data is an indicator variable equal to one if the individual is registered with the SSA in a given calendar month, and zero otherwise.

The analysis in Section 8 is based on the follow-up sample, and we exploit the information from the survey to explore responses to AFAM on additional margins of labor force participation. The first is registered employment, based in the response to a specific question in the follow-up survey and defined as an indicator coded as one for individuals who declared to be a registered employee at the time of the interview and zero otherwise. ${ }^{18}$ The second outcome of interest for our study is unregistered employment, again as stated by the respondent in the follow-up survey. This is an indicator coded as one for individuals who work but state that they are not registered with the SSA, and zero otherwise. The third outcome is non-employment, which is an indicator variable equal to one when the individual declares that she is not working, and zero when she states that she is employed (either as a registered or as an unregistered worker).

\footnotetext{
${ }^{18}$ The specific question in the ECH and in our follow-up survey is: "Are you contributing to a retirement benefit through this job?" ("¿Aporta a alguna caja de jubilaciones por su trabajo actual?"). This is a standard criteria in the analysis of household surveys in Latin America. It is used to define registered or formal work in most of the recent literature for the region - see, for instance, Gasparini and Tornarolli (2009) and Galiani and Weinschelbaum (2012).
} 


\section{Empirical Approach}

\subsection{Empirical Strategy: the Regression Discontinuity Design}

Our identification strategy to estimate the causal effect of the AFAM program on labor market outcomes relies on a regression discontinuity design based on the program's eligibility rule. Our sharp RD strategy exploits the fact that assignment to the program was determined by a deterministic eligibility score (score), which was a function of applicant households' characteristics. Only households with scores above the eligibility threshold were eligible for the program. ${ }^{19}$ We standardize this score so that the eligibility threshold is zero, positive values imply that households were eligible, and negative values imply that households were deemed ineligible. This is clearly illustrated in Figure 1: the discontinuity in the probability of program participation at the threshold is 96 percentage points, implying that the enforcement of the eligibility rule was very strict.

In this type of RD setting, ineligible households far to the left of the eligibility cutoff differ substantially in observable characteristics from eligible households far to the right of the threshold. However, if we narrow the focus to individuals in the neighborhood of the eligibility threshold, it is plausible that assignment to the program was determined by idiosyncratic factors and not by systematic differences in household and individual characteristics that might also be correlated to labor market behavior. Under certain conditions, individuals in households with a value of the eligibility score just below the cutoff (i.e., they were not deemed eligible by a small margin) can serve as a plausible counterfactual for individuals who gained eligibility by a small margin, and the RD setting is akin to a local randomized experiment.

For our baseline $\mathrm{RD}$ analysis, we estimate a regression model within a narrow window around the AFAM eligibility threshold specified as follows:

$$
Y_{i}=\alpha+\beta E L E G_{i}+\delta E L E G_{i} \times f\left(\text { score }_{i}\right)+\kappa f\left(\text { score }_{i}\right)+\epsilon_{i}
$$

where $Y_{i}$ is the outcome of interest for individual $i$;ELEG $G_{i}$ is a dummy equal to one if the individual belongs to an applicant household eligible for the program (i.e. if score $_{i}>0$ ), and zero otherwise; and score is the value of the eligibility score, which as usual in the RD literature is standardized relative to the eligibility threshold $(c)$. The function $f\left(\right.$ score $\left._{i}\right)$ is a smooth control function of the "assignment" variable score. The parameter of interest, $\beta$, captures the causal effect of AFAM on the outcome of interest. When the analysis focuses on the main sample, which is a longitudinal database, standard errors are clustered at the individual level to account for serial correlation of individual outcomes over time. When we

\footnotetext{
${ }^{19}$ See Lee and Lemieux (2010) for a detailed revision of technical issues relative to the RD design.
} 
use the follow-up sample, our estimates are based on regressions with Huber-White robust standard errors.

The functional form of $f($.$) and the window on each side of the cutoff threshold are key$ inputs for the RD design. Our baseline RD specification uses a low-order polynomial approach (linear and quadratic) to control for the assignment variable. ${ }^{20}$ These polynomials are estimated separately on each side of the eligibility threshold. As discussed above, our main sample is based on a bandwidth of \pm 0.1 around the cutoff threshold of the standardized eligibility score. In the Appendix, we provide a full set of robustness and specification checks of our main results, including alternative functional form assumptions for $f($.$) , dif-$ ferent choices of bandwidths, ${ }^{21} \mathrm{RD}$ estimations based on local linear regression, estimations including time fixed effects, and alternative standard error estimates, among others.

The identification of the parameter $\beta$ as a causal effect in an RD setting requires a series of conditions to be met. In terms of the Rubin causal model, let $Y_{i}(1)$ and $Y_{i}(0)$ denote the potential outcomes for eligible and ineligible individuals respectively. Identification in our RD design requires that $E\left[Y_{i}(1) \mid\right.$ score $]$ and $E\left[Y_{i}(0) \mid\right.$ score $]$ are continuous functions at the eligibility threshold $c$. This continuity condition justifies the use of those very close to the threshold as a counterfactual for those at the other side of the cutoff - i.e., the differences between the two groups are plausibly exogenous. Since $E L E G$ is a discontinuous function of the eligibility score, and the control function $f($.$) in equation 2$ is by assumption continuous at $c$, the $\mathrm{RD}$ coefficient $\beta$ is identified if the continuity condition is met. Intuitively, the continuity assumption implies that any discontinuity in the outcome of interest as a function of the score at the cutoff $c$ can be attributed to the causal impact of AFAM eligibility.

This continuity assumption would be violated if individuals were able to manipulate the program's eligibility process. In that case, the difference between the eligible and the ineligible at the threshold would reflect some systematic advantage of the eligible, instead of being determined by plausibly exogenous idiosyncratic factors. This would happen, for instance, if program officials favored households with adults engaged in informal jobs, or if applicants lied about their socioeconomic characteristics when filling-in the application form as a strategy to gain eligibility. Either situation would introduce systematic differences between observable unobservable characteristics of individuals just above and just below the eligibility threshold, potentially biasing the estimates.

Table 2 provides some evidence consistent with the absence of manipulation of the assignment variable. The table presents the average of selected socioeconomic characteristics

\footnotetext{
${ }^{20}$ Gelman and Imbens (2014) argue against the use of higher-order polynomials in RD designs.

${ }^{21}$ For our baseline specification, we selected the more parsimonious \pm 0.1 bandwidth. The Appendix reports results based on a standard set alternative samples, which correspond to restricting the bandwidth to ranges of $\pm 0.02, \pm 0.05, \pm 0.15, \pm 0.2$ and \pm 0.073 of the eligibility score. The latter is the optimal bandwidth computed as in Imbens and Kalyanaraman (2012), which corresponds to local linear regressions and a triangular kernel density that assigns a higher weight to observations closer to the threshold.
} 
at baseline for eligible and ineligible individuals in our main sample. Column (1) and (2) report the mean value of each characteristic for eligible and ineligible individuals, respectively, and column (3) reports the p-value of the differences in means. The raw differences between the means of most variables are statistically significant at standard levels, as indicated by the low p-values in column (3). However, in an RD setting, the right counterfactual for the treatment group in the absence of the program is not the average level of the same variable for the control group. This implicitly assumes that the potential outcome curves are flat at the threshold, but these potential outcome curves might have slopes, as most of the graphical evidence indicates (see the figures in Appendix Section A.4.2). In the type of local randomized experiment produced by the AFAM eligibility rule, the RD specification uses the observed trends in the outcomes on both sides of the eligibility threshold to construct an appropriate counterfactual. Consistent with the absence of manipulation, most of the RD estimates based on equation 2 for the socioeconomic characteristics at baseline (column 4) are not statistically significant, and the small but significant discontinuities (in age, fraction of individuals with secondary education or more, number of children and enrollment in PANES) are not economically large. ${ }^{22}$

To establish whether these small differences in baseline characteristics are jointly relevant and might bias our results, we estimate the combined effect of these variables on post-application registered employment, our key outcome. We compute predicted registered employment from these variables, ${ }^{23}$ and estimate our baseline RD model estimated with the prediction as the dependent variable (Table 2, last row, column 3) - this regression is illustrates in Appendix Figure A.5, which plots predicted registered employment as a function of the eligibility score. The slightly downward trend indicates that individuals with higher eligibility scores (i.e., poorer or more vulnerable individuals) have observable characteristics that are associated, on average, with lower registered employment. However, there is no significant jump in predicted registered employment at the eligibility cutoff, which is confirmed by the small and not statistically significant coefficient in the last row of Table 2. This higher-powered test indicates that baseline characteristics appear to be jointly balanced despite the small discontinuities in some of the underlying variables.

A standard prediction consistent with a well identified regression discontinuity setting is that the distribution of the assignment variable itself should be continuous at the eligibility threshold when potential beneficiaries are unable to manipulate the underlying score. Panel

\footnotetext{
${ }^{22}$ Appendix Figures A.2 through A.4 depict analogous RD plots for each baseline characteristic. To provide a more complete picture of potential discontinuities around the eligibility threshold, Appendix Tables A.2 through A.6 repeats this analysis setting the samples to the standard set of alternative bandwidths. These additional results are qualitatively and quantitatively similar to those reported here.

${ }^{23}$ Specifically, we estimate a regression model for registered employment $(R E)$ in the post-application period as a function of all the baseline characteristics $(X)$ in Table 2, including pre-application registered employment. We then use the vector of estimated coefficients from the regression $(\widehat{\delta})$ to predict postapplication registered employment for each observation $i, \widehat{R E}_{i}=X \widehat{\delta}$.
} 
(a) in Figure A.6 presents the distribution of the assignment variable, the standardized eligibility score. There does not seem to be a major discontinuity in the fraction of applicants around the eligibility threshold, as manipulation of the eligibility score would imply. Panel (b) depicts the estimates corresponding to the McCrary test - i.e., it plots the density of the eligibility score and a smoothed density estimator based on a local linear regression on both sides of the threshold. ${ }^{24}$ We cannot reject the null hypothesis of no discontinuity: for our main sample, the estimated discontinuity in the density is 0.107 with a standard error of 0.108 .

Finally, besides this empirical evidence, the institutional context of AFAM also suggests the absence of selective sorting and of eligibility score manipulation by either beneficiaries or program officials. While individuals had incentives to complete the application form strategically to gain eligibility, they were limited by the fact that the government did not disclose the algorithm to compute the score, the characteristics on which it was based, their underlying weights, nor the level of the eligibility threshold. Moreover, the very sharp and large jump in participation at the threshold illustrated in Figure 1 indicates that the program's rules were strictly enforced.

Taken together, this empirical evidence supports the hypothesis that individuals were nearly randomized around the eligibility threshold. This implies that we can give a causal interpretation to any discontinuity around the threshold in labor market or other postapplication outcomes as the effect of AFAM eligibility.

\subsection{Graphical Analysis of Registered Employment Patterns}

An advantage of the RD research design is that it provides a transparent graphical representation of the relationship between the outcome of interest and the assignment variable in terms of a discontinuity at the eligibility cutoff. The patterns in Figure 2 summarize our main results. In each figure, we plot the unrestricted monthly registered employment means (blue circle) in bins of 0.5 percentage points of the score, and the estimated monthly means (red solid line) using a second degree polynomial model applied to each side of the cutoff point.

Panel (a) in Figure 2 depicts how pre-application registered employment varied around the AFAM eligibility threshold. There appears to be only a small jump, and this is further reinforced by the RD coefficient of 0.027 (as in the corresponding coefficient in Table 3, Panel A, second row), which is not statistically significant. This confirms the balance in preapplication characteristics (in this case, pre-application outcomes) between the two groups, as discussed in the previous section. Registered employment levels in the two groups, however,

\footnotetext{
${ }^{24}$ The formal test is implemented as a Wald test of the null hypothesis that there is no discontinuity in the density of the standardized eligibility score at the eligibility cutoff.
} 
start to diverge significantly after application to AFAM. Panel (b) in Figure 2 displays a much larger jump at the eligibility threshold, and this is confirmed by the RD coefficient of -0.086 , statistically significant at the 1 percent level. These results indicate that registered employment falls substantially at the eligibility cutoff, i.e. when individuals become eligible for the program.

It should be noted that registered employment fluctuates in the 30-40 percent range in the pre-application period, and in the 40-60\% range in the post-application period. This is due to the fact that the program was launched when Uruguay's economy was recovering from the severe crisis of 2005, after which employment rose substantially. The pre-application period is closer in time to the crisis than the post application period, and the difference in average registered employment for applicants in panels (a) and (b) in Figure 2 reflect the recovery of employment during the period we study. This does not affect the difference in employment levels at a given time between the eligible and the ineligible, which is the focus of our analysis. We present complementary evidence based on a regression discontinuitydifference in differences design in Section 6.2 below that controls for these underlying trends and yields similar results.

Finally, these figures also provide some additional evidence on registered employment patterns: this outcome seems to be decreasing in the eligibility score, especially for the ineligible (those with a negative value of the score, to the left of the cutoff). This pattern is consistent with previous results that show that individuals in poorer and more vulnerable households (as proxied by the eligibility score) have a lower propensity to engage in formal or registered work, and achieveworse labor market outcomes in general. We study these issues in more detail in the statistical analysis in the next section.

\section{Registered Employment Response to the Program}

\subsection{Registered Employment Response to AFAM: RD Estimates}

Panel (b) in Figure 2 illustrates the essence of the main result: AFAM generated a substantial fall in registered employment among its beneficiaries. In this section, we analyze this effect in more depth. We first turn to the detailed statistical results presented in Table 3, which presents the estimates of the program's effect based on the RD specification given by equation 2 for our main sample. Column (1) reports the coefficients of our preferred specification, based on a quadratic RD polynomial. Column (2), in turn, presents the results from an alternative specification, a linear polynomial, as a robustness check. Column (3) reports the average registered employment rate for ineligible individuals in the main sample (which we label as our control group). Column (4), in turn, presents the effect in column (1) as a proportion of the registered employment rate in column (3). Panel A presents the estimates 
without controls, while panel B presents equivalent results adding a standard set of covariates to the basic RD model. ${ }^{25}$

The coefficient in panel A, column (1) of Table 3 is the baseline result depicted in Figure 2. We find a large and statistically significant decline of 8.6 percentage points in registered employment of adults eligible for AFAM compared to those ineligible in the post-application period. In terms of the mean outcome of the control group, this effect represents a proportional decrease of 17 percent in registered employment. The coefficient on the same model with registered employment in the pre-application period (column 1, panel A, second row) is also negative but smaller (-2.7 percent) and not statistically significant at standard levels, which is consistent with the previous discussion about the balance in characteristics and pre-treatment outcomes between the eligible and the ineligible. In terms of specification, all of the coefficients in column (2) of Table 3 (from the linear polynomial RD) are very similar to those in column (1) (based on the quadratic polynomial RD), which indicates that our main results are robust to this variation. However, the coefficient for pre-application registered employment computed with the linear RD specification (column 2, panel A, second row) is also small (-2.5 percent) but statistically significant at the 5 percent level. The regressions presented in panel $\mathrm{B}$ of of Table 3 include controls for a series of pre-determined covariates. The impact on post-application registered employment is slightly smaller (-7.9 compared to -8.7 percent - column 1, panel B, first row) and statistically significant at the one percent level, with a very similar pattern for the linear specification. The coefficient for pre-application registered employment in the two specifications with covariates (columns 1 and 2, panel B, second row) are smaller (-1.8 and -1.6 percent compared to -2.7 and -2.5 percent) and not statistically significant. To control for small imbalances such as those documented here and in Table 2 and to gain precision by reducing the residual variance, the results in the remainder of the paper are based on the RD regression with covariates.

The pattern of results in Table 3 is consistent with the theoretical models discussed in Section 3, which predict a decline in formal employment after the introduction of a social assistance program like AFAM. This decline could be due to the income effect generated by the monetary benefit, or to the transition from formal to informal employment induced by the implicit taxation on registered earnings introduced by the program's income test. In Section 8 below, we use additional evidence from the follow-up survey to distinguish between these two channels.

We can also exploit the longitudinal nature of the social security administration records to study the effect of AFAM eligibility on the evolution of registered employment over time before and after application. To do so, we estimate the quadratic polynomial RD model with

\footnotetext{
${ }^{25}$ The standard set of covariates in the regressions are those listed in Table 1, and include gender, head of the household status, age, marital status, educational level (in 3 categories), the number of children aged 0-17 in the household, whether the household was enrolled in the PANES program, residence in Montevideo (Uruguay's capital), and whether the individual was a registered employee in the pre-application period.
} 
covariates separately for each semester before and after application to the program. Figure 3 plots the evolution of these estimates over time, with the baseline period given by each household's application date. The gray area represents the 90 percent confidence intervals. Again, consistent with the previous evidence of quasi-random assignment to the program in the neighborhood of the eligibility cutoff, there are no statistically significant differences between the eligible and the ineligible in the probability to engage in registered employment in the period before the application. This difference starts to increase (in absolute value) after the period of application, and it becomes sizable and statistically significant at the 90 percent level three semesters after application. The difference between the two groups (as captured by the RD estimates) remains negative and statistically significant throughout the remainder of the time-horizon of our estimates (up to the 9th semester after application). This effect reaches a maximum four and a half years after application, with a negative effect of almost 9 percentage points. This persistent negative effect on registered employment may be due to the effects of long-term participation in social assistance programs, which might erode beneficiaries' human capital and cause a loss of skills relevant for the labor market. Other factors mentioned in the literature on welfare dependency include a stigma from participation and the fact that participation might be interpreted as a bad signal by employers (Moffitt, 1992).

\subsection{Robustness Analysis}

This section presents a series of specification checks of our RD design to show the robustness of our main results.

A first check refers to the timing of application and entry to the program. As illustrated in Figure A.1, application to AFAM occurred at different points in time during our period of analysis. The potentially non-random timing in applications might be related to potential outcomes.

In Appendix Table A.1, we study which household and individual characteristics from the baseline application records are related to the date of application. ${ }^{26}$ This evidence indicates that individuals with a higher eligibility score, who are older, more educated, not married and employed before the application process are those who applied earlier to AFAM. Moreover, consistent with the implementation of the program, individuals who were beneficiaries of the previous PANES transfer program also applied to AFAM earlier in the process. While we find some statistically significant correlations between individual characteristics and the timing of application to AFAM, the effects are quantitatively unimportant and most of the variation remains unexplained. This result is consistent with the evidence that most of the

\footnotetext{
${ }^{26}$ The dependent variable in this regression analysis is the month and year of household application date expressed as an index equal to one in January 2008.
} 
applicants' observable characteristics are continuous around the eligibility cutoff, although we cannot rule out discontinuous changes in unobservable characteristics given by the timing of application.

To establish whether this type of potential confounding factors affect our results, and to control for the upward trend in employment during the period we study, we estimate a difference-in-difference specification (RD-DD) of the RD model presented in equation 2. This model basically compares the discontinuity in post-application outcomes to discontinuity in pre-application outcomes for individuals close to the threshold. ${ }^{27}$ The identification assumption of the RD-DD model is that any systematic differences between individuals who apply to AFAM at different points in time - or any other unobservable factor that systematically varies across applicants - are time-invariant close to the threshold. Appendix Table A.10 presents the results of this analysis for a set of different bandwidths of the eligibility score. The size of the estimates is, in general, lower by about 20 percent, but the results are qualitatively similar to those obtained from the standard RD model. This remains true even when we control for month fixed effects in the RD-DD specification.

We also conduct a number of additional robustness checks of the baseline RD specification. First, Appendix Table A.7 examines the robustness of the registered employment estimates based on alternative bandwidths around the eligibility score cutoff $( \pm 0.02, \pm 0.05$, $\pm 0.15, \pm 0.2$ and \pm 0.073 - the Imbens-Kalyanaraman optimal bandwidth), on alternative RD polynomial specifications (linear, quadratic, cubic, and quartic, estimated separately on either side of the threshold), and with and without controlling for covariates and individual fixed effects. The coefficients in Appendix Table A.7 are similar in both magnitude and statistical significance to most of those presented in Table 3. Moreover, in Appendix Table A.8 we present further estimates based on local linear regressions instead of polynomials. The results are qualitatively similar results to those obtained with our preferred specification, a quadratic polynomial. Finally, a large fraction of individuals in our sample (about 45 percent) belong to households with other adults in our sample. The results in Appendix Table A.9 indicate that our main results are robust to clustering the standard errors at the household level (rows 2 and 4) instead of at the individual level (rows 1 and 3, main results for comparison proposes) - i.e., our results remain statistically significant even after accounting for the potential correlations within households.

${ }^{27}$ The RD-DD specification is similar to the standard RD in equation 2 , but it also includes information from the pre-application period. In the regression, we add interactions of a post-application (Post) indicator with each variable. Specifically, the RD-DD that we estimate is given by the following equation:

$Y_{i}=\alpha_{0}+\beta_{0} E L E G_{i} \times$ Post $_{i}+\delta_{0} E L E G_{i} \times f\left(\right.$ score $\left._{i}\right) \times$ Post $_{i}+\kappa_{0} f\left(\right.$ score $\left._{i}\right) \times$ Post $_{i}+$

$\beta_{1} E L E G_{i}+\delta_{1} E_{L E G_{i}} \times f\left(\right.$ score $\left._{i}\right)+\kappa_{1} f\left(\right.$ score $\left._{i}\right)+\gamma_{1}$ Post $_{i}+\epsilon_{i}$ 


\subsection{Heterogeneous Effects by Socio-Economic Groups}

The previous analysis considered average effects among all adult applicants. In the spirit of establishing an anatomy of responses to the AFAM program, we now examine the degree of heterogeneity of responses by subgroups of individuals defined by their baseline socioeconomic and demographic characteristics. Table 4 reports the RD regression results for the different subgroups from the main sample (Appendix Tables A.18 through A.22 present the corresponding results for alternative bandwidth ranges).

The estimates in Table 4 are very informative of the pattern of responses. The effects are clearly stronger for household heads than for other members of the household (-8.9 compared to -4.5 percentage points), and not statistically significant in our baseline specification for the latter (most of the results in the Table are similar with the linear RD polynomial). They are also stronger for adults in mono-parental households (-9.8 p.p.) compared to the effects for adults in households with two parents (-5.4 p.p.). Moreover, the effects are much stronger for women (-10.8 percentage points, significant at the 1 percent level) than for men (-1.1 p.p., not significant), and for female heads (-12 p.p.) than for male heads (6.6 p.p., not significant). They are also stronger for adults below 30 (-12.6 p.p.) compared to effects for those aged 30 or more (-6.9 p.p.), and for the more educated (-8.4 p.p.) compared to those with lower education levels (-6.1 p.p.) - these effects are statistically significant at standard levels for the four groups. These results indicate that those who responded the most to the program's financial incentives were women and those with a higher need to work (household heads, adults in mono-parental households), but also younger and more educated applicants, who were probably closer to the margin of choice between registered and unregistered employment. We study this issue in more detail in the following sections.

\subsection{Generalizing the Baseline Results}

Thus far, the results presented have been based on comparing individuals relatively better off among the poor (those around the eligibility threshold) according to their eligibility score. In this section we explore whether or not the baseline RD estimates can be generalized to a larger population of eligible individuals, in particular to individuals in more severe conditions of poverty. To do this, we expand the bandwidth to the right of the AFAM eligibility threshold - i.e., we include individuals from poorer households (those with higher eligibility scores). As derived from Lee and Lemieux (2010), by extending the bandwidth our RD estimate assigns weight to the effect of AFAM program also for eligible individuals away from the vicinity of the threshold. Figure 4 reports estimates from RD specifications that increase the bandwidth to the right of eligibility threshold by one quarter of a percentage point. The

minimum bandwidth to the right of the cutoff point is 0.10 (baseline) and the maximum bandwidth is 0.60 - i.e., the first point in the figure corresponds to a regression with a 
bandwidth of $[-0.1 ;+0.1]$ while the last point corresponds to a bandwidth of $[-0.1 ;+0.6]$. This exercise is similar in spirit to that of Kostol and Mogstad (2014), who find that the effect of disability insurance on labor force participation declines as the RD bandwidth in the analysis is widened, although the estimates are always sizable. In particular, our RD estimates decline somewhat with the size of the window, but remains sizable even with a bandwidth of $[-0.1 ;+0.6]$. Also as in Kostol and Mogstad (2014), both the standard RD and the away-window-based RD results complement each other: our baseline RD results are informative of the effects of AFAM on registered employment if the program were expanded to less poor populations, whereas the RD estimates with wider bandwidth refer to the impact on the formal employment behavior of more severely impoverished eligible individuals.

\section{Distributional Effects: Propensity to Work Formally}

Economic theory predicts differential effects among individuals with different propensities to work as formal employees - i.e., those closer or further away from the registered/not registered employment margin of choice. We continue the anatomy of responses to the program by studying the effects of AFAM along this dimension.

The first step in this analysis is to estimate the propensity to work formally (in the absence of AFAM) as a function of baseline characteristics for all the individuals in our sample. We estimate a regression model with registered employment as a function of our standard set of covariates for the group of ineligible individuals only (Appendix Table A.11 reports the coefficient estimates for this auxiliary regression). We then use the estimated coefficients to generate predicted values of the probability to work as a registered employee for all individuals in the sample (i.e., including also those deemed eligible). We then divide our samples into three roughly equally-sized groups based on their predicted propensity to work as a registered employee. Finally, we estimate the effects of the program with our baseline RD model for each of the three subgroups separately. ${ }^{28}$

Table 5 reports the RD estimates for these three groups (Appendix Tables A.12 through A.16 present the corresponding results for alternative bandwidth ranges). Column (3) presents the average of the dependent variable, registered employment, for the control group (ineligible individuals). Consistent with the exercise described in the previous paragraph, individuals in the bottom group of propensity to work formally, registered employment is low at 0.22 (panel A), compared to 0.41 for the middle group (panel B) and 0.81 for the high propensity group (panel C).

The effects of the program on registered employment are presented in Column (1) of Table 5. The effect is low (-3.7 p.p., panel A) and not statistically significant for the group

\footnotetext{
${ }^{28}$ Our estimates remain virtually unchanged when we implement the leave-one-out bias correction method for group stratification proposed in Abadie and Chingos (2014).
} 
with a low propensity to work formally. It is higher and statistically significant for the group with a high propensity to work formally ( -5 p.p., panel C), although still below the effect for the full sample. The highest effect of the program is among the group with a middle propensity to work formally: -9.3 p.p., significant at the 1 percent level.

These results are consistent with some form of segmentation among potential beneficiaries of the program. Those with a low probability to work formally do not respond much to the financial incentives of the program because they have limited opportunities to work as registered employees to begin with. The opposite is true for those with a high propensity to work formally: they are not affected by the program's disincentive for registered employment because most of them will work formally anyway. The group with the middle propensity to be formally employed seems to be the one closer to the margin of choice between formal and informal employment, and thus individuals in this group are those who react the most to the new incentives.

\section{Decomposing the Effects of the Program: Informal- ity and Non-Employment}

The main analysis in the previous section was based on registered work histories as recorded in the administrative social security records. As discussed above, this high-quality data source has a limitation in terms of the outcomes of interest: while we can establish the effects of the program on changes in registered employment, we cannot separate the responses in terms of inactivity or non-registered employment - i.e., we cannot know whether the null registered employment status represents a period in which the individual is out of employment or, alternatively, a period of informal employment. This is a fundamental distinction for public policy and is also relevant to an evaluation of the impact of the program on participants' welfare. Our follow-up survey provides information to complement our benchmark specifications for registered employment. As it turns out, the information in the survey allows us to complete the anatomy of responses to the AFAM financial incentives by establishing the comparative magnitude of responses along these two margins.

We base our analysis on the subsample of eligible and ineligible applicants interviewed for the follow-up survey. Table 6 presents the baseline RD estimates of the program for this sample on the three mutually exclusive labor market outcomes: registered employment, nonemployment and unregistered or informal employment. The overall effect for the follow-up survey sample on registered employment is - 13.7 percentage points, larger in absolute value than our baseline RD results based on the full administrative records sample. ${ }^{29}$ In any case,

\footnotetext{
${ }^{29}$ This difference in levels can be attributed to the fact that we the follow-up survey covered only a sub-sample of the main sample, and only for a specific period of time and not for the full period under study.
} 
we still find a large (about 25 percent with respect to the employment level for the ineligible) and statistically significant reduction in registered employment.

The most valuable information in Table 6 is given by the following two rows: the 13.7 p.p. reduction in registered employment was given by an increase in non-employment among the eligible of 4.6 p.p., and an increase in informal employment of 9.1 p.p. - while the two coefficients are not statistically significant, we can reject the null that they are both jointly equal to zero (p-value of 0.052 ).

In the discussion of the predicted effects of the program, we posited that the transfer could cause an increase in non-employment due to an income effect or a shift towards informal employment induced by the characteristics of the means test, which is based on administrative information about registered employment earnings. We find evidence of the two types of effects. To sum up, these results indicate that the observed reduction in registered employment induced by the program can be attributed to a larger extent (about two thirds) to an increase in unregistered employment, and to a lesser extent (about one third) to a shift towards non-employment.

\section{$9 \quad$ Elasticity of Participation and Efficiency Effects}

\subsection{The Elasticity of Participation in Registered Employment}

The results presented so far indicate that individuals eligible for AFAM responded to the program's financial incentives schedule by reducing their participation in registered employment (Table 3). The average absolute response in terms of formal employment rates was relatively large - about 8 percentage points, or about 15 percent with respect to the 51.8 percent participation for the control group. In this section, we establish the magnitude of these responses in relation to the size of the program's financial incentives. We use these results to establish a more general parameter, the aggregate elasticity of participation in formal employment to net of registered employment participation tax rate - that is, the percentage change in formal employment for each percentage point change in the net average tax rate. ${ }^{30}$ This elasticity is the main behavioral parameter that captures the sensitivity of responses to tax and transfers policies along the extensive margin (Eissa et al., 2006, 2008), and a key input to compute the efficiency effects of the program.

Eissa et al. (2006) derive the participation elasticity in a context of labor force participation responses to tax and benefits. Waseem (2015) extends this setup to a context where formal employment is the relevant extensive margin of response. As in Waseem (2015), we

\footnotetext{
${ }^{30}$ As discussed in Section 3, the income testing in the AFAM eligibility rule introduces a discrete change in the budget set. In contexts of tax-transfer schedules such as these, the participation tax rate is generally considered more relevant to behavioral participation responses than the marginal tax rates (e.g., Eissa et. al., 2006).
} 
incorporate the decision to be a registered employee to the basic model of labor supply by assuming that formal employment provides a discrete utility cost $q^{i}$ to individuals. This utility cost include direct costs associated to formal employment (e.g. regulations, transportation costs to large urban areas where formal firms tends to agglomerate, etc). but also indirect costs, such as other social benefits that the worker would have to disregard as a registered employee (Galiani and Weinschelbaum, 2012). The utility maximization process is described in two stages. First, an agent chooses her optimal hours (or earnings) conditional on participation in registered employment. Second, the agent must decide whether to participate or not. Let $w$ represent earnings from registered employment, let the function $T(w)$ be the tax and transfer schedule, and let $-T(0)$ represent the program's benefit (e.g., the AFAM cash transfer) which for simplicity we assume is received only by those who are not formally employed. An individual participates in formal employment if and only if the utility of doing so, $u^{i}(w-T(w))-q^{i}$, exceeds the utility from non-participation, which we assume to be $u_{0}^{i}(-T(0)) .{ }^{31}$ This leads to the following condition for participation in registered employment:

$$
q^{i} \leq u^{i}(w-T(w))-u_{0}^{i}(-T(0)) \equiv \bar{q}_{i}
$$

This expression defines an upper bound $\bar{q}_{i}$ on the discrete utility gain from participation in registered employmen. The size of $\bar{q}_{i}$ reflects the utility gain from participating in registered employment accounting for taxes and transfers. That is, individuals with fixed cost $q^{i}$ below $\bar{q}_{i}$ decide to participate in labor market as formal employees. If $q^{i}$ is distributed in the population according to a smooth function $R(q)$, the fraction of individuals in registered employment is given by $R(\bar{q})$. The elasticity of participation in registered employment captures movements into and out of formal employment as a consequence of the tax and transfer schedule:

$$
\epsilon_{R}=\frac{1-p t r}{R(q)} \cdot \frac{\triangle R(q)}{\triangle(1-p t r)}
$$

This elasticity is defined as the percentage change in participation in registered employment, $R(q)$, induced by a one percentage point change in the average net of participation in registered employment tax rate, $1-p t r .{ }^{32}$. It should be noted that the $p t r$ corresponds to the effective average tax rate, which includes the loss of the program's benefit following entry into registered employment (when the resulting earnings exceed the program's income testing threshold).

We compute the aggregate elasticity of participation in registered employment, $\epsilon_{R}$, in the context of our RD analysis by closely following the procedure developed by Kostol and

\footnotetext{
${ }^{31}$ This fixed cost is only incurred if the individual participates in registered employment. For simplicity, we assume that it is additively separable in utility.

${ }^{32}$ For small changes in taxes and transfers, $\triangle(1-p t r)=d(1-p t r)$ and $\triangle R(q)=d R(q)$, so that the elasticity is given by $\epsilon_{R}=\frac{1-p t r}{R(q)} \cdot \frac{d R(q)}{d(1-p t r)}$
} 
Mogstad (2014) in their analysis of the effects of disability insurance on labor supply in Norway. In particular, we define $\triangle R(q)$ as the difference in registered employment between eligible and ineligible individuals, whereas $R(q)$ is given by the rate of registered employment for the ineligible. Since we do not have information on earnings in our data, we must make some assumptions regarding the definition and the computation of the participation tax rate $p t r$, a key input to find the elasticity $\epsilon_{R}$. We compute earnings from Uruguay's National Household Survey (Encuesta Continua de Hogares) for the period 2008-2012. Based on a sample of registered workers with household income below the poverty line, we regress registered earnings on a set of standard covariates. ${ }^{33}$ We use the estimated coefficients to predict registered employment earnings for all the individuals in our AFAM database. Based on these imputed incomes and on Uruguay's tax and transfer schedule, we compute the net of $p t r$ for every individual in our data. ${ }^{34}$ In Appendix Sections A.1 and A.2, we describe in more detail the procedure for computing $\epsilon_{R}$ and imputing earnings.

Table 7 presents the elasticities that result from this exercise. Each column presents the estimates of the components of equation (4) and the resulting elasticity, with column (1) presenting results for the overall sample, and columns (2), (3) and (4) presenting the estimates for the subsamples of individuals with low, medium and high probabilities of working as registered employees, as in the discussion of Tables 3 and 5. The difference in registered employment (first row), our proxy for $\triangle R(q)$, is 7.8 percentage points for the overall sample, and -3.4, -9.4 and -5.5 p.p. for those with low, medium and high propensities to work formally, respectively. The average registered employment level for ineligible individuals (second row), our proxy for $R(q)$, is 51.5 percent, and consistent with the classification of individuals in the three categories, it was 22.5 percent, 40.9 percent and 80.8 percent for those with low, medium and high propensities to work as registered employees, respectively. ${ }^{35}$ The average change in the net-of ptr (third row), given by the loss of the entire AFAM cash transfer at the income eligibility threshold, is 7.1 percent points - the implied tax rate over the benefit is 100 percent at the threshold, but we average over the whole distribution to

\footnotetext{
${ }^{33}$ We use the standard covariates listed in the notes to Table 3, with the exception of the variables for enrollment in the PANES program and employment at baseline, which are not available in the household survey.

${ }^{34}$ The tax and transfer schedule for low income registered workers in Uruguay is fairly simple - their earnings are only subject to a payroll tax (social security contributions) amounting to 21 percent of gross earnings, paid by the employer, and they are eligible for the AFAM benefit if they meet the program's eligibility criteria. The income tax minimum threshold is well above the earnings of low income workers. Employers are liable for payroll tax on earnings in the form of social security contributions of up to 13 percent of gross earnings. We implicitly assume that workers and employers each pay the statutory rate assigned by the tax authorities. If registered employees bear the full incidence of the sum of employee and employer payroll taxes, the effective tax rate would be higher than what we use in our computation.

${ }^{35}$ There are some small differences between the point estimates reported in the first and second rows of Table 7 and those in Tables 3 and 5 . This is due to the fact that we were unable to impute registered labor income for about 5 percent of the sample due to missing information for covariates in the administrative records. The differences are small and do not alter the conclusions drawn from these results.
} 
obtain the change in the average tax rate. Finally, the participation tax rate (fourth row) is about 79 percent, consistent with the 21 percent payroll tax rate, the only tax levied on the registered employment earnings of these low-income workers.

The bottom row of Table 7 presents our estimates for the registered employment elasticity implied by the taxes and benefits for the relevant population. Our results indicate an average elasticity of participation in registered employment with respect to the net-of-participation in registered employment tax rate of 1.689, i.e., a reduction of 1 percent in this rate (the net-of-tax share of income that individuals can keep) reduces registered employment by 1.7 percent. Consistent with the estimated effects of the program for the different subgroups, the elasticity is substantially higher (about 2.6) for those with a medium propensity to work as a registered employee, compared to an elasticity of 1.67 for those with a low propensity to work formally and an elasticity of 0.76 for those in the group with a high propensity to work formally. These results reflect the fact that the middle group is the most responsive to changes in the tax and transfer schedule.

Our results for Uruguay indicate that individuals in developing countries react in their labor market entry decisions to the incentives implied by the tax and transfer schedule they face, although they react along the formal/informal employment margin of labor supply since taxes apply to (and transfers depend on) earnings from registered employment only. Moreover, even based on very different populations, and very different tax and transfer systems and reforms, our estimate of the average participation elasticity is within the range (although close to the higher bound) of previous results in the literature for developed countries. For instance, Eissa, Kleven and Kreiner's (2006) review of empirical studies concludes that the extensive margin responses to tax reforms for single mothers "correspond to participation elasticities in the range from 0.35 to 1.7". Bargain and Doorley (2011) summarize the empirical evidence for France, stating that the participation elasticities for married women in families with children is close to 1 . However, the elasticity estimates for developed countries capture the change in labor supply, whereas our estimate reflects the response in terms of non-participation but also in terms of movements between formal and informal employment. The results in Section 8 indicate that the program reduced registered employment, with the informality margin accounting for two thirds and the non-employment margin accounting for one third of the response. Using these results, a back of the envelope calculation results in a participation elasticity of about 0.56 , more in line with the literature on developed countries, with about 1.14 for the formal-informal margin of adjustment.

\subsection{Welfare and Efficiency Implications of the AFAM Program}

The empirical analysis performed thus far has shown that AFAM created incentives to reduce participation in registered employment. With the elasticity computed in the previous section, 
we can establish the size of the deadweight loss given by the loss in tax revenue from the reduction in registered employment induced by this policy.

As discussed above, Eissa, Kleven, and Claus Kreiner (2006, 2008) model the discrete labor market entry and exit decisions given by non-convexities in preferences and budget sets, and they incorporate these results into the standard framework for the efficiency evaluation of tax reforms. In the context of AFAM, the non-convexities are substantial, and this framework allows us to capture the first-order welfare effects of behavioral responses along the extensive (participation) margin of labor supply. More specifically, Eissa et al. (2006) show that the marginal deadweight burden of a tax reform is given by the effect of behavioral responses on government revenue. In their setup, the impact on revenue from the behavioral response is given by reactions at both the intensive margin (change in hours of work for those who are working) and the extensive margin of labor supply brought about by the tax-induced change in labor force participation. We concentrate on the latter because we do not have information on hours worked in our data.

We adapt Eissa, Kleven and Kreine's (2006) formula for the marginal deadweight burden as a proportion of total labor income as:

$$
\frac{d D B / d \theta}{w P}=\frac{p t r}{(1-p t r)} \cdot \frac{\partial p t r}{\partial \theta} \cdot \epsilon_{R}
$$

where $D B$ is the deadweight burden, $w$ is the wage, $P$ is the probability of being employed, $p t r$ is the participation tax rate, $\epsilon_{R}$ is the elasticity of participation in registered employment, and $\theta$ is an abstract parameter used to derive the effects of the policy. The deadweight loss is directly related to the relevant elasticity in the context of AFAM, and the welfare cost is a function of the tax rate at the extensive (participation) margin of labor supply, ptr. This includes (as in Eissa et al., 2006) the loss of the cash transfer from participation in registered employment and the payroll tax. The change in $p t r$ is basically associated to the loss of the AFAM benefit at the eligibility threshold (i.e. analogous to the elasticity calculation above).

We compute this deadweight loss as an average for a representative agent based on the elasticity and the tax rate from the previous section. Specifically, the deadweight loss from the behavioral response at the extensive margin of labor supply is the result of multiplying the average tax ratio, the average tax rate change, and the participation elasticity from Table 7. The results are presented in Table 8. We find that the behavioral responses to AFAM imply a deadweight loss (or efficiency cost) of about 3.2 percent of total labor income. As a benchmark, Eissa, Kleven, and Claus Kreiner (2006) find that the welfare gains from extensive margin changes induced by the Earned Income Tax Credit and the 1986 tax reform in the United States range from 3.27 percent to 7.64 percent of wage income. The efficiency cost from AFAM for the representative agent thus seem significant but not exceedingly large. However, this discussion does not take into account other plausible negative implications of not participating in the formal labor market over the long term. "Inactivity traps" have 
detrimental effects, for instance the depreciation of human capital over time. Informal jobs, on the other hand, imply higher risks (since they do not provide access to social insurance), and are associated with worse working conditions, lower job stability and flatter earnings profiles over time.

\section{Conclusion}

The AFAM program's eligibility rules, based on verification of reported earnings, create a strong disincentive for registered employment - a notch in beneficiaries budget constraints. Individuals in households that applied to the program reacted as predicted by economic theory. We built an anatomy of the labor market responses induced by the program's financial incentives along four dimensions. First, we established that beneficiaries responded to the program's incentives by reducing their levels of registered employment by about 8 percentage points. Second, we found substantial heterogeneity in these effects: the program had a stronger negative effect for individuals with a medium probability to be a registered employee, suggesting some form of segmentation in which those with a low probability to work formally did not respond much to the financial incentives of the program, probably because they had limited opportunities to work as registered employees to start with. Third, by matching administrative data with a follow-up survey, we established that the fall in registered employment was due to a greater extent (about two thirds) to an increase in unregistered employment, and to a lesser extent (about one third) to a shift towards nonemployment. Fourth, we found an elasticity of participation in registered employment of about 1.7. The program lead to a deadweight loss from the behavioral responses of about 3.2 percent of total labor income. The efficiency cost from AFAM for the representative agent is significant but not exceedingly large, although there might be other detrimental effects from lowered participation in formal employment.

Our results allow us to draw valuable lessons that can be used to minimize programs' disincentives and efficiency costs. When designing programs of this type, policy makers in developing countries must consider reactions along the registered/unregistered employment margin, and find ways to mitigate these unintended adverse results. A first implication of our analysis is that AFAM authorities (and those designing similar initiatives in countries with widespread informal employment) could consider some way to smooth out the cash notch implied by the program's eligibility rule. For instance, the income test could be modified by introducing a more continuous schedule with phase in and phase out regions that withdraw the benefit gradually and with lower implicit tax rates, rather than generating a total loss of the benefit at the income threshold. Alternatively, the authorities could test the effects of allowing beneficiaries to continue in the program while having earnings from registered employment above the threshold for a transitory period. This temporary earnings disregard 
could ease the transition to formal employment, and mitigate the possibility that beneficiaries might prefer lower but more stable income from the program rather than higher but riskier earnings from registered employment.

The fact that there was significant heterogeneity among responses to the program as a function of individuals' propensities to engage in formal employment also has direct consequences for the design of programs of this type, and particularly for their incentive structures. For instance, specific incentives or conditionalities that are costly to monitor (such as minimum working hours requirements) may only be worthwhile for those who might be expected to react to the program's incentives. The poorest beneficiaries (as proxied by a low propensity to be a formal employee) seem to be infra-marginal in terms of the formal/informal work decision, and thus concerns about disincentives to registered employment are less relevant for this group. They could benefit more form other policy initiatives, such as direct job creation (Knoef and Ours, 2016). At the same time, the high responsiveness among the less poor beneficiaries suggests that the program could incorporate differential incentives for this group. Just as work incentives guided welfare reforms in developed countries, the new generation of cash transfer and social assistance programs in developing countries could incorporate measures to reduce the disincentives to formal employment. For instance, programs such as AFAM could encourage registered employment drawing from the design of programs such as the United States' Earned Income Tax Credit - for certain groups, the programs could pay a higher level of benefit to beneficiaries who switch to registered employment.

\section{References}

Albrecht, J., Navarro, L., Vroman, S., 2009. The Effects of Labour Market Policies in an Economy with an Informal Sector. The Economic Journal 119 (539), 1105-1129.

Alzua, M. L., Cruces, G., Ripani, L., 2012. Welfare programs and labor supply in developing countries: experimental evidence from Latin America. Journal of Population Economics 26 (4), $1255-1284$.

Amarante, V., Ferrando, M., Vigorito, A., 2013. Teenage School Attendance and Cash Transfers: An Impact Evaluation of PANES. EconomÃa 14 (1), 61-102.

Amarante, V., Manacorda, M., Vigorito, A., Zerpa, M., 2011. Social Assistance and Labor Market Outcomes: Evidence from the Uruguayan PANES.

Amarante, V., Vigorito, A., 2011. Una propuesta para la evaluacion de impacto del programa Asignaciones Familiares-Plan de Equidad y la Tarjeta Alimentaria del MIDES.

Araujo, M. C., Bosch, M., Maldonado, R., Schady, N., 2016. The Effect of Welfare Payments on Work in a Middle-Income Country.

Banerjee, A., Rema, H., Gabriel, K., Benjamin, O., 2015. Debunking the Myth of the Lazy Welfare Recipient: Evidence from Cash Transfer Programs Worldwide. 
Bargain, O., Doorley, K., 2011. Caught in the trap? Welfare's disincentive and the labor supply of single men. Journal of Public Economics 95 (9-10), 1096-1110.

Bastagli, F., 2009. From social safety net to social policy?: the role of conditional cash transfers in welfare state development in Latin America.

Behrman, J. R., 1999. Chapter 43 Labor markets in developing countries. Vol. 3, Part B. Elsevier, pp. 2859-2939.

Ben-Shalom, Y., Moffitt, R. A., Scholz, J., 2011. An assessment of the effectiveness of antipoverty programs in the United States. In: Jefferson, P. (Ed.), Oxford Handbook of the Economics of Poverty, oxford university press Edition.

Bergolo, M., Cruces, G., 2014. Work and tax evasion incentive effects of social insurance programs: Evidence from an employment-based benefit extension. Journal of Public Economics 117, 211228.

Bergolo, M., Dean, A., Perazzo, I., Vigorito, A., 2016. Evaluacion impacto del programa Asignaciones Familiares-Plan de Equidad y la Tarjeta Alimentaria del MIDES.

Bergolo, M., Galvan, E., 2016. Social Assistance and Labor Market Intra-Household Decisions. Evidence from a Regression Discontinuity Design.

Bitler, M. P., Gelbach, J. B., Hoynes, H. W., 2006. What Mean Impacts Miss: Distributional Effects of Welfare Reform Experiments. American Economic Review 96 (4), 988-1012.

Bosch, M., Campos-Vazquez, R. M., 2014. The trade-offs of welfare policies in labor markets with informal jobs: the case of the Seguro Popular program in Mexico. American Economic Journal: Economic Policy 6 (4), 71-99.

Bosch, M., Esteban-Pretel, J., 2012. Job creation and job destruction in the presence of informal markets. Journal of Development Economics 98 (2), 270-286.

Bosch, M., Manacorda, M., 2012. Social policies and labor market outcomes in Latin America and the Caribbean: a review of the existing evidence. Tech. Rep. 32, Center for Economic Performance.

Chetty, R., Guren, A., Manoli, D., Weber, A., 2013. Does Indivisible Labor Explain the Difference between Micro and Macro Elasticities? A Meta-Analysis of Extensive Margin Elasticities. NBER Macroeconomics Annual 2012 27, 1-56.

Eissa, N., Kleven, H., Claus Kreiner, 2006. Welfare Effects of Tax Reform and Labor Supply at the Intensive and Extensive Margins. In: Agell, J., Sorensen, P. B. (Eds.), Tax Policy and Labor Market Performance. MIT Press, Cambridge, pp. 147-185.

Eissa, N., Kleven, H. J., Kreiner, C. T., 2008. Evaluation of four tax reforms in the United States: Labor supply and welfare effects for single mothers. Journal of Public Economics 92 (3-4), 795816.

Fields, G., 2009. Segmented Labor Market Models in Developing Countries. In: Kincaid, H., Ross, D. (Eds.), The Oxford handbook of philosophy of economics. Oxford University Press, Oxford, pp. $476-510$.

Fiszbein, A., Schady, N. R., 2009. Conditional cash transfers: reducing present and future poverty. World Bank, Washington D.C. 
Galiani, S., Weinschelbaum, F., 2012. Modeling Informality Formally: Households and Firms. Economic Inquiry 50 (3), 821-838.

Garganta, S., Gasparini, L., 2015. The impact of a social program on labor informality: The case of AUH in Argentina. Journal of Development Economics 115, 99-110.

Gasparini, L., Tornarolli, L., 2009. Labor Informality in Latin America and the Caribbean: Patterns and Trends from Household Survey Microdata. Desarrollo y Sociedad 63, 13-80.

Gelman, A., Imbens, G., 2014. Why High-order Polynomials Should not be Used in Regression Discontinuity Designs. Working Paper 20405, National Bureau of Economic Research.

Gunter, S. P., 2013. State Eearned Income Tax Credits and Participation in Regular and Informal Work. National Tax Journal 66 (1), 33-62.

Hahn, J., Todd, P., Van der Klaauw, W., 2001. Identification and Estimation of Treatment Effects with a Regression-Discontinuity Design. Econometrica 69 (1), 201-209.

Harris, J. R., Todaro, M. P., 1970. Migration, Unemployment and Development: A Two-Sector Analysis. The American Economic Review 60 (1), 126-142.

Imbens, G., Kalyanaraman, K., 2012. Optimal Bandwidth Choice for the Regression Discontinuity Estimator. The Review of Economic Studies 79 (3), 933-959.

Imbert, C., Papp, J., 2015. Labor Market Effects of Social Programs: Evidence from India's Employment Guarantee. American Economic Journal: Applied Economics 7 (2), 233-263.

Kleven, H. J., 2016. Bunching. Annual Review of Economics 8 (1), null.

Kleven, H. J., Waseem, M., 2013. Using notches to uncover optimization frictions and structural elasticities: Theory and evidence from Pakistan. The Quarterly Journal of Economics, 669-723.

Kline, P., Tartari, M., 2016. Bounding the Labor Supply Responses to a Randomized Welfare Experiment: A Revealed Preference Approach. American Economic Review 106 (4), 972-1014.

Knoef, M., Ours, J. C. v., 2016. How to stimulate single mothers on welfare to find a job: evidence from a policy experiment. Journal of Population Economics 29 (4), 1025-1061.

URL http://dx.doi.org/10.1007/s00148-016-0593-0

Kostol, A. R., Mogstad, M., 2014. How Financial Incentives Induce Disability Insurance Recipients to Return to Work. American Economic Review 104 (2), 624-655.

La Porta, R., Shleifer, A., 2014. Informality and Development. Journal of Economic Perspectives 28 (3), 109-126.

LaLumia, S., 2009. The Earned Income Tax Credit and Reported Self-Employment Income. National Tax Journal 62 (2), 191-217.

Laroque, G., 2005. Income Maintenance and Labor Force Participation. Econometrica 73 (2), 341376.

Lee, D. S., Lemieux, T., 2010. Regression Discontinuity Designs in Economics. Journal of Economic Literature 48 (2), 281-355. 
Levy, S., 2008. Good intentions, bad outcomes. Social policy, informality and economic growth in Mexico. Brookings Institution Press, Washington.

Levy, S., Schady, N., 2013. Latin AmericaÂŽs Social Policy Challenge: Education, Social Insurance, Redistribution. Journal of Economic Perspectives 27 (2), 193-218.

Maloney, W. F., 1999. Does Informality Imply Segmentation in Urban Labor Markets? Evidence from Sectoral Transitions in Mexico. World Bank Economic Review 13 (2), 275-302.

Maloney, W. F., 2004. Informality Revisited. World Development 32 (7), 1159-1178.

Manacorda, M., Miguel, E., Vigorito, A., 2011. Government Transfers and Political Support. American Economic Journal: Applied Economics 3 (3), 1-28.

Meghir, C., Narita, R., Robin, J.-M., 2015. Wages and Informality in Developing Countries. American Economic Review 105 (4), 1509-1546.

Moffitt, R. A., 2002. Chapter 34 Welfare programs and labor supply. Vol. 4. Elsevier, pp. 2393-2430.

Moffitt, R. A., 2003. The Temporary Assistance for Needy Families Program. In: Moffitt, R. A. (Ed.), Means-Tested Transfer Programs in the United States. NBER and University of Chicago Press, pp. 291-363.

Saez, E., 2002. Optimal Income Transfer Programs: Intensive versus Extensive Labor Supply Responses. The Quarterly Journal of Economics 117 (3), 1039-1073.

Schneider, F., Buehn, A., Montenegro, C. E., 2010. New Estimates for the Shadow Economies all over the World. International Economic Journal 24 (4), 443-461.

Scholz, J., Levin, K., 2001. The Evolution of Income Support Policy in Recent Decades. In: Danziger, S. H., Haveman, R. H. (Eds.), Understanding Poverty. Harvard University Press and Russell Sage.

Waseem, M., 2015. Taxes, Informality and Income Shifting: Evidence from a Recent Pakistani Tax Reform. Working Paper. 


\section{Figures and Tables}

Table 1: Comparison of Samples: Applicants to AFAM, Main and Follow-Up Samples

\begin{tabular}{|c|c|c|c|}
\hline & $\begin{array}{c}\text { Population } \\
\text { (All applicant HHs) }\end{array}$ & $\begin{array}{l}\text { Main Sample } \\
\text { (bandw:+/-.1) }\end{array}$ & $\begin{array}{l}\text { Follow-Up Sample } \\
\text { (bandw:-.04;+.08) }\end{array}$ \\
\hline & (1) & $(2)$ & $(3)$ \\
\hline Female applicants (\%) & $\begin{array}{c}68.29 \\
(46.53)\end{array}$ & $\begin{array}{l}71.00 \\
(45.38)\end{array}$ & $\begin{array}{c}71.78 \\
(45.02)\end{array}$ \\
\hline Household head (\%) & $\begin{array}{c}76.30 \\
(42.52)\end{array}$ & $\begin{array}{c}78.38 \\
(41.16)\end{array}$ & $\begin{array}{c}78.46 \\
(41.12)\end{array}$ \\
\hline Female head (within heads) (\%) & $\begin{array}{c}72.89 \\
(44.45)\end{array}$ & $\begin{array}{l}77.08 \\
(42.03)\end{array}$ & $\begin{array}{c}79.71 \\
(40.23)\end{array}$ \\
\hline Age at application to AFAM & $\begin{array}{l}35.00 \\
(9.17)\end{array}$ & $\begin{array}{l}36.94 \\
(9.07)\end{array}$ & $\begin{array}{l}37.57 \\
(9.00)\end{array}$ \\
\hline Less than Primary (\%) & $\begin{array}{c}1.17 \\
(10.73)\end{array}$ & $\begin{array}{c}0.43 \\
(6.56)\end{array}$ & $\begin{array}{c}0.47 \\
(6.85)\end{array}$ \\
\hline Complete Primary (\%) & $\begin{array}{c}50.76 \\
(49.99)\end{array}$ & $\begin{array}{c}30.00 \\
(45.83)\end{array}$ & $\begin{array}{c}26.69 \\
(44.24)\end{array}$ \\
\hline Secondary or more $(\%)$ & $\begin{array}{c}40.84 \\
(49.15)\end{array}$ & $\begin{array}{c}57.41 \\
(49.45)\end{array}$ & $\begin{array}{l}59.16 \\
(49.16)\end{array}$ \\
\hline Married/in couple (\%) & $\begin{array}{c}49.24 \\
(49.99)\end{array}$ & $\begin{array}{c}44.64 \\
(49.71)\end{array}$ & $\begin{array}{c}44.90 \\
(49.75)\end{array}$ \\
\hline Single mother (within singles) (\%) & $\begin{array}{l}85.75 \\
(34.96)\end{array}$ & $\begin{array}{l}87.73 \\
(32.81)\end{array}$ & $\begin{array}{l}89.76 \\
(30.33)\end{array}$ \\
\hline Number of children & $\begin{array}{c}2.09 \\
(1.35)\end{array}$ & $\begin{array}{c}1.42 \\
(0.85)\end{array}$ & $\begin{array}{l}1.40 \\
(0.84)\end{array}$ \\
\hline Enrolled in PANES (\%) & $\begin{array}{c}42.43 \\
(49.42)\end{array}$ & $\begin{array}{l}10.37 \\
(30.49)\end{array}$ & $\begin{array}{c}9.51 \\
(29.34)\end{array}$ \\
\hline Montevideo (capital city) (\%) & $\begin{array}{c}31.16 \\
(46.32)\end{array}$ & $\begin{array}{c}29.54 \\
(45.63)\end{array}$ & $\begin{array}{l}31.96 \\
(46.64)\end{array}$ \\
\hline Employed (\%) & $\begin{array}{c}53.79 \\
(49.86)\end{array}$ & $\begin{array}{c}54.81 \\
(49.77)\end{array}$ & $\begin{array}{c}55.62 \\
(49.69)\end{array}$ \\
\hline Observations & 241,091 & 24,563 & 2,544 \\
\hline
\end{tabular}

Notes: The sample corresponds to heads of households and spouses of heads of households aged 18 to 57 at the time of the AFAM application during the period January 2008 to September 2010. The dataset corresponds to the AFAM baseline application records (January 2008 to September 2010) matched with the registered employment work histories for the period January 2005 to December 2012 from the Social Security Administration's administrative records (see Section 4.4 for a detailed description of the data). The "Population" in column (1) refers to individuals in these age categories in all households applying to AFAM during the period under study - i.e., the the entire population of AFAM applicants. The "Main Sample" in column (2) refers to the subset of individuals from households within a range of $[-0.1 ;+0.1]$ of the eligibility score - i.e., individuals close to the eligibility score threshold which we use for our main results. The "Follow-Up Sample" in column (3) corresponds to the subset of individuals interviewed for the program's follow-up survey during the period September 201-February 2013, drawn from households within a range of $[-0.0426 ;+0.0727]$ of the eligibility score (see Section $\underline{4.3}$ for more details). All individual/household characteristics presented in this table are measured at the date of application, i.e. before the administrative decision on enrollment to the program. 
Table 2: Mean and Regression Discontinuity Differences in Baseline Characteristics, Eligible and Ineligible Individuals, Main Sample

\begin{tabular}{|c|c|c|c|c|}
\hline & $\begin{array}{c}\text { Eligible } \\
\text { Individuals } \\
\end{array}$ & $\begin{array}{c}\text { Ineligible } \\
\text { Individuals }\end{array}$ & $\begin{array}{c}\text { P-Value } \\
\text { of the Difference }\end{array}$ & $\begin{array}{c}\mathrm{RD} \\
\text { Estimate }\end{array}$ \\
\hline & $(1)$ & $(2)$ & (3) & (4) \\
\hline Female applicants (\%) & $\begin{array}{l}71.33 \\
(0.33)\end{array}$ & $\begin{array}{l}69.95 \\
(0.60)\end{array}$ & 0.04 & $\begin{array}{l}-0.12 \\
(2.09)\end{array}$ \\
\hline Household head (\%) & $\begin{array}{l}79.03 \\
(0.30)\end{array}$ & $\begin{array}{l}76.27 \\
(0.56)\end{array}$ & 0.00 & $\begin{array}{c}0.91 \\
(1.92)\end{array}$ \\
\hline Female head (within heads) (\%) & $\begin{array}{l}77.25 \\
(0.34)\end{array}$ & $\begin{array}{l}76.49 \\
(0.64)\end{array}$ & 0.29 & $\begin{array}{l}-0.58 \\
(2.17)\end{array}$ \\
\hline Age at application to AFAM & $\begin{array}{l}36.50 \\
(0.07)\end{array}$ & $\begin{array}{l}38.36 \\
(0.11)\end{array}$ & 0.00 & $\begin{array}{c}-1.28^{* *} \\
(0.41)\end{array}$ \\
\hline Less than Primary (\%) & $\begin{array}{c}0.45 \\
(0.05)\end{array}$ & $\begin{array}{c}0.36 \\
(0.08)\end{array}$ & 0.37 & $\begin{array}{c}0.40 \\
(0.25)\end{array}$ \\
\hline Complete Primary (\%) & $\begin{array}{l}31.56 \\
(0.34)\end{array}$ & $\begin{array}{l}24.89 \\
(0.57)\end{array}$ & 0.00 & $\begin{array}{l}1.86 \\
(2.07)\end{array}$ \\
\hline Secondary or more $(\%)$ & $\begin{array}{l}55.98 \\
(0.36)\end{array}$ & $\begin{array}{l}62.05 \\
(0.64)\end{array}$ & 0.00 & $\begin{array}{l}-5.61^{*} \\
(2.27)\end{array}$ \\
\hline Married/in couple (\%) & $\begin{array}{l}43.46 \\
(0.37)\end{array}$ & $\begin{array}{l}48.45 \\
(0.67)\end{array}$ & 0.00 & $\begin{array}{c}0.03 \\
(2.35)\end{array}$ \\
\hline Single mother (within singles) (\%) & $\begin{array}{l}87.58 \\
(0.33)\end{array}$ & $\begin{array}{l}88.25 \\
(0.60)\end{array}$ & 0.34 & $\begin{array}{l}1.45 \\
(2.05)\end{array}$ \\
\hline Number of children & $\begin{array}{l}1.47 \\
(0.01)\end{array}$ & $\begin{array}{l}1.25 \\
(0.01)\end{array}$ & 0.00 & $\begin{array}{l}0.12^{* *} \\
(0.04)\end{array}$ \\
\hline Enrolled in PANES (\%) & $\begin{array}{l}12.27 \\
(0.24)\end{array}$ & $\begin{array}{c}4.19 \\
(0.26)\end{array}$ & 0.00 & $\begin{array}{l}3.14^{* *} \\
(1.13)\end{array}$ \\
\hline Montevideo (capital city) (\%) & $\begin{array}{l}27.68 \\
(0.33)\end{array}$ & $\begin{array}{l}35.61 \\
(0.63)\end{array}$ & 0.00 & $\begin{array}{l}-4.06 \\
(2.19)\end{array}$ \\
\hline Employed (\%) & $\begin{array}{l}54.05 \\
(0.36)\end{array}$ & $\begin{array}{l}57.28 \\
(0.65)\end{array}$ & 0.00 & $\begin{array}{l}-1.66 \\
(2.31)\end{array}$ \\
\hline Registered 36 months pre (\%) & $\begin{array}{l}32.09 \\
(0.28)\end{array}$ & $\begin{array}{l}37.64 \\
(0.53)\end{array}$ & 0.00 & $\begin{array}{l}-2.75 \\
(1.82)\end{array}$ \\
\hline Predicted Reg. Employ. (\%) & $\begin{array}{l}42.21 \\
(0.19)\end{array}$ & $\begin{array}{l}46.39 \\
(0.36)\end{array}$ & 0.00 & $\begin{array}{l}-2.00 \\
(1.23)\end{array}$ \\
\hline Observations & 18,790 & 5,773 & & \\
\hline
\end{tabular}

Notes: The sample corresponds to heads of households and spouses of heads of households aged 18 to 57 at the time of the AFAM application during the period January 2008 to September 2010, from households within a range of $[-0.1 ;+0.1]$ of the eligibility score. The dataset corresponds to the AFAM baseline application records (January 2008 to September 2010) matched with the registered employment work histories for the period January 2005 to December 2012 from the Social Security Administration's administrative records (see Section 4.4 for a detailed description of the data). All individual/household characteristics included in this table correspond to the household's application date, with the exception of the last two rows in the main panel. "Registered 36 months pre" refers to each individual's average registered employment rate for the 36 months before application to AFAM. "Predicted Reg. Employ." refers to a measure of post-application registered employment predicted using the characteristics in 1 and pre-application registered employment data. Columns (1) and (2) present the average characteristics for individuals from eligible and ineligible households, respectively. Column (3) reports the p-value on the difference in means of each row's characteristic between individuals in the two groups. Column (4), in turn, reports the coefficient of the AFAM eligibility indicator from a standard RD specification described in Equation (2), with the respective characteristic as the dependent variable. The coefficient's standard errors in parentheses. ${ }^{*}$ significant at $10 \%$; $*$ significant at $5 \%$; $* *$ significant at $1 \%$. 
Table 3: Effect of AFAM Eligibility on Registered Employment, RD Estimates

\begin{tabular}{|c|c|c|c|c|c|}
\hline & $\begin{array}{c}\text { Quadratic RD } \\
\text { Polynomial }\end{array}$ & $\begin{array}{l}\text { Linear RD } \\
\text { Polynomial }\end{array}$ & $\begin{array}{l}\text { Mean for } \\
\text { Ineligibles }\end{array}$ & $\begin{array}{c}\% \Delta \\
\text { w.r.t. (1) }\end{array}$ & Obs. \\
\hline & $(1)$ & $(2)$ & $(3)$ & $(4)$ & $(5)$ \\
\hline \multicolumn{6}{|l|}{ Panel A. No Covariates } \\
\hline Elegible(post application) & $\begin{array}{c}-0.086^{* * *} \\
(0.019)\end{array}$ & $\begin{array}{c}-0.087^{* * *} \\
(0.013)\end{array}$ & 0.518 & -16.61 & $1,140,362$ \\
\hline Elegible(pre application) & $\begin{array}{l}-0.027 \\
(0.018)\end{array}$ & $\begin{array}{c}-0.025^{* *} \\
(0.012)\end{array}$ & 0.376 & -7.29 & 908,831 \\
\hline \multicolumn{6}{|l|}{ Panel B. With Covariates } \\
\hline Elegible(post application) & $\begin{array}{c}-0.079 * * * \\
(0.017)\end{array}$ & $\begin{array}{c}-0.080^{* * *} \\
(0.012)\end{array}$ & 0.518 & -15.23 & $1,140,362$ \\
\hline Elegible(pre application) & $\begin{array}{l}-0.018 \\
(0.017)\end{array}$ & $\begin{array}{l}-0.016 \\
(0.011)\end{array}$ & 0.376 & -4.75 & 908,831 \\
\hline
\end{tabular}

Notes: The sample corresponds to heads of households and spouses of heads of households aged 18 to 57 at the time of the AFAM application during the period January 2008 to September 2010, from households within a range of $[-0.1 ;+0.1]$ of the eligibility score. The dataset corresponds to the AFAM baseline application records (January 2008 to September 2010) matched with the registered employment work histories for the period January 2005 to December 2012 from the Social Security Administration's administrative records (see Section 4.4 for a detailed description of the data). Panels A and B present the regression estimates from the basic model in Equation (2) without covariates and with covariates, respectively. The regressions are estimated as linear probability models. In columns (1) and (2), the dependent variable is registered employment, measured as an indicator variable equal to one if the SSA records indicate that there are social security contributions from employment for the individual in a given calendar month, and zero otherwise. The coefficients correspond to the "Eligible" variable, an indicator equal to one if the individual belongs to a household eligible for the program according to the AFAM eligibility rules (i.e., if $s c o r e_{i}>0$ ), and zero otherwise. The first row in each of the Panels presents results for registered employment during the post-application period, whereas the second row presents results for registered employment during the pre-application period. The covariates in the regressions in Panel B include gender, head of the household status, age, marital status, educational level (in 3 categories), the number of children aged $0-17$ in the household, whether the household was enrolled in the PANES program, residence in Montevideo (Uruguay's capital), and whether the individual was a registered employee. All covariates correspond to the date when the household applied to the program. Column (1) presents results based on a quadratic RD polynomial estimated separately on either side of the eligibility threshold. Column (2) presents results from a linear RD polynomial estimated separately on either side of cutoff. Column (3) reports the mean for each dependent variable for ineligible individuals (the control group). Column (4) reports the program's effect from the quadratic RD polynomial model (Column 1) as a percentage of the mean of the dependent variable for ineligible individuals (Column 3). Column (5) reports the total number of observations, which correspond to 24,563 individuals for up to 54 post-application months and 37 pre-application months. Standard errors clustered at the individual level in parentheses. ${ }^{*}$ significant at $10 \% ; * *$ significant at $5 \% ; * * *$ significant at $1 \%$. 
Table 4: Heterogeneous Effects of AFAM Eligibility by Socio-Demographic Sub-Groups

\begin{tabular}{|c|c|c|c|c|c|}
\hline \multirow[t]{2}{*}{ Sub-groups } & $\begin{array}{c}\text { Quadratic RD } \\
\text { Polynomial }\end{array}$ & $\begin{array}{l}\text { Linear RD } \\
\text { Polynomial }\end{array}$ & $\begin{array}{l}\text { Mean for } \\
\text { Ineligibles }\end{array}$ & $\begin{array}{c}\% \Delta \\
\text { w.r.t. (1) }\end{array}$ & Obs. \\
\hline & $(1)$ & $(2)$ & $(3)$ & $(4)$ & $(5)$ \\
\hline Household head & $\begin{array}{c}-0.089^{* * *} \\
(0.019)\end{array}$ & $\begin{array}{c}-0.082^{* * *} \\
(0.013)\end{array}$ & 0.526 & -16.88 & 888,947 \\
\hline Other HH. member & $\begin{array}{l}-0.045 \\
(0.038)\end{array}$ & $\begin{array}{c}-0.077^{* * *} \\
(0.025)\end{array}$ & 0.491 & -9.09 & 251,415 \\
\hline Female applicants & $\begin{array}{c}-0.108^{* * *} \\
(0.020)\end{array}$ & $\begin{array}{c}-0.100 * * * \\
(0.013)\end{array}$ & 0.477 & -22.57 & 806,274 \\
\hline Male applicants & $\begin{array}{c}-0.011 \\
(0.034)\end{array}$ & $\begin{array}{c}-0.036 \\
(0.022)\end{array}$ & 0.614 & -1.86 & 334,088 \\
\hline Two parent $\mathrm{HH}$ & $\begin{array}{c}-0.054^{* *} \\
(0.027)\end{array}$ & $\begin{array}{c}-0.063^{* * *} \\
(0.018)\end{array}$ & 0.510 & -10.62 & 493,940 \\
\hline Single parent $\mathrm{HH}$ & $\begin{array}{c}-0.098^{* * *} \\
(0.023)\end{array}$ & $\begin{array}{c}-0.094^{* * *} \\
(0.016)\end{array}$ & 0.521 & -18.73 & 592,950 \\
\hline Female heads & $\begin{array}{c}-0.120^{* * *} \\
(0.025)\end{array}$ & $\begin{array}{c}-0.107^{* * *} \\
(0.017)\end{array}$ & 0.509 & -23.64 & 519,633 \\
\hline Male heads & $\begin{array}{c}0.066 \\
(0.072)\end{array}$ & $\begin{array}{c}0.001 \\
(0.048)\end{array}$ & 0.614 & 10.82 & 73,317 \\
\hline Low education & $\begin{array}{c}-0.061^{*} \\
(0.033)\end{array}$ & $\begin{array}{c}-0.053^{* *} \\
(0.022)\end{array}$ & 0.481 & -12.64 & 350,780 \\
\hline Medium-high education & $\begin{array}{c}-0.084^{* * *} \\
(0.022)\end{array}$ & $\begin{array}{c}-0.094^{* * *} \\
(0.015)\end{array}$ & 0.533 & -15.84 & 649,242 \\
\hline Aged below 30 & $\begin{array}{c}-0.126^{* * *} \\
(0.035)\end{array}$ & $\begin{array}{c}-0.107^{* * *} \\
(0.024)\end{array}$ & 0.507 & -24.93 & 254,306 \\
\hline Aged 30 or more & $\begin{array}{c}-0.069^{* * *} \\
(0.020)\end{array}$ & $\begin{array}{c}-0.074^{* * *} \\
(0.013)\end{array}$ & 0.520 & -13.25 & 886,056 \\
\hline
\end{tabular}

Notes: The sample corresponds to heads of households and spouses of heads of households aged 18 to 57 at the time of the AFAM application during the period January 2008 to September 2010, from households within a range of $[-0.1 ;+0.1]$ of the eligibility score. The dataset corresponds to the AFAM baseline application records (January 2008 to September 2010) matched with the registered employment work histories for the period January 2005 to December 2012 from the Social Security Administration's administrative records (see Section 4.4 for a detailed description of the data). Each row presents the regression estimates from the basic model in Equation (2) with covariates at time of application to the program as in the notes to Table 3. The regressions are estimated as linear probability models. In columns (1) and (2), the dependent variable is registered employment, measured as an indicator variable equal to one if the SSA records indicate that there are social security contributions from employment for the individual in a given calendar month, and zero otherwise. The coefficients correspond to the "Eligible" variable, an indicator equal to one if the individual belongs to a household eligible for the program according to the AFAM eligibility rules (i.e., if score $_{i}>0$ ), and zero otherwise. Each row presents results for registered employment during the post-application period for the corresponding subgroup. Column (1) presents results based on a quadratic RD polynomial estimated separately on either side of the eligibility threshold. Column (2) presents results from a linear RD polynomial estimated separately on either side of cutoff. Column (3) reports the mean for each dependent variable for ineligible individuals (the control group). Column (4) reports the program's effect from the quadratic RD polynomial model (Column 1) as a percentage of the mean of the dependent variable for ineligible individuals (Column 3). Column (5) reports the total number of observations, which correspond to 24,563 individuals for up to 54 post-application months. Standard errors clustered at the individual level in parentheses. ${ }^{*}$ significant at $10 \%$; ** significant at $5 \%$; ** significant at $1 \%$. 
Table 5: Effect of AFAM Eligibility on Registered Employment by Propensity to be a Registered Employee

\begin{tabular}{|c|c|c|c|c|c|}
\hline & $\begin{array}{c}\text { Quadratic RD } \\
\text { Polynomial } \\
\end{array}$ & $\begin{array}{l}\text { Linear RD } \\
\text { Polynomial } \\
\end{array}$ & $\begin{array}{c}\text { Mean for } \\
\text { Ineligibles } \\
\end{array}$ & $\begin{array}{c}\% \Delta \\
\text { w.r.t. (1) }\end{array}$ & Obs. \\
\hline & $(1)$ & $(2)$ & $(3)$ & $(4)$ & $(5)$ \\
\hline \multicolumn{6}{|c|}{ Panel A. Low prop. to be formal } \\
\hline Elegible(post application) & $\begin{array}{l}-0.037 \\
(0.023)\end{array}$ & $\begin{array}{c}-0.059^{* * *} \\
(0.016)\end{array}$ & 0.224 & -16.39 & 383,109 \\
\hline Elegible(pre application) & $\begin{array}{c}-0.007^{* *} \\
(0.004)\end{array}$ & $\begin{array}{c}-0.005^{* *} \\
(0.002)\end{array}$ & 0.015 & -48.25 & 299,959 \\
\hline \multicolumn{6}{|c|}{ Panel B. Medium prop. to be formal } \\
\hline Elegible(post application) & $\begin{array}{c}-0.093^{* * *} \\
(0.030)\end{array}$ & $\begin{array}{c}-0.055^{* * *} \\
(0.020)\end{array}$ & 0.412 & -22.53 & 381,226 \\
\hline Elegible(pre application) & $\begin{array}{l}-0.006 \\
(0.010)\end{array}$ & $\begin{array}{l}-0.001 \\
(0.006)\end{array}$ & 0.135 & -4.12 & 301,846 \\
\hline \multicolumn{6}{|c|}{ Panel C. High prop. to be formal } \\
\hline Elegible(post application) & $\begin{array}{c}-0.050^{* *} \\
(0.023)\end{array}$ & $\begin{array}{c}-0.089^{* * *} \\
(0.015)\end{array}$ & 0.808 & -6.25 & 376,027 \\
\hline Elegible(pre application) & $\begin{array}{c}0.006 \\
(0.016)\end{array}$ & $\begin{array}{c}-0.022^{* *} \\
(0.010)\end{array}$ & 0.821 & 0.75 & 307,026 \\
\hline
\end{tabular}

Notes: The sample corresponds to heads of households and spouses of heads of households aged 18 to 57 at the time of the AFAM application during the period January 2008 to September 2010 , from households within a range of $[-0.1 ;+0.1]$ of the eligibility score. The dataset corresponds to the AFAM baseline application records (January 2008 to September 2010) matched with the registered employment work histories for the period January 2005 to December 2012 from the Social Security Administration's administrative records (see Section 4.4 for a detailed description of the data). Each row presents the regression estimates from the basic model in Equation (2) with covariates at time of application to the program, as in the notes to Table 3. The regressions are estimated as linear probability models. In columns (1) and (2), the dependent variable is registered employment, measured as an indicator variable equal to one if the SSA records indicate that there are social security contributions from employment for the individual in a given calendar month, and zero otherwise. The coefficients correspond to the "Eligible" variable, an indicator equal to one if the individual belongs to a household eligible for the program according to the AFAM eligibility rules (i.e., if score $_{i}>0$ ), and zero otherwise. Panels A, B and C present the regression estimates for the subgroups of individuals with Low, Medium and High predicted propensity to work as a registered employee, respectively. See Section 7 for a detailed explanation of the procedure to determine these predicted probabilities. The first row in each of the Panels presents results for registered employment during the post-application period, whereas the second row presents results for registered employment during the pre-application period. Column (1) presents results based on a quadratic RD polynomial estimated separately on either side of the eligibility threshold. Column (2) presents results from a linear RD polynomial estimated separately on either side of cutoff. Column (3) reports the mean for each dependent variable for ineligible individuals (the control group). Column (4) reports the program's effect from the quadratic RD polynomial model (Column 1) as a percentage of the mean of the dependent variable for ineligible individuals (Column 3). Column (5) reports the total number of observations, which correspond to 24,563 individuals for up to 54 post-application months and 37 pre-application months. Standard errors clustered at the individual level in parentheses. $*$ significant at $10 \% ; *$ significant at $5 \%$; ** significant at $1 \%$. 
Table 6: Effect of AFAM Eligibility on Different Margins of Participation, Follow-Up Sample

\begin{tabular}{|c|c|c|c|c|c|}
\hline & $\begin{array}{c}\text { Quadratic RD } \\
\text { Polynomial }\end{array}$ & $\begin{array}{l}\text { Linear RD } \\
\text { Polynomial }\end{array}$ & $\begin{array}{l}\text { Mean for } \\
\text { Ineligibles }\end{array}$ & $\begin{array}{c}\% \Delta \\
\text { w.r.t. }(1)\end{array}$ & Obs. \\
\hline & $(1)$ & $(2)$ & $(3)$ & $(4)$ & $(5)$ \\
\hline Registered Employment & $\begin{array}{c}-0.137^{* *} \\
(0.054)\end{array}$ & $\begin{array}{c}-0.130 * * * \\
(0.039)\end{array}$ & 0.541 & -25.27 & 2,410 \\
\hline Non-Employment & $\begin{array}{c}0.046 \\
(0.049)\end{array}$ & $\begin{array}{c}0.044 \\
(0.035)\end{array}$ & 0.196 & 23.20 & 2,410 \\
\hline Informal Employment & $\begin{array}{c}0.091 \\
(0.056)\end{array}$ & $\begin{array}{c}0.086^{* *} \\
(0.039)\end{array}$ & 0.262 & 34.77 & 2,410 \\
\hline Joint p-value $(2 \& 3=0)$ & 0.052 & 0.004 & & & \\
\hline
\end{tabular}

Notes: The results in this table are based on the "Follow-Up Sample," which includes heads of households and spouses of heads of households aged 18 to 57 at the time of the AFAM application during the period January 2008 to September 2010. This sample corresponds to the subset of individuals who were interviewed for the program's follow-up survey during the period September 2011-February 2013. The survey's sample was drawn from households within a range of $[-0.0426 ;+0.0727]$ of the eligibility score (see Section 4.3 for more details). The dataset corresponds to the AFAM baseline application records (January 2008 to September 2010) matched with information from the program's follow-up survey data (see Section 4.4 for a detailed description of the data). Each row presents the regression estimates from the basic model in Equation (2) with covariates at time of application to the program as in the notes to Table 3. The regressions are estimated as linear probability models. In the first row, the dependent variable is the registered employment status as reported by the individual at the time of the interview (one if she is working as a registered employee, zero otherwise). In the second row, the dependent variable is non-employment, again as reported by the individual at the time of the interview, which is equal to one if the individual is not working, and equal to zero if she is working (as a registered or as a non-registered employee). In the third row, the dependent variable is informal employment at the time of the interview, which is equal to one if the individual is working as an informal (or non-registered) employee, and zero otherwise (i.e., working as a registered employee or not working). Each of these rows presents the regression estimates from the basic model in Equation (2) with covariates at time of application to the program, as in the notes to Table 3. The coefficients correspond to the "Eligible" variable, an indicator equal to one if the individual belongs to a household eligible for the program according to the AFAM eligibility rules (i.e., if score $_{i}>0$ ), and zero otherwise. The fourth row presents the p-value of the test that the coefficients for the "Non-Employment" and "Informal Employment" regressions are jointly equal to zero. Column (1) presents results based on a quadratic RD polynomial estimated separately on either side of the eligibility threshold. Column (2) presents results from a linear RD polynomial estimated separately on either side of cutoff. Column (3) reports the mean for each dependent variable for ineligible individuals (the control group). Column (4) reports the program's effect from the quadratic $\mathrm{RD}$ polynomial model (Column 1) as a percentage of the mean of the dependent variable for ineligible individuals (Column 3). Column (5) reports the total number of observations. Huber-White robust standard errors shown in parentheses, * significant at $10 \% ; * *$ significant at $5 \%$; ** significant at $1 \%$. 
Table 7: Elasticity of Participation in Registered Employment

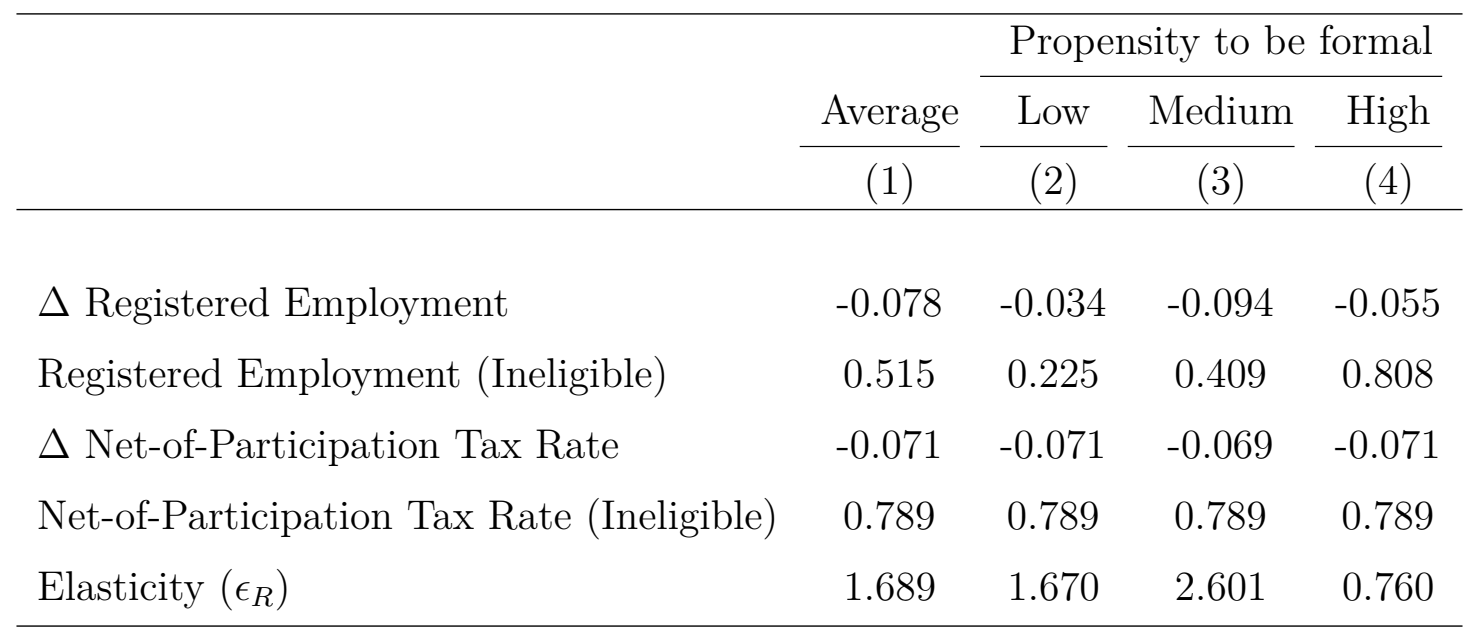

Notes: The sample corresponds to heads of households and spouses of heads of households aged 18 to 57 at the time of the AFAM application during the period January 2008 to September 2010, from households within a range of $[-0.1 ;+0.1]$ of the eligibility score. The dataset corresponds to the AFAM baseline application records (January 2008 to September 2010) matched with the registered employment work histories for the period January 2005 to December 2012 from the Social Security Administration's administrative records (see Section 4.4 for a detailed description of the data). The elasticity formula is given in Equation (4) and discussed in Section 9.1. See Appendix A.1 for more details. "Average" refers to the estimates for the whole sample. Columns (2), (3) and (4) correspond to estimates for the subgroups of individuals with Low, Medium and High predicted propensity to work as a registered employee, respectively. See Section 7 for a detailed explanation of the procedure to determine these predicted probabilities. " $\triangle$ Registered Employment" represents the differences in registered employment between eligible and ineligible individuals as given by the quadratic polynomial RD model with covariates in Table 3 (Panel B, Column (1), first row) and Table 5 (Column (1), first row). "Registered Employment (Ineligible)" denotes the registered employment rate for ineligible individuals (the control group). The "Net-of-Participation Tax Rate" is given by Equation (3) in Appendix A.1, and it is derived from the combination of taxes and transfers (including the AFAM schedule) faced by individuals at the bottom of the income distribution in Uruguay. The differences in this tax between eligible and ineligible individuals are given by Equation (4) in Appendix A.1. The "Net-of-Participation Tax Rate (Ineligible)" is computed as the mean value for ineligible individuals.

Table 8: Efficiency Effects of AFAM

\begin{tabular}{lc}
\hline Participation Tax Rate $(p t r)$ without AFAM Benefit (Ineligible) & 0.211 \\
Average Participation Tax Ratio (Ineligible) & 0.268 \\
$\triangle$ in $p t r$ (due to AFAM's Withdrawal) & 0.071 \\
Elasticity $\left(\epsilon_{R}\right)$ & 1.689 \\
Deadweight Loss as Percentage of Total Labor Income & $3.198 \%$ \\
\hline
\end{tabular}

Notes: The results in this Table are derived from those in Table 7. See the notes to Table 7 and the discussion in Sections 9.1,

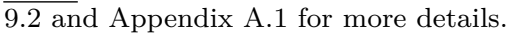


Figure 1: The AFAM Intake Process: Participation Rates and Eligibility Score

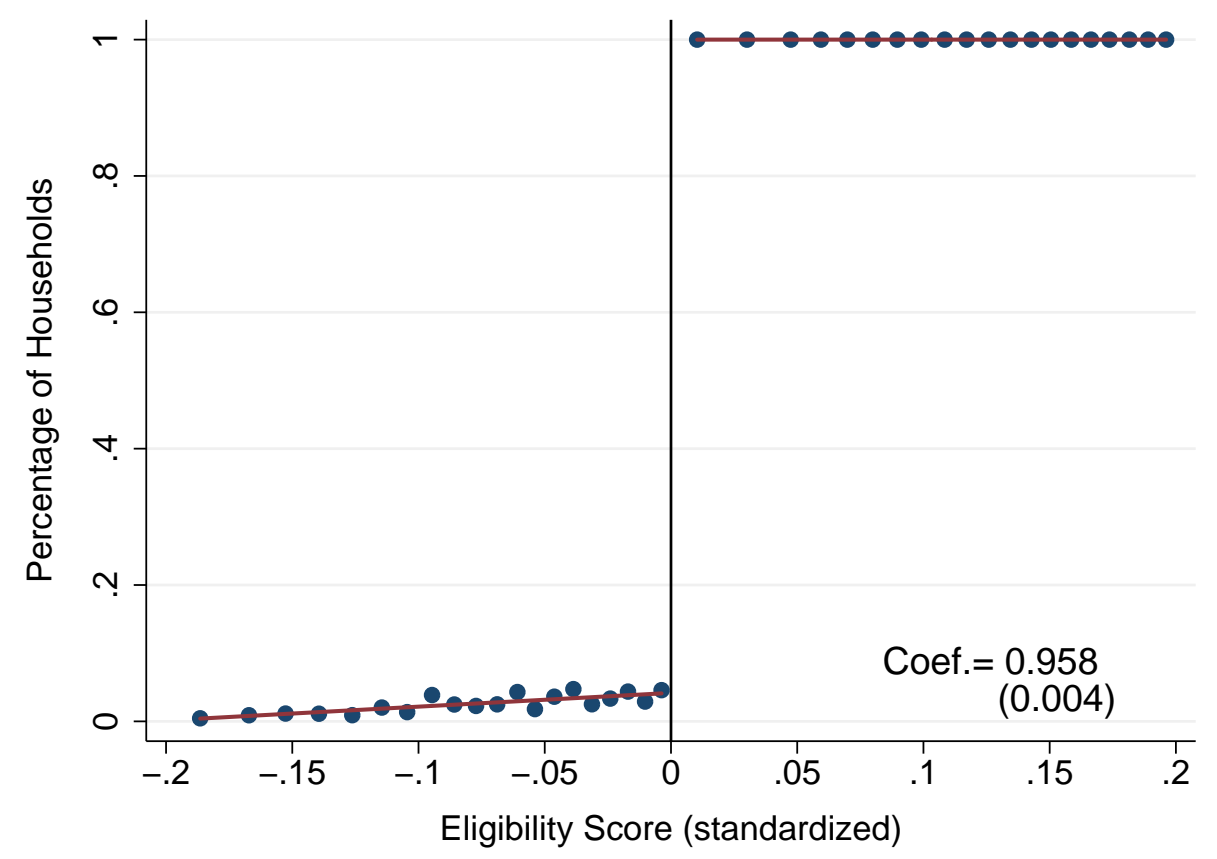

Notes: This figure plots participation in AFAM against the eligibility score for the sample of households with heads and spouses of $\overline{\text { heads }}$ aged 18 to 57 at the time of the application to the program, from households within a range of $[-0.2 ;+0.2]$ of the eligibility score. The dataset corresponds to the AFAM baseline application records (January 2008 to September 2010). The eligibility score is standardized so that the eligibility threshold is zero, with positive scores indicating individuals in eligible households and negative scores indicating ineligible households. Each point (blue circle) in the plot represents the percentage of individuals in applicant households that participated in AFAM in eligibility score bins of one percentage point. The red solid line plots predicted values from a second degree polynomial model estimated at each side of the eligibility threshold. "Coef." reports the estimated coefficient (and its corresponding standard error in parenthesis) from a quadratic polynomial RD regression without additional covariates. 
Figure 2: Registered Employment Rates by Eligibility Score, Pre and Post Application

a) Pre-Application period

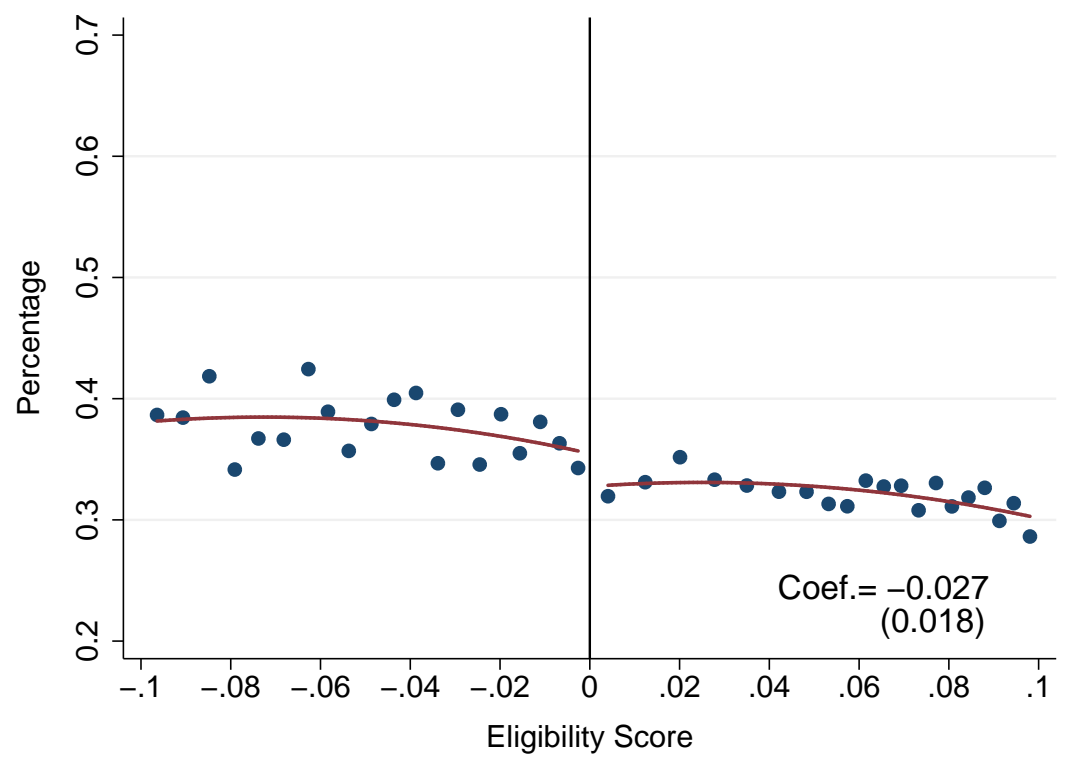

b) Post-Application period

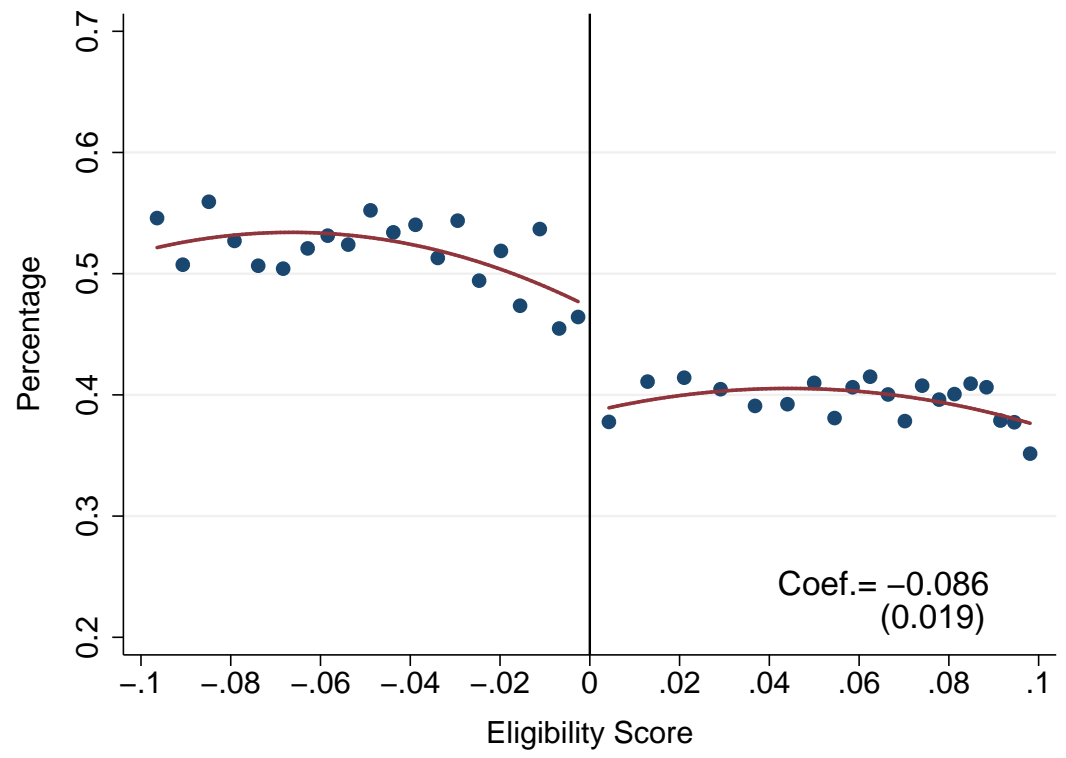

Notes: This figure plots registered employment against the eligibility score. The sample corresponds to heads of households and spouses of heads of households aged 18 to 57 at the time of application to AFAM during the period January 2008 to September 2010 , from households within a range of $[-0.1 ;+0.1]$ of the eligibility score. The dataset corresponds to the AFAM baseline application records (January 2008 to September 2010) matched with the registered employment work histories for the period January 2005 to December 2012 from the Social Security Administration's administrative records (see Section 4.4 for a detailed description of the data). The eligibility score is standardized so that the eligibility threshold is zero, with positive scores indicating individuals in eligible households and negative scores indicating individuals in ineligible households. Each point (blue circle) in the plot represents the average value of the outcome variable in eligibility score bins of one half of a percentage point. The red solid line plots predicted values from a second degree polynomial model estimated at each side of the eligibility threshold. "Coef." reports the estimated coefficient (and its corresponding standard error in parenthesis) from a quadratic polynomial RD regression without additional covariates. 
Figure 3: Effect of AFAM Eligibility on Registered Employment Over Time. Estimates by Semester

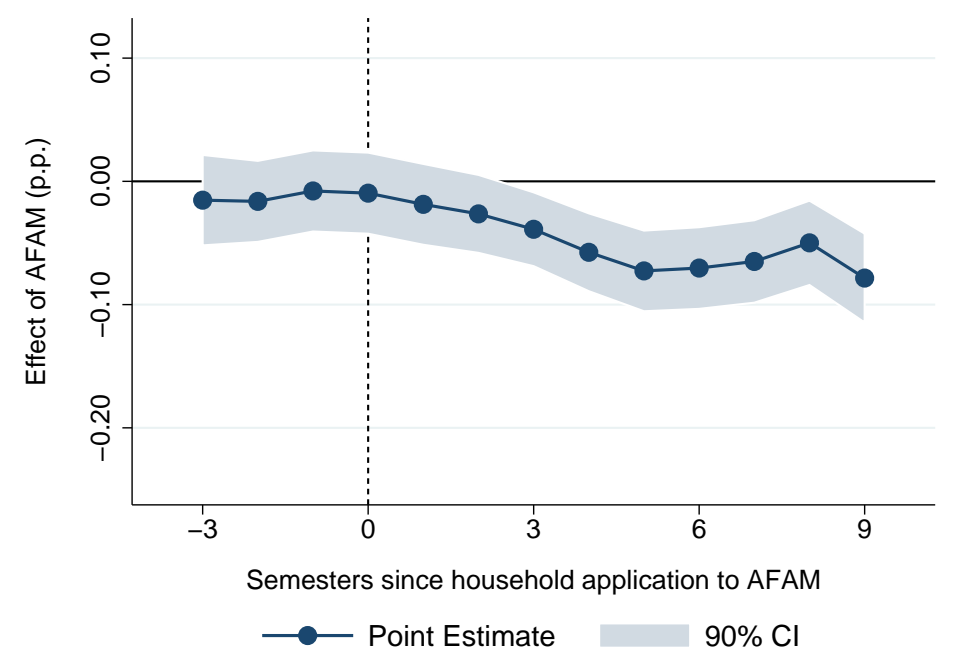

Notes: The sample corresponds to heads of households and spouses of heads of households aged 18 to 57 at the time of application to AFAM during the period January 2008 to September 2010, from households within a range of $[-0.1 ;+0.1]$ of the eligibility score. The dataset corresponds to the AFAM baseline application records (January 2008 to September 2010) matched with the registered employment work histories for the period January 2005 to December 2012 from the Social Security Administration's administrative records (see Section 4.4 for a detailed description of the data). Each point (blue circle) in the plot represents the estimate of the effect of eligibility on registered employment for a specific semester from one to three semesters before application to AFAM, and up to 9 semesters after applying to the program. All regressions include covariates as controls (see notes to Table 3). The estimates correspond to the quadratic RD polynomial, estimated separately on either side of the eligibility cutoff. The gray band plots $90 \%$ confidence interval based on standard errors clustered at the individual level.

Figure 4: RD Estimates of AFAM Eligibility on Registered Employment for Different Bandwidths

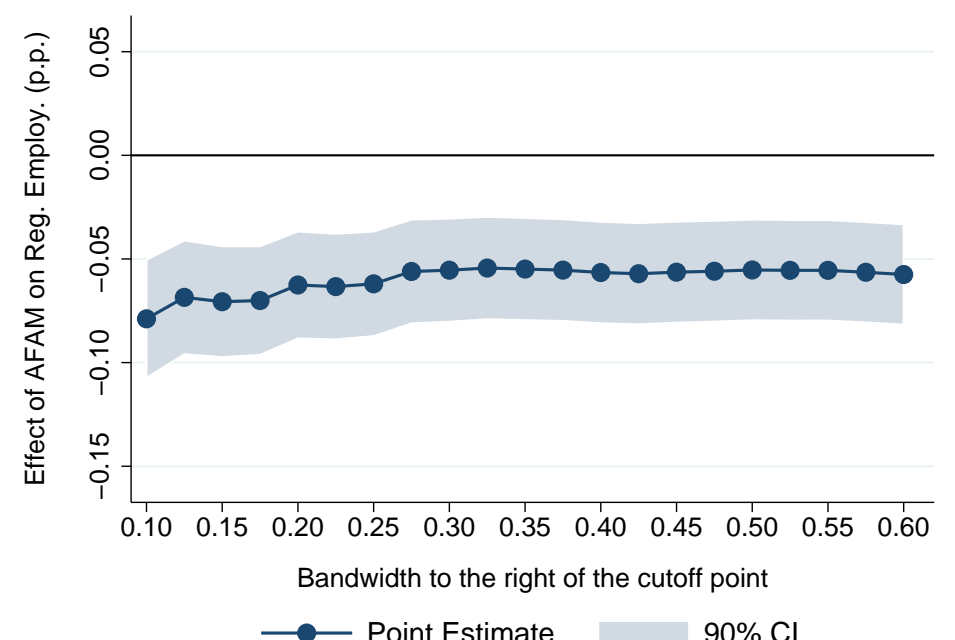

Notes: This figure plots the effect of AFAM eligibility on registered employment for different bandwidths. The sample corresponds to heads of households and spouses of heads of households aged 18 to 57 at the time of application to AFAM during the period January 2008 to September 2010, from households within different ranges of the eligibility score. The dataset corresponds to the AFAM baseline application records (January 2008 to September 2010) matched with the registered employment work histories for the period January 2005 to December 2012 from the Social Security Administration's administrative records (see Section 4.4 for a detailed description of the data). Each point represents the results from a different RD specification, in which we increase the bandwidth to the right of the eligibility threshold by one quarter of a percentage point - i.e., the first point in the figure corresponds to a regression with a bandwidth of $[-0.1 ;+0.1]$ while the last point corresponds to a bandwidth of $[-0.1 ;+0.6]$. All regressions include covariates as controls (see notes to Table 3). The estimates correspond to the quadratic RD polynomial, estimated separately on either side of the eligibility cutoff. The gray band plots $90 \%$ confidence interval based on standard errors clustered at the individual level. 


\title{
APPENDIX: ONLY FOR ONLINE PUBLICATION
}

\author{
The Anatomy of Behavioral Responses to Social Assistance \\ when Informal Employment is High \\ Marcelo Bergolo and Guillermo Cruces
}

August 2016 


\section{A.1 Computation of the Elasticity of Participation in Reg- istered Employment}

As discussed in the main text, we compute the elasticity of participation in registered employment with respect to the participation tax rate (ptr) based on the Kostol and Mogstad (2014) framework. In Section 9 (main text), we defined this elasticity as:

$$
\epsilon_{R}=\frac{1-p t r}{R(q)} \cdot \frac{\triangle R(q)}{\triangle(1-p t r)}
$$

where we define the relevant variables as follows:

- (1-ptr) is the mean of the net participation tax rate for the ineligible group - i.e., (1$\left.p t r_{\text {ineligible }}\right)$.

- $\triangle(1-p t r)$ is the difference in the net of participation tax rate between eligible and ineligible applicants.

- $R(q)$ is the registered employment rate for ineligible individuals - i.e., $R_{\text {ineligible }}$

- $\triangle R(q)$ is the difference in registered employment between eligible and ineligible individuals, i.e., $\triangle R$.

By using this change of notation we can express $\epsilon_{R}$ in equation (A.1.1) as:

$$
\epsilon_{R}=\frac{1-p t r_{\text {ineligible }}}{R_{\text {ineligible }}} \cdot \frac{\triangle R}{\triangle(1-p t r)}
$$

Our analysis covers both the entire sample and the three sub-samples of individuals grouped according to their propensity to work as a formal employee, as in Section 7. We obtain estimates of $R_{\text {ineligible }}$ as the average registered employment rate for ineligible individuals for the whole sample and for the three subgroups separately. Finally, $\triangle R$ corresponds to the estimates from the RD model with controls, with results presented in Tables 3 and 5 .

Since we do not have information on earnings in our data, we must make some assumptions regarding the definition and the computation of the participation tax rate ptr, a key input to find the elasticity $\epsilon_{R}$. We obtain earnings from an imputation based on Uruguay's National Household Survey (Encuesta Continua de Hogares) for the period 2008-2012. Based on a sample of registered workers with household income below the poverty line, we regress registered earnings on a series of covariates listed in Table 3 (with the exception of variables for: previous enrollment in PANES program and being employed at baseline, due to those variables are unavailable in the Household Survey). As described in detail in the following section, we use the estimated coefficients to predict registered employment earnings $\widehat{y}_{i}$ (from work as wage earners and as self-employed) for all individuals in our AFAM database. 
We obtain the net transfers $T\left(\widehat{y}_{i}\right)$ based on Uruguay's tax levels and the AFAM transfer schedule according to each individual and her household characteristics. The tax schedule for low income registered workers in Uruguay is fairly simple - their earnings are only subject to a payroll tax (in fact, social security contributions) amounting to 18.09 percent for very low incomes and 21.13 percent for the next range of gross earnings, paid by the employer. ${ }^{36}$ The income tax minimum threshold is well above the earnings of low income workers, so we assume that the target population of AFAM is not liable for personal income taxes. We compute the exact AFAM benefit for each individual according to the formula given by equation (1) (main text of the paper). We obtained the information required to compute the exact benefit from the program's administrative database. The effective ptr also accounts for the loss of the AFAM benefit when earnings from registered earnings are above the program's eligibility threshold.

Based on these inputs - imputed incomes, taxes and transfers - we compute the ptr for every individual in our database. The effective $p t r$ at a given level of imputed earnings from registered employment $\widehat{y}_{k}$ is given by the difference between net taxes and transfers at that level of income $T\left(\widehat{y}_{k}\right)$ and at zero earnings from registered employment, $T(0)$. The ptr as a proportion of imputed earnings is thus:

$$
p t r_{k}=\frac{T\left(\widehat{y}_{k}\right)-T(0)}{\widehat{y}_{k}}
$$

We then define the difference in $p t r$ as the weighted difference between the $p t r$ rates for eligible and ineligible individuals:

$$
\triangle p t r=\sum\left[E\left(p t r_{k} \mid \text { eligible }\right)-E\left(p t r_{k} \mid \text { ineligible }\right)\right] p_{k}
$$

where we define $k=10$ bins of earnings from registered earnings $\widehat{y}_{k}$ by $d k$ increments, and we compute $p t r_{k}$ at the average income for each bin. E (PTR $R_{k} \mid$ eligible $)$ is the average $p t r$ for eligible individuals and $E\left(P T R_{k} \mid\right.$ ineligible $)$ is the average $p t r$ for ineligible individuals. The weights $p_{k}$ reflect the density of the income distribution function for the ineligible individuals, and they are computed as:

$$
p_{k}=\frac{\operatorname{Pr}\left(k \leq \widehat{y}_{k}<k+d k \mid \text { ineligible }\right)}{\sum_{k>0} \operatorname{Pr}\left(k \leq \widehat{y}_{k}<k+d k \mid \text { ineligible }\right)}
$$

This implies that $\triangle p t r$ is the weighted sum of the differences between registered employment participation tax rates for eligible and ineligible individuals, with weights given by the (conditional) density of the registered earnings of ineligible individuals who work as registered employees.

In the context of our analysis, the payroll tax does not vary substantially between individuals, so the main source of variation in the incentives to participation in registered employment is

\footnotetext{
${ }^{36}$ Employers are liable for payroll tax on earnings in the form of social security contributions of up to 13 percent of gross earnings. We implicitly assume that workers and employers each pay the statutory rate assigned by the tax authorities. If registered employees bear the full incidence of the sum of employee and employer payroll taxes, the effective tax rate would be higher than what we use in our computation.
} 
the variation given by the gain/loss of the AFAM transfer above/below the program's registered earnings eligibility threshold.

\section{A.2 Imputation of Individual Earnings from Registered Employment}

A key input to compute the participation tax rate is the level of earnings from registered employment at the individual level, which is not available in our data. We rely on a standard imputation procedure based on the data from the 2008-2012 Uruguay's National Household Survey (Encuesta Continua de Hogares, henceforth ECH). The ECH is a nationally representative household survey conducted according to international standards. It combines elements of living standards and labor force surveys, and it is the main source for socioeconomic, labor and demographic indicators in Uruguay. The microdata and supporting documents, such as questionnaires and details on sample selection and stratification, are all made available to the public by the Instituto Nacional de Estadísticas. ${ }^{37}$

The imputation procedure consists of a series of steps. First, based on the ECH microdata we estimate the likelihood that an individual participates in (and has earnings from) registered employment for the subsample of individuals under the poverty line - i.e., the population targeted by the AFAM program - in a baseline year. The imputation of earnings from registered employment is based on a simple earnings regression, specified as follows:

$$
R E_{i}=X_{i} \alpha+\widehat{P}_{i} \beta+\varepsilon_{i}
$$

where $R E_{i}$ is earnings for individual $i$, and $X$ corresponds to a set of demographic and household characteristics, including age, head of the household indicator, marital status, education level (in three categories), the number children in the household under 18, an indicator for residency in the capital city (Montevideo), and an indicator for participation in AFAM. To account for the self-selection of workers in registered employment, we include a propensity score - the predicted probability of participation in registered employment - as an additional control in the earnings equation. We estimate this predicted probability from a probit model as follows:

$$
P\left(P R E_{i}=1\right)=\Phi\left(Z_{i} \gamma\right)
$$

where $P R E$ is participation in registered employment, and the variables $Z$ include the same demographic controls as in $X$ in the earnings equation, plus an additional variable indicating whether the spouse of the individual is a registered employee, as in Galiani and Weinschelbaum (2012). Thus, we identify the selection effect based on the registered participation of the individual's spouse.

The next step implies using the estimated coefficients of the earnings model for each year to

\footnotetext{
${ }^{37}$ http://www.ine.gub.uy
} 
predict the earnings from registered employment among individuals in our AFAM database. We impute potential earnings from registered employment for individuals who are working and for those who are not. Finally, we use the predicted earnings to simulate the participation tax rates (with and without the AFAM program) as described in the previous section. 


\section{A.3 Additional Results: Tables}

\section{A.3.1 Timing of Application to AFAM}

Table A.1: Determinants of Household Application Date to AFAM

\begin{tabular}{|c|c|}
\hline \multicolumn{2}{|l|}{ Dep. Var.: Date of application } \\
\hline Eligibility Score & $\begin{array}{c}-6.997^{* * *} \\
(0.155)\end{array}$ \\
\hline Female applicants & $\begin{array}{c}-0.613^{* * *} \\
(0.039)\end{array}$ \\
\hline Age at application to AFAM & $\begin{array}{c}-0.057^{* * *} \\
(0.002)\end{array}$ \\
\hline Household head & $\begin{array}{c}0.150^{* * *} \\
(0.041)\end{array}$ \\
\hline Montevideo & $\begin{array}{c}0.270^{* * *} \\
(0.034)\end{array}$ \\
\hline Less than Primary (\%) & $\begin{array}{c}2.386^{* * *} \\
(0.159)\end{array}$ \\
\hline Complete Primary (\%) & $\begin{array}{c}-0.344^{* * *} \\
(0.065)\end{array}$ \\
\hline Secondary or more (\%) & $\begin{array}{c}-0.214^{* * *} \\
(0.065)\end{array}$ \\
\hline Married & $\begin{array}{c}1.794^{* * *} \\
(0.041)\end{array}$ \\
\hline Married missing & $\begin{array}{c}3.361^{* * *} \\
(0.084)\end{array}$ \\
\hline Enrolled & $\begin{array}{c}-5.826^{* * *} \\
(0.036)\end{array}$ \\
\hline Number of children $<18$ years at home & $\begin{array}{c}-0.053 \\
(0.038)\end{array}$ \\
\hline Employed & $\begin{array}{c}-0.835^{* * *} \\
(0.034)\end{array}$ \\
\hline Employed missing & $\begin{array}{c}-2.825^{* * *} \\
(0.079)\end{array}$ \\
\hline Constant & $\begin{array}{c}14.726^{* * *} \\
(0.117)\end{array}$ \\
\hline R-squared & 0.22 \\
\hline Observations & 240,145 \\
\hline
\end{tabular}

Notes: The sample corresponds to the entire population of applicant households with adults aged 18 to 57 at the time of the $\overline{\text { AFAM }}$ application during the period January 2008 to September 2010. The dataset corresponds to the AFAM baseline application records (January 2008 to September 2010). The dependent variable is date of application to AFAM defined as the month and year of household application date expressed as an index equal to one in January 2008. All individual/household characteristics presented in this table are measured at the date of application, i.e. before the administrative decision on enrollment to the program. Huber-White robust standard errors in parentheses. ${ }^{*}$ significant at $10 \%$; ${ }^{*}$ significant at $5 \%$; ${ }^{* * *}$ significant at $1 \%$. 


\section{A.3.2 Robustness of Balance Checks}

Table A.2: Baseline Characteristics - Range of $[-0.02 ; 0.02]$ of the Eligibility Score

\begin{tabular}{|c|c|c|c|c|}
\hline & $\begin{array}{c}\text { Eligible } \\
\text { Individuals } \\
\end{array}$ & $\begin{array}{c}\text { Ineligible } \\
\text { Individuals } \\
\end{array}$ & $\begin{array}{c}\text { P-Value } \\
\text { of the Difference }\end{array}$ & $\begin{array}{c}\mathrm{RD} \\
\text { Estimate }\end{array}$ \\
\hline & (1) & $(2)$ & $(3)$ & $(4)$ \\
\hline Female applicants (\%) & $\begin{array}{l}70.92 \\
(0.94)\end{array}$ & $\begin{array}{l}71.00 \\
(1.26)\end{array}$ & 0.96 & $\begin{array}{l}-0.30 \\
(4.80)\end{array}$ \\
\hline Household head (\%) & $\begin{array}{l}78.55 \\
(0.85)\end{array}$ & $\begin{array}{l}77.43 \\
(1.16)\end{array}$ & 0.43 & $\begin{array}{c}0.57 \\
(4.38)\end{array}$ \\
\hline Female head (within heads) (\%) & $\begin{array}{l}78.09 \\
(0.96)\end{array}$ & $\begin{array}{l}77.57 \\
(1.31)\end{array}$ & 0.75 & $\begin{array}{c}0.44 \\
(4.89)\end{array}$ \\
\hline Age at application to AFAM & $\begin{array}{l}36.66 \\
(0.18)\end{array}$ & $\begin{array}{l}38.38 \\
(0.24)\end{array}$ & 0.00 & $\begin{array}{l}-1.17 \\
(0.95)\end{array}$ \\
\hline Less than Primary (\%) & $\begin{array}{c}0.59 \\
(0.16)\end{array}$ & $\begin{array}{c}0.23 \\
(0.13)\end{array}$ & 0.12 & $\begin{array}{c}0.63 \\
(0.47)\end{array}$ \\
\hline Complete Primary $(\%)$ & $\begin{array}{l}30.18 \\
(0.95)\end{array}$ & $\begin{array}{l}27.93 \\
(1.24)\end{array}$ & 0.15 & $\begin{array}{l}-6.25 \\
(4.81)\end{array}$ \\
\hline Secondary or more $(\%)$ & $\begin{array}{l}55.62 \\
(1.02)\end{array}$ & $\begin{array}{l}61.21 \\
(1.35)\end{array}$ & 0.00 & $\begin{array}{c}1.63 \\
(5.31)\end{array}$ \\
\hline Married/in couple (\%) & $\begin{array}{l}44.38 \\
(1.05)\end{array}$ & $\begin{array}{l}45.40 \\
(1.40)\end{array}$ & 0.56 & $\begin{array}{c}2.33 \\
(5.41)\end{array}$ \\
\hline Single mother (within singles) (\%) & $\begin{array}{l}88.04 \\
(0.92)\end{array}$ & $\begin{array}{l}87.35 \\
(1.27)\end{array}$ & 0.66 & $\begin{array}{c}4.45 \\
(4.56)\end{array}$ \\
\hline Number of children & $\begin{array}{c}1.47 \\
(0.02)\end{array}$ & $\begin{array}{c}1.29 \\
(0.02)\end{array}$ & 0.00 & $\begin{array}{c}0.04 \\
(0.09)\end{array}$ \\
\hline Enrolled in PANES (\%) & $\begin{array}{c}9.83 \\
(0.61)\end{array}$ & $\begin{array}{c}5.74 \\
(0.64)\end{array}$ & 0.00 & $\begin{array}{l}5.45^{*} \\
(2.45)\end{array}$ \\
\hline Montevideo (capital city) (\%) & $\begin{array}{l}31.16 \\
(0.95)\end{array}$ & $\begin{array}{l}35.35 \\
(1.32)\end{array}$ & 0.01 & $\begin{array}{c}0.02 \\
(5.05)\end{array}$ \\
\hline Employed (\%) & $\begin{array}{l}53.88 \\
(1.03)\end{array}$ & $\begin{array}{l}55.85 \\
(1.37)\end{array}$ & 0.25 & $\begin{array}{c}1.67 \\
(5.41)\end{array}$ \\
\hline Predicted Reg. Employ. (\%) & $\begin{array}{l}43.33 \\
(0.54)\end{array}$ & $\begin{array}{l}45.19 \\
(0.78)\end{array}$ & 0.04 & $\begin{array}{l}-0.48 \\
(2.87)\end{array}$ \\
\hline Observations & 2,359 & 1,307 & & \\
\hline
\end{tabular}

Notes: The sample corresponds to heads of households and spouses of heads of households aged 18 to 57 at the time of the AFAM

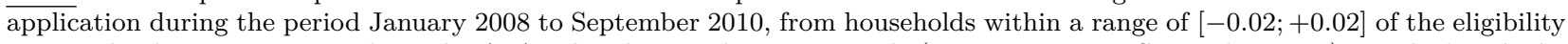
score. The dataset corresponds to the AFAM baseline application records (January 2008 to September 2010) matched with the registered employment work histories for the period January 2005 to December 2012 from the Social Security Administration's administrative records (see Section 4.4 for a detailed description of the data). All individual/household characteristics included in this table correspond to the household's application date, with the exception of the last two rows in the main panel. "Registered 36 months pre" refers to each individual's average registered employment rate for the 36 months before application to AFAM. "Predicted Reg. Employ." refers to a measure of post-application registered employment predicted using the characteristics in Table 1 and pre-application registered employment data. Columns (1) and (2) present the average characteristics for individuals from eligible and ineligible households, respectively. Column (3) reports the p-value on the difference in means of each row's characteristic between individuals in the two groups. Column (4), in turn, reports the coefficient of the AFAM eligibility indicator from a standard RD specification described in Equation (2), with the respective characteristic as the dependent variable. Standard errors in parentheses. * significant at $10 \%$; $*$ significant at $5 \%$; *** significant at $1 \%$. 
Table A.3: Baseline Characteristics - Range of [-0.05; 0.05] of the Eligibility Score

\begin{tabular}{|c|c|c|c|c|}
\hline & $\begin{array}{c}\text { Eligible } \\
\text { Individuals } \\
\end{array}$ & $\begin{array}{c}\text { Ineligible } \\
\text { Individuals } \\
\end{array}$ & $\begin{array}{c}\text { P-Value } \\
\text { of the Difference }\end{array}$ & $\begin{array}{c}\mathrm{RD} \\
\text { Estimate }\end{array}$ \\
\hline & (1) & $(2)$ & $(3)$ & $(4)$ \\
\hline Female applicants (\%) & $\begin{array}{l}70.72 \\
(0.57)\end{array}$ & $\begin{array}{l}70.12 \\
(0.82)\end{array}$ & 0.55 & $\begin{array}{l}-0.41 \\
(2.99)\end{array}$ \\
\hline Household head (\%) & $\begin{array}{l}78.64 \\
(0.51)\end{array}$ & $\begin{array}{l}76.97 \\
(0.76)\end{array}$ & 0.07 & $\begin{array}{c}0.99 \\
(2.75)\end{array}$ \\
\hline Female head (within heads) (\%) & $\begin{array}{l}77.09 \\
(0.59)\end{array}$ & $\begin{array}{l}76.21 \\
(0.87)\end{array}$ & 0.40 & $\begin{array}{l}-0.36 \\
(3.08)\end{array}$ \\
\hline Age at application to AFAM & $\begin{array}{l}36.75 \\
(0.11)\end{array}$ & $\begin{array}{l}38.41 \\
(0.16)\end{array}$ & 0.00 & $\begin{array}{c}-1.56^{* *} \\
(0.58)\end{array}$ \\
\hline Less than Primary (\%) & $\begin{array}{c}0.45 \\
(0.08)\end{array}$ & $\begin{array}{c}0.32 \\
(0.10)\end{array}$ & 0.35 & $\begin{array}{c}0.47 \\
(0.31)\end{array}$ \\
\hline Complete Primary (\%) & $\begin{array}{l}30.17 \\
(0.57)\end{array}$ & $\begin{array}{l}27.71 \\
(0.80)\end{array}$ & 0.01 & $\begin{array}{l}-2.61 \\
(2.97)\end{array}$ \\
\hline Secondary or more $(\%)$ & $\begin{array}{l}56.94 \\
(0.62)\end{array}$ & $\begin{array}{l}59.75 \\
(0.88)\end{array}$ & 0.01 & $\begin{array}{l}-1.92 \\
(3.27)\end{array}$ \\
\hline Married/in couple (\%) & $\begin{array}{l}44.53 \\
(0.64)\end{array}$ & $\begin{array}{l}47.18 \\
(0.92)\end{array}$ & 0.02 & $\begin{array}{l}-0.68 \\
(3.37)\end{array}$ \\
\hline Single mother (within singles) (\%) & $\begin{array}{l}87.80 \\
(0.57)\end{array}$ & $\begin{array}{l}87.65 \\
(0.83)\end{array}$ & 0.88 & $\begin{array}{c}0.91 \\
(2.84)\end{array}$ \\
\hline Number of children & $\begin{array}{c}1.45 \\
(0.01)\end{array}$ & $\begin{array}{c}1.26 \\
(0.01)\end{array}$ & 0.00 & $\begin{array}{l}0.17^{* *} \\
(0.06)\end{array}$ \\
\hline Enrolled in PANES (\%) & $\begin{array}{l}10.32 \\
(0.38)\end{array}$ & $\begin{array}{c}4.84 \\
(0.39)\end{array}$ & 0.00 & $\begin{array}{l}5.91^{* *} \\
(1.58)\end{array}$ \\
\hline Montevideo (capital city) (\%) & $\begin{array}{l}29.89 \\
(0.57)\end{array}$ & $\begin{array}{l}34.79 \\
(0.86)\end{array}$ & 0.00 & $\begin{array}{l}-4.04 \\
(3.14)\end{array}$ \\
\hline Employed (\%) & $\begin{array}{l}53.72 \\
(0.62)\end{array}$ & $\begin{array}{l}57.40 \\
(0.89)\end{array}$ & 0.00 & $\begin{array}{l}-4.71 \\
(3.33)\end{array}$ \\
\hline Predicted Reg. Employ. (\%) & $\begin{array}{l}43.26 \\
(0.33)\end{array}$ & $\begin{array}{l}46.28 \\
(0.49)\end{array}$ & 0.00 & $\begin{array}{l}-2.33 \\
(1.76)\end{array}$ \\
\hline Observations & 6,377 & 3,096 & & \\
\hline
\end{tabular}

Notes: The sample corresponds to heads of households and spouses of heads of households aged 18 to 57 at the time of the AFAM

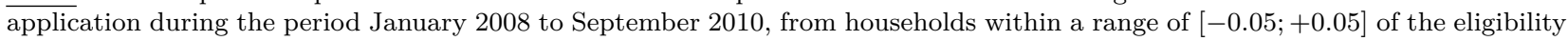
score. The dataset corresponds to the AFAM baseline application records (January 2008 to September 2010) matched with the registered employment work histories for the period January 2005 to December 2012 from the Social Security Administration's administrative records (see Section 4.4 for a detailed description of the data). All individual/household characteristics included in this table correspond to the household's application date, with the exception of the last two rows in the main panel. "Registered 36 months pre" refers to each individual's average registered employment rate for the 36 months before application to AFAM. "Predicted Reg. Employ." refers to a measure of post-application registered employment predicted using the characteristics in Table 1 and pre-application registered employment data. Columns (1) and (2) present the average characteristics for individuals from eligible and ineligible households, respectively. Column (3) reports the p-value on the difference in means of each row's characteristic between individuals in the two groups. Column (4), in turn, reports the coefficient of the AFAM eligibility indicator from a standard RD specification described in Equation (2), with the respective characteristic as the dependent variable. Standard errors in parentheses. $*$ significant at $10 \%$; ${ }^{* *}$ significant at $5 \%$; ${ }^{* * *}$ significant at $1 \%$. 
Table A.4: Baseline Characteristics - Range of $[-0.15 ; 0.15]$ of the Eligibility Score

\begin{tabular}{|c|c|c|c|c|}
\hline & $\begin{array}{c}\text { Eligible } \\
\text { Individuals } \\
\end{array}$ & $\begin{array}{c}\text { Ineligible } \\
\text { Individuals } \\
\end{array}$ & $\begin{array}{c}\text { P-Value } \\
\text { of the Difference }\end{array}$ & $\begin{array}{c}\mathrm{RD} \\
\text { Estimate }\end{array}$ \\
\hline & (1) & $(2)$ & $(3)$ & $(4)$ \\
\hline Female applicants (\%) & $\begin{array}{l}71.30 \\
(0.25)\end{array}$ & $\begin{array}{l}70.02 \\
(0.52)\end{array}$ & 0.03 & $\begin{array}{l}-0.97 \\
(1.72)\end{array}$ \\
\hline Household head (\%) & $\begin{array}{l}79.03 \\
(0.22)\end{array}$ & $\begin{array}{l}76.17 \\
(0.49)\end{array}$ & 0.00 & $\begin{array}{c}0.17 \\
(1.58)\end{array}$ \\
\hline Female head (within heads) (\%) & $\begin{array}{l}77.25 \\
(0.26)\end{array}$ & $\begin{array}{l}76.38 \\
(0.56)\end{array}$ & 0.15 & $\begin{array}{c}0.08 \\
(1.79)\end{array}$ \\
\hline Age at application to AFAM & $\begin{array}{l}36.27 \\
(0.05)\end{array}$ & $\begin{array}{l}38.55 \\
(0.10)\end{array}$ & 0.00 & $\begin{array}{c}-1.72^{* *} \\
(0.33)\end{array}$ \\
\hline Less than Primary (\%) & $\begin{array}{c}0.51 \\
(0.04)\end{array}$ & $\begin{array}{c}0.37 \\
(0.07)\end{array}$ & 0.11 & $\begin{array}{c}0.42 \\
(0.22)\end{array}$ \\
\hline Complete Primary (\%) & $\begin{array}{l}33.51 \\
(0.26)\end{array}$ & $\begin{array}{l}23.66 \\
(0.49)\end{array}$ & 0.00 & $\begin{array}{c}0.01 \\
(1.69)\end{array}$ \\
\hline Secondary or more $(\%)$ & $\begin{array}{l}54.47 \\
(0.27)\end{array}$ & $\begin{array}{l}63.52 \\
(0.55)\end{array}$ & 0.00 & $\begin{array}{l}-3.04 \\
(1.86)\end{array}$ \\
\hline Married/in couple (\%) & $\begin{array}{l}43.42 \\
(0.28)\end{array}$ & $\begin{array}{l}48.75 \\
(0.58)\end{array}$ & 0.00 & $\begin{array}{c}1.50 \\
(1.93)\end{array}$ \\
\hline Single mother (within singles) (\%) & $\begin{array}{l}87.45 \\
(0.24)\end{array}$ & $\begin{array}{l}88.62 \\
(0.52)\end{array}$ & 0.05 & $\begin{array}{c}1.37 \\
(1.70)\end{array}$ \\
\hline Number of children & $\begin{array}{c}1.51 \\
(0.00)\end{array}$ & $\begin{array}{c}1.24 \\
(0.01)\end{array}$ & 0.00 & $\begin{array}{l}0.13^{* *} \\
(0.03)\end{array}$ \\
\hline Enrolled in PANES (\%) & $\begin{array}{l}14.41 \\
(0.19)\end{array}$ & $\begin{array}{c}3.60 \\
(0.21)\end{array}$ & 0.00 & $\begin{array}{l}3.16^{* *} \\
(0.93)\end{array}$ \\
\hline Montevideo (capital city) (\%) & $\begin{array}{l}27.73 \\
(0.24)\end{array}$ & $\begin{array}{l}36.58 \\
(0.55)\end{array}$ & 0.00 & $\begin{array}{l}-3.75^{*} \\
(1.80)\end{array}$ \\
\hline Employed (\%) & $\begin{array}{l}54.49 \\
(0.27)\end{array}$ & $\begin{array}{l}57.61 \\
(0.57)\end{array}$ & 0.00 & $\begin{array}{l}-2.85 \\
(1.89)\end{array}$ \\
\hline Predicted Reg. Employ. (\%) & $\begin{array}{l}41.13 \\
(0.14)\end{array}$ & $\begin{array}{l}46.29 \\
(0.31)\end{array}$ & 0.00 & $\begin{array}{l}-1.96 \\
(1.02)\end{array}$ \\
\hline Observations & 34,058 & 7,658 & & \\
\hline
\end{tabular}

Notes: The sample corresponds to heads of households and spouses of heads of households aged 18 to 57 at the time of the AFAM

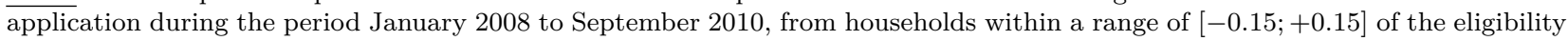
score. The dataset corresponds to the AFAM baseline application records (January 2008 to September 2010) matched with the registered employment work histories for the period January 2005 to December 2012 from the Social Security Administration's administrative records (see Section 4.4 for a detailed description of the data). All individual/household characteristics included in this table correspond to the household's application date, with the exception of the last two rows in the main panel. "Registered 36 months pre" refers to each individual's average registered employment rate for the 36 months before application to AFAM. "Predicted Reg. Employ." refers to a measure of post-application registered employment predicted using the characteristics in Table 1 and pre-application registered employment data. Columns (1) and (2) present the average characteristics for individuals from eligible and ineligible households, respectively. Column (3) reports the p-value on the difference in means of each row's characteristic between individuals in the two groups. Column (4), in turn, reports the coefficient of the AFAM eligibility indicator from a standard RD specification described in Equation (2), with the respective characteristic as the dependent variable. Standard errors in parentheses. * significant at $10 \% ; * *$ significant at $5 \% ; * * *$ significant at $1 \%$. 
Table A.5: Baseline Characteristics - Range of $[-0.2 ; 0.2]$ of the Eligibility Score

\begin{tabular}{|c|c|c|c|c|}
\hline & $\begin{array}{c}\text { Eligible } \\
\text { Individuals } \\
\end{array}$ & $\begin{array}{c}\text { Ineligible } \\
\text { Individuals } \\
\end{array}$ & $\begin{array}{c}\text { P-Value } \\
\text { of the Difference }\end{array}$ & $\begin{array}{c}\mathrm{RD} \\
\text { Estimate }\end{array}$ \\
\hline & (1) & $(2)$ & $(3)$ & $(4)$ \\
\hline Female applicants (\%) & $\begin{array}{l}70.92 \\
(0.94)\end{array}$ & $\begin{array}{l}71.00 \\
(1.26)\end{array}$ & 0.96 & $\begin{array}{l}-0.30 \\
(4.80)\end{array}$ \\
\hline Household head (\%) & $\begin{array}{l}78.55 \\
(0.85)\end{array}$ & $\begin{array}{l}77.43 \\
(1.16)\end{array}$ & 0.43 & $\begin{array}{c}0.57 \\
(4.38)\end{array}$ \\
\hline Female head (within heads) (\%) & $\begin{array}{l}78.09 \\
(0.96)\end{array}$ & $\begin{array}{l}77.57 \\
(1.31)\end{array}$ & 0.75 & $\begin{array}{c}0.44 \\
(4.89)\end{array}$ \\
\hline Age at application to AFAM & $\begin{array}{l}36.66 \\
(0.18)\end{array}$ & $\begin{array}{l}38.38 \\
(0.24)\end{array}$ & 0.00 & $\begin{array}{l}-1.17 \\
(0.95)\end{array}$ \\
\hline Less than Primary (\%) & $\begin{array}{c}0.59 \\
(0.16)\end{array}$ & $\begin{array}{c}0.23 \\
(0.13)\end{array}$ & 0.12 & $\begin{array}{c}0.63 \\
(0.47)\end{array}$ \\
\hline Complete Primary (\%) & $\begin{array}{l}30.18 \\
(0.95)\end{array}$ & $\begin{array}{l}27.93 \\
(1.24)\end{array}$ & 0.15 & $\begin{array}{l}-6.25 \\
(4.81)\end{array}$ \\
\hline Secondary or more $(\%)$ & $\begin{array}{l}55.62 \\
(1.02)\end{array}$ & $\begin{array}{l}61.21 \\
(1.35)\end{array}$ & 0.00 & $\begin{array}{c}1.63 \\
(5.31)\end{array}$ \\
\hline Married/in couple (\%) & $\begin{array}{l}44.38 \\
(1.05)\end{array}$ & $\begin{array}{l}45.40 \\
(1.40)\end{array}$ & 0.56 & $\begin{array}{c}2.33 \\
(5.41)\end{array}$ \\
\hline Single mother (within singles) (\%) & $\begin{array}{l}88.04 \\
(0.92)\end{array}$ & $\begin{array}{l}87.35 \\
(1.27)\end{array}$ & 0.66 & $\begin{array}{c}4.45 \\
(4.56)\end{array}$ \\
\hline Number of children & $\begin{array}{c}1.47 \\
(0.02)\end{array}$ & $\begin{array}{c}1.29 \\
(0.02)\end{array}$ & 0.00 & $\begin{array}{c}0.04 \\
(0.09)\end{array}$ \\
\hline Enrolled in PANES (\%) & $\begin{array}{c}9.83 \\
(0.61)\end{array}$ & $\begin{array}{c}5.74 \\
(0.64)\end{array}$ & 0.00 & $\begin{array}{l}5.45^{*} \\
(2.45)\end{array}$ \\
\hline Montevideo (capital city) (\%) & $\begin{array}{l}31.16 \\
(0.95)\end{array}$ & $\begin{array}{l}35.35 \\
(1.32)\end{array}$ & 0.01 & $\begin{array}{c}0.02 \\
(5.05)\end{array}$ \\
\hline Employed (\%) & $\begin{array}{l}53.88 \\
(1.03)\end{array}$ & $\begin{array}{l}55.85 \\
(1.37)\end{array}$ & 0.25 & $\begin{array}{c}1.67 \\
(5.41)\end{array}$ \\
\hline Predicted Reg. Employ. (\%) & $\begin{array}{l}43.33 \\
(0.54)\end{array}$ & $\begin{array}{l}45.19 \\
(0.78)\end{array}$ & 0.04 & $\begin{array}{l}-0.48 \\
(2.87)\end{array}$ \\
\hline Observations & 2,359 & 1,307 & & \\
\hline
\end{tabular}

Notes: The sample corresponds to heads of households and spouses of heads of households aged 18 to 57 at the time of the AFAM application during the period January 2008 to September 2010 , from households within a range of $[-0.2 ;+0.2]$ of the eligibility score. The dataset corresponds to the AFAM baseline application records (January 2008 to September 2010) matched with the registered employment work histories for the period January 2005 to December 2012 from the Social Security Administration's administrative records (see Section 4.4 for a detailed description of the data). All individual/household characteristics included in this table correspond to the household's application date, with the exception of the last two rows in the main panel. "Registered 36 months pre" refers to each individual's average registered employment rate for the 36 months before application to AFAM. "Predicted Reg. Employ." refers to a measure of post-application registered employment predicted using the characteristics in Table 1 and pre-application registered employment data. Columns (1) and (2) present the average characteristics for individuals from eligible and ineligible households, respectively. Column (3) reports the p-value on the difference in means of each row's characteristic between individuals in the two groups. Column (4), in turn, reports the coefficient of the AFAM eligibility indicator from a standard RD specification described in Equation (2), with the respective characteristic as the dependent variable. Standard errors in parentheses. * significant at $10 \% ; * *$ significant at $5 \% ; * * *$ significant at $1 \%$. 
Table A.6: Baseline Characteristics - Range of $[-0.073 ; 0.073]$ of the Eligibility Score (Optimal Bandwidth)

\begin{tabular}{|c|c|c|c|c|}
\hline & $\begin{array}{c}\text { Eligible } \\
\text { Individuals } \\
\end{array}$ & $\begin{array}{c}\text { Ineligible } \\
\text { Individuals } \\
\end{array}$ & $\begin{array}{c}\text { P-Value } \\
\text { of the Difference } \\
\end{array}$ & $\begin{array}{c}\mathrm{RD} \\
\text { Estimate }\end{array}$ \\
\hline & $(1)$ & (2) & $(3)$ & $(4)$ \\
\hline Female applicants (\%) & $\begin{array}{l}70.86 \\
(0.42)\end{array}$ & $\begin{array}{l}70.21 \\
(0.69)\end{array}$ & 0.42 & $\begin{array}{l}-1.98 \\
(2.46)\end{array}$ \\
\hline Household head (\%) & $\begin{array}{l}78.85 \\
(0.38)\end{array}$ & $\begin{array}{l}76.64 \\
(0.64)\end{array}$ & 0.00 & $\begin{array}{c}0.22 \\
(2.26)\end{array}$ \\
\hline Female head (within heads) (\%) & $\begin{array}{l}76.93 \\
(0.44)\end{array}$ & $\begin{array}{l}76.18 \\
(0.73)\end{array}$ & 0.38 & $\begin{array}{l}-2.80 \\
(2.54)\end{array}$ \\
\hline Age at application to AFAM & $\begin{array}{l}36.60 \\
(0.08)\end{array}$ & $\begin{array}{l}38.52 \\
(0.13)\end{array}$ & 0.00 & $\begin{array}{c}-1.54^{* *} \\
(0.48)\end{array}$ \\
\hline Less than Primary (\%) & $\begin{array}{c}0.47 \\
(0.06)\end{array}$ & $\begin{array}{c}0.32 \\
(0.08)\end{array}$ & 0.18 & $\begin{array}{l}0.57^{*} \\
(0.28)\end{array}$ \\
\hline Complete Primary $(\%)$ & $\begin{array}{l}30.34 \\
(0.43)\end{array}$ & $\begin{array}{l}25.77 \\
(0.66)\end{array}$ & 0.00 & $\begin{array}{c}3.78 \\
(2.43)\end{array}$ \\
\hline Secondary or more $(\%)$ & $\begin{array}{l}56.88 \\
(0.46)\end{array}$ & $\begin{array}{l}61.27 \\
(0.73)\end{array}$ & 0.00 & $\begin{array}{c}-8.86^{* *} \\
(2.67)\end{array}$ \\
\hline Married/in couple (\%) & $\begin{array}{l}43.96 \\
(0.47)\end{array}$ & $\begin{array}{l}47.63 \\
(0.76)\end{array}$ & 0.00 & $\begin{array}{c}1.71 \\
(2.76)\end{array}$ \\
\hline Single mother (within singles) (\%) & $\begin{array}{l}87.29 \\
(0.42)\end{array}$ & $\begin{array}{l}87.87 \\
(0.69)\end{array}$ & 0.47 & $\begin{array}{l}-0.24 \\
(2.38)\end{array}$ \\
\hline Number of children & $\begin{array}{l}1.45 \\
(0.01)\end{array}$ & $\begin{array}{l}1.25 \\
(0.01)\end{array}$ & 0.00 & $\begin{array}{c}0.14^{* *} \\
(0.04)\end{array}$ \\
\hline Enrolled in PANES (\%) & $\begin{array}{l}11.14 \\
(0.29)\end{array}$ & $\begin{array}{c}4.47 \\
(0.31)\end{array}$ & 0.00 & $\begin{array}{l}3.44^{* *} \\
(1.32)\end{array}$ \\
\hline Montevideo (capital city) (\%) & $\begin{array}{l}28.62 \\
(0.42)\end{array}$ & $\begin{array}{l}34.82 \\
(0.72)\end{array}$ & 0.00 & $\begin{array}{l}-2.81 \\
(2.57)\end{array}$ \\
\hline Employed (\%) & $\begin{array}{l}53.93 \\
(0.46)\end{array}$ & $\begin{array}{l}57.55 \\
(0.74)\end{array}$ & 0.00 & $\begin{array}{c}0.32 \\
(2.72)\end{array}$ \\
\hline Predicted Reg. Employ. (\%) & $\begin{array}{l}42.65 \\
(0.24)\end{array}$ & $\begin{array}{l}46.36 \\
(0.42)\end{array}$ & 0.00 & $\begin{array}{l}-1.14 \\
(1.46)\end{array}$ \\
\hline Observations & 11,698 & 4,431 & & \\
\hline
\end{tabular}

Notes: The sample corresponds to heads of households and spouses of heads of households aged 18 to 57 at the time of the AFAM application during the period January 2008 to September 2010, from households within a range of $[-0.073 ;+0.073]$ of the eligibility score. The dataset corresponds to the AFAM baseline application records (January 2008 to September 2010) matched with the registered employment work histories for the period January 2005 to December 2012 from the Social Security Administration's administrative records (see Section 4.4 for a detailed description of the data). All individual/household characteristics included in this table correspond to the household's application date, with the exception of the last two rows in the main panel. "Registered 36 months pre" refers to each individual's average registered employment rate for the 36 months before application to AFAM. "Predicted Reg. Employ." refers to a measure of post-application registered employment predicted using the characteristics in Table 1 and pre-application registered employment data. Columns (1) and (2) present the average characteristics for individuals from eligible and ineligible households, respectively. Column (3) reports the p-value on the difference in means of each row's characteristic between individuals in the two groups. Column (4), in turn, reports the coefficient of the AFAM eligibility indicator from a standard RD specification described in Equation (2), with the respective characteristic as the dependent variable. Standard errors in parentheses. ${ }^{*}$ significant at $10 \% ; * *$ significant at $5 \% ; * * *$ significant at $1 \%$. 
A.3.3 Robustness of the Regression Discontinuity Results 
Table A.7: Effect of AFAM Eligibility on Registered Employment, Alternative Bandwidths and Polynomial Models

\begin{tabular}{|c|c|c|c|c|c|c|c|c|c|c|c|c|}
\hline & \multicolumn{12}{|c|}{ Bandwidths } \\
\hline & \multicolumn{2}{|c|}{ \pm 0.02} & \multicolumn{2}{|c|}{ \pm 0.05} & \multicolumn{2}{|c|}{ \pm 0.10} & \multicolumn{2}{|c|}{ \pm 0.15} & \multicolumn{2}{|c|}{ \pm 0.2} & \multicolumn{2}{|c|}{ \pm 0.073} \\
\hline & $\begin{array}{l}\text { Post } \\
\text { App }\end{array}$ & $\begin{array}{l}\text { Pre } \\
\text { App }\end{array}$ & $\begin{array}{l}\text { Post } \\
\text { App }\end{array}$ & $\begin{array}{c}\text { Pre } \\
\text { App } \\
\end{array}$ & $\begin{array}{l}\text { Post } \\
\text { App } \\
\end{array}$ & $\begin{array}{l}\text { Pre } \\
\text { App }\end{array}$ & $\begin{array}{l}\text { Post } \\
\text { App }\end{array}$ & $\begin{array}{c}\text { Pre } \\
\text { App } \\
\end{array}$ & $\begin{array}{l}\text { Post } \\
\text { App }\end{array}$ & $\begin{array}{l}\text { Pre } \\
\text { App }\end{array}$ & $\begin{array}{l}\text { Post } \\
\text { App }\end{array}$ & $\begin{array}{l}\text { Pre } \\
\text { App } \\
\end{array}$ \\
\hline & $(1)$ & $(2)$ & $(3)$ & $(4)$ & $(5)$ & $(6)$ & $(7)$ & $(8)$ & $(9)$ & $(10)$ & $(11)$ & $(12)$ \\
\hline Linear & $\begin{array}{c}-0.100^{* * *} \\
(0.029)\end{array}$ & $\begin{array}{l}-0.037 \\
(0.027)\end{array}$ & $\begin{array}{c}-0.072^{* * *} \\
(0.018)\end{array}$ & $\begin{array}{c}-0.022 \\
(0.017)\end{array}$ & $\begin{array}{c}-0.087^{* * *} \\
(0.013)\end{array}$ & $\begin{array}{c}-0.025^{* *} \\
(0.012)\end{array}$ & $\begin{array}{c}-0.088^{* * *} \\
(0.010)\end{array}$ & $\begin{array}{c}-0.028 * * * \\
(0.010)\end{array}$ & $\begin{array}{c}-0.088^{* * *} \\
(0.009)\end{array}$ & $\begin{array}{c}-0.025^{* * *} \\
(0.009)\end{array}$ & $\begin{array}{c}-0.089^{* * *} \\
(0.015)\end{array}$ & $\begin{array}{c}-0.024^{*} \\
(0.014)\end{array}$ \\
\hline Linear w/Covariates & $\begin{array}{c}-0.092^{* * *} \\
(0.026)\end{array}$ & $\begin{array}{l}-0.022 \\
(0.025)\end{array}$ & $\begin{array}{c}-0.075^{* * *} \\
(0.016)\end{array}$ & $\begin{array}{l}-0.018 \\
(0.016)\end{array}$ & $\begin{array}{c}-0.080^{* * *} \\
(0.012)\end{array}$ & $\begin{array}{l}-0.016 \\
(0.011)\end{array}$ & $\begin{array}{c}-0.079^{* * *} \\
(0.009)\end{array}$ & & $\begin{array}{c}-0.078^{* * *} \\
(0.008)\end{array}$ & & $\begin{array}{c}-0.083^{* * *} \\
(0.014)\end{array}$ & $\begin{array}{l}-0.015 \\
(0.013)\end{array}$ \\
\hline Linear w/Covariates and FE & $\begin{array}{c}-0.100^{* * *} \\
(0.026)\end{array}$ & $\begin{array}{l}-0.036 \\
(0.025)\end{array}$ & $\begin{array}{c}-0.084^{* * *} \\
(0.017)\end{array}$ & $\begin{array}{c}-0.033^{* *} \\
(0.016)\end{array}$ & $\begin{array}{c}-0.091^{* * *} \\
(0.012)\end{array}$ & $\begin{array}{c}-0.033^{* * *} \\
(0.011)\end{array}$ & $\begin{array}{c}-0.087^{* * *} \\
(0.009)\end{array}$ & $\begin{array}{c}-0.032^{* * *} \\
(0.009)\end{array}$ & $\begin{array}{c}-0.085^{* * *} * \\
(0.008)\end{array}$ & $\begin{array}{c}-0.027^{* * *} \\
(0.008)\end{array}$ & $\begin{array}{c}-0.094^{* * *} \\
(0.014)\end{array}$ & $\begin{array}{c}-0.032^{* *} \\
(0.013)\end{array}$ \\
\hline Quadratic & $\begin{array}{c}-0.083^{*} \\
(0.044)\end{array}$ & $\begin{array}{l}-0.018 \\
(0.041)\end{array}$ & $\begin{array}{c}-0.073^{* * *} \\
(0.027)\end{array}$ & $\begin{array}{c}-0.029 \\
(0.026)\end{array}$ & $\begin{array}{c}-0.086^{* * *} \\
(0.019)\end{array}$ & $\begin{array}{l}-0.027 \\
(0.018)\end{array}$ & $\begin{array}{c}-0.093^{* * *} \\
(0.015)\end{array}$ & $\begin{array}{c}-0.025^{*} \\
(0.015)\end{array}$ & $\begin{array}{c}-0.087^{* * *} \\
(0.014)\end{array}$ & $\begin{array}{c}-0.028^{* *} \\
(0.013)\end{array}$ & $\begin{array}{c}-0.063^{* * *} \\
(0.022)\end{array}$ & $\begin{array}{l}-0.019 \\
(0.021)\end{array}$ \\
\hline Quadratic w/Covariates & $\begin{array}{c}-0.087^{* *} \\
(0.040)\end{array}$ & $\begin{array}{l}-0.011 \\
(0.039)\end{array}$ & $\begin{array}{c}-0.059^{* *} \\
(0.025)\end{array}$ & $\begin{array}{l}-0.010 \\
(0.024)\end{array}$ & $\begin{array}{c}-0.079 * * * \\
(0.017)\end{array}$ & $\begin{array}{l}-0.018 \\
(0.017)\end{array}$ & $\begin{array}{c}-0.084^{* * * *} \\
(0.014)\end{array}$ & $\begin{array}{l}-0.014 \\
(0.014)\end{array}$ & $\begin{array}{c}-0.080^{* * *} \\
(0.012)\end{array}$ & $\begin{array}{l}-0.019 \\
(0.012)\end{array}$ & $\begin{array}{c}-0.064^{* * *} \\
(0.020)\end{array}$ & $\begin{array}{l}-0.014 \\
(0.020)\end{array}$ \\
\hline Quadratic w/Covariates and FE & $\begin{array}{c}-0.093^{* *} \\
(0.041)\end{array}$ & $\begin{array}{l}-0.022 \\
(0.039)\end{array}$ & $\begin{array}{c}-0.066^{* * *} \\
(0.025)\end{array}$ & $\begin{array}{l}-0.021 \\
(0.024)\end{array}$ & $\begin{array}{c}-0.090^{* * *} \\
(0.017)\end{array}$ & $\begin{array}{c}-0.036^{* *} \\
(0.017)\end{array}$ & $\begin{array}{c}-0.094^{* * *} \\
(0.014)\end{array}$ & $\begin{array}{c}-0.032^{* *} \\
(0.014)\end{array}$ & $\begin{array}{c}-0.089^{* * *} \\
(0.012)\end{array}$ & $\begin{array}{c}-0.035^{* * *} \\
(0.012)\end{array}$ & $\begin{array}{c}-0.072^{* * *} \\
(0.020)\end{array}$ & $\begin{array}{l}-0.028 \\
(0.020)\end{array}$ \\
\hline Cubic & $\begin{array}{c}-0.109^{*} \\
(0.060)\end{array}$ & $\begin{array}{c}0.003 \\
(0.056)\end{array}$ & $\begin{array}{c}-0.113^{* * *} \\
(0.037)\end{array}$ & $\begin{array}{l}-0.041 \\
(0.035)\end{array}$ & $\begin{array}{c}-0.049^{*} \\
(0.025)\end{array}$ & $\begin{array}{l}-0.012 \\
(0.024)\end{array}$ & $\begin{array}{c}-0.064^{* * *} \\
(0.021)\end{array}$ & $\begin{array}{l}-0.018 \\
(0.020)\end{array}$ & $\begin{array}{c}-0.085^{* * *} \\
(0.018)\end{array}$ & $\begin{array}{l}-0.020 \\
(0.017)\end{array}$ & $\begin{array}{c}-0.077^{* *} \\
(0.030)\end{array}$ & $\begin{array}{l}-0.035 \\
(0.028)\end{array}$ \\
\hline Cubic w/Covariates & $\begin{array}{c}-0.116^{* *} \\
(0.055)\end{array}$ & $\begin{array}{c}0.004 \\
(0.053)\end{array}$ & $\begin{array}{c}-0.111^{* * *} \\
(0.034)\end{array}$ & $\begin{array}{l}-0.032 \\
(0.033)\end{array}$ & $\begin{array}{c}-0.053^{* *} \\
(0.023)\end{array}$ & $\begin{array}{l}-0.010 \\
(0.023)\end{array}$ & $\begin{array}{c}-0.063^{* * *} \\
(0.019)\end{array}$ & $\begin{array}{l}-0.014 \\
(0.018)\end{array}$ & $\begin{array}{c}-0.078^{* * *} \\
(0.017)\end{array}$ & $\begin{array}{l}-0.010 \\
(0.016)\end{array}$ & $\begin{array}{c}-0.066^{* *} \\
(0.027)\end{array}$ & $\begin{array}{l}-0.020 \\
(0.027)\end{array}$ \\
\hline Cubic w/Covariates and FE & $\begin{array}{c}-0.125^{* *} \\
(0.055)\end{array}$ & $\begin{array}{c}-0.011 \\
(0.053)\end{array}$ & $\begin{array}{c}-0.119^{* * *} \\
(0.034)\end{array}$ & $\begin{array}{l}-0.045 \\
(0.033)\end{array}$ & $\begin{array}{c}-0.060^{* *} \\
(0.023)\end{array}$ & $\begin{array}{l}-0.023 \\
(0.023)\end{array}$ & $\begin{array}{c}-0.073^{* * *} \\
(0.019)\end{array}$ & $\begin{array}{c}-0.031^{*} \\
(0.018)\end{array}$ & $\begin{array}{c}-0.089^{* * *} \\
(0.017)\end{array}$ & $\begin{array}{l}-0.029^{*} \\
(0.016)\end{array}$ & $\begin{array}{c}-0.072^{* * *} \\
(0.028)\end{array}$ & $\begin{array}{l}-0.030 \\
(0.027)\end{array}$ \\
\hline Quartic & $\begin{array}{c}-0.167^{* *} \\
(0.077)\end{array}$ & $\begin{array}{l}-0.064 \\
(0.071)\end{array}$ & $\begin{array}{c}-0.095^{* *} \\
(0.046)\end{array}$ & $\begin{array}{l}-0.007 \\
(0.044)\end{array}$ & $\begin{array}{c}-0.091^{* * *} * \\
(0.032)\end{array}$ & $\begin{array}{l}-0.043 \\
(0.030)\end{array}$ & $\begin{array}{c}-0.073^{* * *} \\
(0.026)\end{array}$ & $\begin{array}{l}-0.030 \\
(0.025)\end{array}$ & $\begin{array}{c}-0.063^{* * *} \\
(0.023)\end{array}$ & $\begin{array}{l}-0.023 \\
(0.022)\end{array}$ & $\begin{array}{c}-0.113^{* * *} \\
(0.038)\end{array}$ & $\begin{array}{l}-0.033 \\
(0.036)\end{array}$ \\
\hline Quartic w/Covariates & $\begin{array}{c}-0.161^{* *} \\
(0.071)\end{array}$ & $\begin{array}{l}-0.050 \\
(0.068)\end{array}$ & $\begin{array}{c}-0.098^{* *} \\
(0.043)\end{array}$ & $\begin{array}{l}-0.002 \\
(0.041)\end{array}$ & $\begin{array}{c}-0.077^{* * *} \\
(0.029)\end{array}$ & $\begin{array}{l}-0.027 \\
(0.029)\end{array}$ & $\begin{array}{c}-0.068^{* * *} \\
(0.024)\end{array}$ & $\begin{array}{l}-0.021 \\
(0.023)\end{array}$ & $\begin{array}{c}-0.063^{* * *} \\
(0.021)\end{array}$ & $\begin{array}{l}-0.019 \\
(0.020)\end{array}$ & $\begin{array}{c}-0.097^{* * *} \\
(0.035)\end{array}$ & $\begin{array}{l}-0.014 \\
(0.034)\end{array}$ \\
\hline Quartic w/Covariates and FE & $\begin{array}{c}-0.170^{* *} \\
(0.071) \\
\end{array}$ & $\begin{array}{l}-0.065 \\
(0.068) \\
\end{array}$ & $\begin{array}{c}-0.105^{* *} \\
(0.043) \\
\end{array}$ & $\begin{array}{l}-0.013 \\
(0.041) \\
\end{array}$ & $\begin{array}{c}-0.083^{* * *} \\
(0.030) \\
\end{array}$ & $\begin{array}{l}-0.037 \\
(0.029) \\
\end{array}$ & $\begin{array}{c}-0.076^{* * *} \\
(0.024) \\
\end{array}$ & $\begin{array}{c}-0.035 \\
(0.023) \\
\end{array}$ & $\begin{array}{c}-0.071^{* * *} \\
(0.021) \\
\end{array}$ & $\begin{array}{c}-0.034^{*} \\
(0.020) \\
\end{array}$ & $\begin{array}{c}-0.105^{* * *} \\
(0.035) \\
\end{array}$ & $\begin{array}{l}-0.026 \\
(0.034) \\
\end{array}$ \\
\hline Observations & 167,085 & 135,642 & 429,565 & 350,501 & $1,140,362$ & 908,831 & $1,954,463$ & $1,543,492$ & $2,870,596$ & $2,249,637$ & 742,119 & 596,773 \\
\hline
\end{tabular}

Notes: The sample corresponds to heads of households and spouses of heads of households aged 18 to 57 at the time of the AFAM application during the period January 2008 to September 2010. The columns correspond to different specifications of the bandwidth - the ranges of the eligibility score from which the households were selected. The dataset corresponds to the AFAM baseline application records (January 2008 to September 2010) matched with the registered employment work histories for the period January 2005 to December 2012 from the Social Security Administration's administrative records (see Section 4.4 for a detailed description of the data). In columns (1), (3), $(5),(7),(9)$, and (11) the dependent variable is registered employment in the post-application period. In columns (2), (4), (6), (8), (10), and (12) the dependent variable is registered employment in the pre-application period. Registered employment, measured as an indicator variable equal to one if the SSA records indicate that there are social security contributions from employment for the individual in a given calendar month, and zero otherwise. All rows and columns report the coefficient on the AFAM eligibility indicator, equal to one if the individual belongs to a household eligible for the program according to the AFAM eligibility rules (i.e., if $s c o r e_{i}>0$ ), and zero otherwise. The rows correspond to different specifications of the RD polynomial, time fixed effects, and controls. When corresponding, the covariates in the regressions include gender, head of the household status, age, marital status, educational level (in 3 categories), the number of children aged 0-17 in the household, whether the household was enrolled in the PANES program, residence in Montevideo (Uruguay's capital), and whether the individual was a registered employee. All covariates correspond to the date when the household applied to the program. Standard errors clustered at the individual level in parentheses. ${ }^{*}$ significant at $10 \% ;{ }^{* *}$ significant at $5 \%$; $* * *$ significant at $1 \%$. 
Table A.8: Effect of AFAM Eligibility on Registered Employment, Local Linear Regression Estimates

\begin{tabular}{|c|c|c|c|c|c|c|c|c|c|c|c|c|}
\hline & \multicolumn{12}{|c|}{ Bandwidths } \\
\hline & \multicolumn{2}{|c|}{ \pm 0.073} & \multicolumn{2}{|c|}{ \pm 0.02} & \multicolumn{2}{|c|}{ \pm 0.05} & \multicolumn{2}{|c|}{ \pm 0.10} & \multicolumn{2}{|c|}{ \pm 0.15} & \multicolumn{2}{|c|}{ \pm 0.2} \\
\hline & $\begin{array}{l}\text { Post } \\
\text { App }\end{array}$ & $\begin{array}{l}\text { Pre } \\
\text { App }\end{array}$ & $\begin{array}{l}\text { Post } \\
\text { App }\end{array}$ & $\begin{array}{l}\text { Pre } \\
\text { App }\end{array}$ & $\begin{array}{l}\text { Post } \\
\text { App }\end{array}$ & $\begin{array}{l}\text { Pre } \\
\text { App }\end{array}$ & $\begin{array}{l}\text { Post } \\
\text { App }\end{array}$ & $\begin{array}{l}\text { Pre } \\
\text { App }\end{array}$ & $\begin{array}{l}\text { Post } \\
\text { App }\end{array}$ & $\begin{array}{l}\text { Pre } \\
\text { App }\end{array}$ & $\begin{array}{l}\text { Post } \\
\text { App }\end{array}$ & $\begin{array}{l}\text { Pre } \\
\text { App }\end{array}$ \\
\hline & $(1)$ & $(2)$ & $(3)$ & $(4)$ & $(5)$ & $(6)$ & $(7)$ & $(8)$ & $(9)$ & $(10)$ & $(11)$ & $(12)$ \\
\hline \multicolumn{13}{|c|}{ Panel A. No Covariates } \\
\hline Elegible & $\begin{array}{c}-0.070^{* * *} \\
(0.016)\end{array}$ & $\begin{array}{c}-0.022 \\
(0.015)\end{array}$ & $\begin{array}{c}-0.081^{* * *} \\
(0.031)\end{array}$ & $\begin{array}{l}-0.030 \\
(0.029)\end{array}$ & $\begin{array}{c}-0.063^{* * *} \\
(0.019)\end{array}$ & $\begin{array}{c}-0.025 \\
(0.019)\end{array}$ & $\begin{array}{c}-0.079^{* * *} \\
(0.014)\end{array}$ & $\begin{array}{c}-0.026^{* *} \\
(0.013)\end{array}$ & $\begin{array}{c}-0.081^{* * *} \\
(0.011)\end{array}$ & $\begin{array}{c}-0.027^{* * *} \\
(0.011)\end{array}$ & $\begin{array}{c}-0.079^{* * *} \\
(0.010)\end{array}$ & $\begin{array}{c}-0.026^{* * *} \\
(0.009)\end{array}$ \\
\hline Observations & 16,129 & 16,129 & 3,666 & 3,666 & 9,473 & 9,473 & 24,563 & 24,563 & 41,716 & 41,716 & 60,801 & 60,801 \\
\hline \multicolumn{13}{|c|}{ Panel B. With Covariates } \\
\hline Elegible & $\begin{array}{c}-0.065^{* * *} \\
(0.015)\end{array}$ & $\begin{array}{l}-0.013 \\
(0.014)\end{array}$ & $\begin{array}{c}-0.076^{* * *} \\
(0.028)\end{array}$ & $\begin{array}{l}-0.018 \\
(0.028)\end{array}$ & $\begin{array}{c}-0.056^{* * *} \\
(0.018)\end{array}$ & $\begin{array}{c}-0.014 \\
(0.017)\end{array}$ & $\begin{array}{c}-0.071^{* * *} \\
(0.013)\end{array}$ & $\begin{array}{l}-0.014 \\
(0.012)\end{array}$ & $\begin{array}{c}-0.073^{* * *} \\
(0.010)\end{array}$ & $\begin{array}{c}-0.015 \\
(0.010)\end{array}$ & $\begin{array}{c}-0.071^{* * *} \\
(0.009)\end{array}$ & $\begin{array}{c}-0.015^{*} \\
(0.009)\end{array}$ \\
\hline Observations & 16,129 & 16,129 & 3,666 & 3,666 & 9,473 & 9,473 & 24,563 & 24,563 & 41,716 & 41,716 & 60,801 & 60,801 \\
\hline
\end{tabular}

Notes: The sample corresponds to heads of households and spouses of heads of households aged 18 to 57 at the time of the AFAM application during the period January 2008 to September 2010. The columns correspond to different specifications of the bandwidth - the ranges of the eligibility score from which the households were selected. The dataset corresponds to the AFAM baseline application records (January 2008 to September 2010) matched with the registered employment work histories for the period January 2005 to December 2012 from the Social Security Administration's administrative records (see Section 4.4 for a detailed description of the data). Panels A and B present estimates from the regression discontinuity model without covariates and with covariates, respectively. The estimation uses a local linear regression with a triangular kernel density function on each side of the eligibility threshold. In columns (1), (3), (5), (7), (9), and (11) the dependent variable is registered employment in the post-application period. In columns (2), (4), (6), (8), (10), and (12) the dependent variable is registered employment in the pre-application period. Registered employment is measured as an indicator variable equal to one if the SSA records indicate that there are social security contributions from employment for the individual in a given calendar month, and zero otherwise. The coefficients correspond to the "Eligible" variable, an indicator equal to one if the individual belongs to a household eligible for the program according to the otherwise. The coefficients correspond to the "Eligible" variable, an indicator equal to one if the individual belongs to a household eligible for the program according to the
AFAM eligibility rules (i.e., if score $_{i}>0$ ), and zero otherwise. The covariates in the regressions in Panel B include gender, head of the household status, age, marital status, educational level (in 3 categories), the number of children aged 0-17 in the household, whether the household was enrolled in the PANES program, residence in Montevideo (Uruguay's capital), and whether the individual was a registered employee. All covariates correspond to the date when the household applied to the program. Standard errors clustered at the individual level in parentheses. ${ }^{*}$ significant at $10 \%$; ${ }^{* *}$ significant at $5 \%$; ${ }^{* *}$ significant at $1 \%$. 
Table A.9: Effect of AFAM Eligibility on Registered Employment, Alternative Standard Errors

\begin{tabular}{|c|c|c|c|c|c|c|c|c|c|c|c|c|}
\hline & \multicolumn{12}{|c|}{ Bandwidths } \\
\hline & \multicolumn{2}{|c|}{ \pm 0.02} & \multicolumn{2}{|c|}{ \pm 0.05} & \multicolumn{2}{|c|}{ \pm 0.10} & \multicolumn{2}{|c|}{ \pm 0.15} & \multicolumn{2}{|c|}{ \pm 0.2} & \multicolumn{2}{|c|}{ \pm 0.073} \\
\hline & $\begin{array}{l}\text { Post } \\
\text { App } \\
\end{array}$ & $\begin{array}{l}\text { Pre } \\
\text { App }\end{array}$ & $\begin{array}{l}\text { Post } \\
\text { App }\end{array}$ & $\begin{array}{l}\text { Pre } \\
\text { App }\end{array}$ & $\begin{array}{l}\text { Post } \\
\text { App }\end{array}$ & $\begin{array}{l}\text { Pre } \\
\text { App }\end{array}$ & $\begin{array}{l}\text { Post } \\
\text { App }\end{array}$ & $\begin{array}{l}\text { Pre } \\
\text { App }\end{array}$ & $\begin{array}{l}\text { Post } \\
\text { App }\end{array}$ & $\begin{array}{l}\text { Pre } \\
\text { App }\end{array}$ & $\begin{array}{l}\text { Post } \\
\text { App }\end{array}$ & $\begin{array}{l}\text { Pre } \\
\text { App }\end{array}$ \\
\hline & $(1)$ & $(2)$ & $(3)$ & $(4)$ & $(5)$ & $(6)$ & $(7)$ & $(8)$ & $(9)$ & $(10)$ & $(11)$ & $(12)$ \\
\hline \multicolumn{13}{|c|}{ Panel A. Linear RD polynomial } \\
\hline Cluster at individual level & $\begin{array}{c}-0.092^{* * *} \\
(0.026)\end{array}$ & $\begin{array}{l}-0.022 \\
(0.025)\end{array}$ & $\begin{array}{c}-0.075 * * * \\
(0.016)\end{array}$ & $\begin{array}{l}-0.018 \\
(0.016)\end{array}$ & $\begin{array}{c}-0.080^{* * *} \\
(0.012)\end{array}$ & $\begin{array}{l}-0.016 \\
(0.011)\end{array}$ & $\begin{array}{c}-0.079^{* * *} \\
(0.009)\end{array}$ & $\begin{array}{c}-0.018^{*} \\
(0.009)\end{array}$ & $\begin{array}{c}-0.078^{* * *} \\
(0.008)\end{array}$ & $\begin{array}{c}-0.015^{*} \\
(0.008)\end{array}$ & $\begin{array}{c}-0.083^{* * *} \\
(0.014)\end{array}$ & $\begin{array}{l}-0.015 \\
(0.013)\end{array}$ \\
\hline Cluster at household level & $\begin{array}{c}-0.092^{* * *} \\
(0.027)\end{array}$ & $\begin{array}{l}-0.022 \\
(0.026)\end{array}$ & $\begin{array}{c}-0.075^{* * *} \\
(0.017)\end{array}$ & $\begin{array}{l}-0.018 \\
(0.017)\end{array}$ & $\begin{array}{c}-0.080^{* * *} \\
(0.012)\end{array}$ & $\begin{array}{c}-0.016 \\
(0.012)\end{array}$ & $\begin{array}{c}-0.079^{* * *} \\
(0.010)\end{array}$ & $\begin{array}{l}-0.018^{*} \\
(0.010)\end{array}$ & $\begin{array}{c}-0.078^{* * *} \\
(0.008)\end{array}$ & $\begin{array}{l}-0.015^{*} \\
(0.009)\end{array}$ & $\begin{array}{c}-0.083^{* * *} \\
(0.014)\end{array}$ & $\begin{array}{l}-0.015 \\
(0.014)\end{array}$ \\
\hline \multicolumn{13}{|c|}{ Panel B. Quadratic RD polynomial } \\
\hline Cluster at individual level & $\begin{array}{c}-0.087^{* *} \\
(0.040)\end{array}$ & $\begin{array}{l}-0.011 \\
(0.039)\end{array}$ & $\begin{array}{c}-0.059^{* *} \\
(0.025)\end{array}$ & $\begin{array}{l}-0.010 \\
(0.024)\end{array}$ & $\begin{array}{c}-0.079^{* * *} \\
(0.017)\end{array}$ & $\begin{array}{l}-0.018 \\
(0.017)\end{array}$ & $\begin{array}{c}-0.084^{* * *} \\
(0.014)\end{array}$ & $\begin{array}{l}-0.014 \\
(0.014)\end{array}$ & $\begin{array}{c}-0.080^{* * *} \\
(0.012)\end{array}$ & $\begin{array}{l}-0.019 \\
(0.012)\end{array}$ & $\begin{array}{c}-0.064^{* * *} \\
(0.020)\end{array}$ & $\begin{array}{l}-0.014 \\
(0.020)\end{array}$ \\
\hline Cluster at household level & $\begin{array}{c}-0.087^{* *} \\
(0.041)\end{array}$ & $\begin{array}{l}-0.011 \\
(0.040)\end{array}$ & $\begin{array}{c}-0.059^{* *} \\
(0.025)\end{array}$ & $\begin{array}{l}-0.010 \\
(0.025)\end{array}$ & $\begin{array}{c}-0.079^{* * *} * \\
(0.018)\end{array}$ & $\begin{array}{c}-0.018 \\
(0.018)\end{array}$ & $\begin{array}{c}-0.084^{* * * *} \\
(0.014)\end{array}$ & $\begin{array}{c}-0.014 \\
(0.014) \\
\end{array}$ & $\begin{array}{c}-0.080^{* * *} \\
(0.013)\end{array}$ & $\begin{array}{c}-0.019 \\
(0.013)\end{array}$ & $\begin{array}{c}-0.064^{* * * *} \\
(0.021)\end{array}$ & $\begin{array}{l}-0.014 \\
(0.021)\end{array}$ \\
\hline
\end{tabular}

Notes: The sample corresponds to heads of households and spouses of heads of households aged 18 to 57 at the time of the AFAM application during the period January 2008 to September 2010. The columns correspond to different specifications of the bandwidth - the ranges of the eligibility score from which the households were selected. The dataset corresponds to the AFAM baseline application records (January 2008 to September 2010) matched with the registered employment work histories for the period January 2005 to December 2012 from the Social Security Administration's administrative records (see Section 4.4 for a detailed description of the data). In columns (1), (3), (5), (7), (9), and (11) the dependent variable is registered employment in the post-application period. In columns (2), (4), (6), (8), (10), and (12) the dependent variable is registered employment in the pre-application period. Registered employment is measured as an indicator variable equal to one if the SSA records indicate that there are social security contributions from employment for the individual in a given calendar month, and zero otherwise. All rows and columns report the coefficient on the AFAM eligibility indicator, equal to one if the individual belongs to a household eligible for the program according to the AFAM eligibility rules (i.e., if score ${ }_{i}>0$ ), and zero otherwise. The rows correspond to different criteria to compute clustered standard errors: at individual level or at household level. Panel A presents results based on a linear RD polynomial estimated separately on either side of the eligibility threshold. Panel B presents results from a quadratic RD polynomial estimated separately on either side of cutoff. The covariates in the regressions include gender, head of the household status, age, marital status, educational level (in 3 categories), the number of children aged 0-17 in the household, whether the household was enrolled in the PANES program, residence in Montevideo (Uruguay's capital), and whether the individual was a registered employee. All covariates correspond to the date when the household applied to the program. ${ }^{*}$ significant at $10 \%$; ${ }^{* *}$ significant at $5 \%$; $* * *$ significant at $1 \%$. 


\section{A.3.4 Robustness of the Regression Discontinuity/Difference-in-Difference (RD-DD) Results}

Table A.10: Effect of AFAM Eligibility on Registered Employment, RD-DD Estimates for Alternative Bandwidths

\begin{tabular}{|c|c|c|c|c|c|c|c|c|c|c|c|c|}
\hline & \multicolumn{12}{|c|}{ Bandwidths } \\
\hline & \multicolumn{2}{|c|}{ \pm 0.02} & \multicolumn{2}{|c|}{ \pm 0.05} & \multicolumn{2}{|c|}{ \pm 0.10} & \multicolumn{2}{|c|}{ \pm 0.15} & \multicolumn{2}{|c|}{ \pm 0.2} & \multicolumn{2}{|c|}{ \pm 0.073} \\
\hline & $\begin{array}{c}\text { No Fixed } \\
\text { Effects }\end{array}$ & $\begin{array}{l}\text { Month } \\
\text { Effects }\end{array}$ & $\begin{array}{c}\text { No Fixed } \\
\text { Effects }\end{array}$ & $\begin{array}{l}\text { Month } \\
\text { Effects }\end{array}$ & $\begin{array}{c}\text { No Fixed } \\
\text { Effects }\end{array}$ & $\begin{array}{l}\text { Month } \\
\text { Effects }\end{array}$ & $\begin{array}{c}\text { No Fixed } \\
\text { Effects }\end{array}$ & $\begin{array}{l}\text { Month } \\
\text { Effects }\end{array}$ & $\begin{array}{c}\text { No Fixed } \\
\text { Effects }\end{array}$ & $\begin{array}{l}\text { Month } \\
\text { Effects }\end{array}$ & $\begin{array}{c}\text { No Fixed } \\
\text { Effects }\end{array}$ & $\begin{array}{l}\text { Month } \\
\text { Effects }\end{array}$ \\
\hline \multicolumn{13}{|c|}{ Panel A. Quadratic score polynomial } \\
\hline Elegible x Post App. & $\begin{array}{c}-0.065^{*} \\
(0.036)\end{array}$ & $\begin{array}{l}-0.059 \\
(0.036)\end{array}$ & $\begin{array}{c}-0.045^{* *} \\
(0.023)\end{array}$ & $\begin{array}{c}-0.039 * \\
(0.023)\end{array}$ & $\begin{array}{c}-0.059^{* * *} \\
(0.016)\end{array}$ & $\begin{array}{c}-0.051^{* * *} \\
(0.016)\end{array}$ & $\begin{array}{c}-0.068^{* * *} \\
(0.013)\end{array}$ & $\begin{array}{c}-0.059^{* * *} \\
(0.013)\end{array}$ & $\begin{array}{c}-0.059^{* * *} \\
(0.011)\end{array}$ & $\begin{array}{c}-0.051^{* * *} \\
(0.011)\end{array}$ & $\begin{array}{c}-0.045^{* *} \\
(0.019)\end{array}$ & $\begin{array}{c}-0.038^{* *} \\
(0.018)\end{array}$ \\
\hline \multicolumn{13}{|c|}{ Panel B. Linear score polynomial } \\
\hline Elegible x Post App. & $\begin{array}{c}-0.064^{* * *} \\
(0.024)\end{array}$ & $\begin{array}{c}-0.057^{* *} \\
(0.024)\end{array}$ & $\begin{array}{c}-0.050^{* * *} \\
(0.015)\end{array}$ & $\begin{array}{c}-0.044^{* * *} \\
(0.015)\end{array}$ & $\begin{array}{c}-0.062^{* * *} \\
(0.011)\end{array}$ & $\begin{array}{c}-0.054^{* * *} \\
(0.011)\end{array}$ & $\begin{array}{c}-0.060^{* * *} \\
(0.009)\end{array}$ & $\begin{array}{c}-0.053^{* * *} \\
(0.009)\end{array}$ & $\begin{array}{c}-0.062^{* * *} * \\
(0.008)\end{array}$ & $\begin{array}{c}-0.056^{* * *} \\
(0.008)\end{array}$ & $\begin{array}{c}-0.064^{* * *} \\
(0.012)\end{array}$ & $\begin{array}{c}-0.057^{* * * *} \\
(0.012)\end{array}$ \\
\hline Observations & 302,727 & 302,727 & 780,066 & 780,066 & $2,049,193$ & $2,049,193$ & $3,497,955$ & $3,497,955$ & $5,120,233$ & $5,120,233$ & $1,338,892$ & $1,338,892$ \\
\hline
\end{tabular}

Notes: The sample corresponds to heads of households and spouses of heads of households aged 18 to 57 at the time of the AFAM application during the period January 2008 to September 2010. The columns correspond to different specifications of the bandwidth - the ranges of the eligibility score from which the households were selected. The dataset corresponds to the AFAM baseline application records (January 2008 to September 2010) matched with the registered employment work histories for the period January 2005 to December 2012 from the Social Security Administration's administrative records (see Section 4.4 for a detailed description of the data). The dependent variable is registered employment, measured as an indicator variable equal to one if the SSA records indicate that there are social security contributions from employment for the individual in a given calendar month, and zero otherwise. "Eligible" is an indicator equal to one if the individual belongs to a household eligible for the program according to the AFAM eligibility rules (i.e., if score $_{i}>0$ ), and zero otherwise. "Post App" is an indicator equal to one if the observation occurred in the post-application period. Columns (1), (3), (5), (7), (9), and (11) include covariates; while columns (2), (4), (6), (8), (10), and (12) adds month fixed effects. Estimates in Panel A include a quadratic eligibility score polynomial interacted with the eligible and post application period indicators, and in Panel B include a linear eligibility score polynomial interacted with the eligible and post application period indicators. The covariates in the regressions include gender, head of the household status, age, marital status, educational level (in 3 categories), the number of children aged 0-17 in the household, whether the household was enrolled in the PANES program, residence in Montevideo (Uruguay's capital), and whether the individual was a registered employee. All covariates correspond to the date when the household applied to the program. The columns correspond to different specifications of the bandwidth. Standard errors clustered at the individual level in parentheses. ${ }^{*}$ significant at $10 \%$; ${ }^{* *}$ significant at $5 \%$; ${ }^{* *}$ significant at $1 \%$. 


\section{A.3.5 Robustness of the Distributional Effects of AFAM on Registered Employment}

Table A.11: Determinants of Propensity to be a Registered Employee

\begin{tabular}{|c|c|}
\hline \multicolumn{2}{|l|}{ Dep. Var.: Registered Employee } \\
\hline Eligibility Score & $\begin{array}{l}-0.275^{*} \\
(0.145)\end{array}$ \\
\hline Female applicants & $\begin{array}{l}-0.008 \\
(0.010)\end{array}$ \\
\hline Age at application to AFAM & $\begin{array}{c}-0.003^{* * *} \\
(0.000)\end{array}$ \\
\hline Household head & $\begin{array}{c}0.019 \\
(0.012)\end{array}$ \\
\hline Montevideo & $\begin{array}{c}0.037^{* * *} \\
(0.009)\end{array}$ \\
\hline Less than Primary (\%) & $\begin{array}{c}0.004 \\
(0.067)\end{array}$ \\
\hline Complete Primary (\%) & $\begin{array}{l}-0.014 \\
(0.014)\end{array}$ \\
\hline Secondary or more $(\%)$ & $\begin{array}{c}0.016 \\
(0.013)\end{array}$ \\
\hline Married & $\begin{array}{c}0.001 \\
(0.011)\end{array}$ \\
\hline Married missing & $\begin{array}{l}0.039^{*} \\
(0.022)\end{array}$ \\
\hline Enrolled & $\begin{array}{l}-0.032 \\
(0.020)\end{array}$ \\
\hline Number of children $<18$ years at home & $\begin{array}{c}0.006 \\
(0.005)\end{array}$ \\
\hline Employed & $\begin{array}{c}0.166^{* * *} \\
(0.010)\end{array}$ \\
\hline Employed missing & $\begin{array}{c}0.159^{* * * *} \\
(0.015)\end{array}$ \\
\hline Registered 36 months pre (\%) & $\begin{array}{c}0.560^{* * *} \\
(0.011)\end{array}$ \\
\hline Constant & $\begin{array}{c}0.269^{* * *} \\
(0.029)\end{array}$ \\
\hline $\begin{array}{l}\text { R-squared } \\
\text { Observations }\end{array}$ & $\begin{array}{c}0.29 \\
284,763\end{array}$ \\
\hline
\end{tabular}

Notes: The sample corresponds to heads of households and spouses of heads of households aged 18 to 57 at the time of the AFAM application during the period January 2008 to September 2010, from households within a range of $[-0.2 ;+0.2]$ of the eligibility score. The dataset corresponds to the AFAM baseline application records (January 2008 to September 2010) matched with the registered employment work histories for the period January 2005 to December 2012 from the Social Security Administration's administrative records (see Section 4.4 for a detailed description of the data). The dependent variable is registered employment, measured as an indicator variable equal to one if the SSA records indicate that there are social security contributions from employment for the individual in a given calendar month, and zero otherwise. All individual/household characteristics presented in this table are measured at the date of application or before, i.e. before the administrative decision on enrollment to the program. Huber-White robust standard errors in parentheses. ${ }^{*}$ significant at $10 \%$; ${ }^{* *}$ significant at $5 \%$; ${ }^{* * *}$ significant at $1 \%$. 
Table A.12: Effect of AFAM Eligibility on Registered Employment by Propensity to be a Registered Employee - Range of [-0.02; 0.02] of the Eligibility Score

\begin{tabular}{cccccc}
\hline & \multicolumn{3}{c}{ Polynomial Order } & \\
\cline { 2 - 3 } & $\frac{\text { Linear }}{(1)}$ & $\frac{\text { Quadratic }}{(2)}$ & $\frac{\text { Cubic }}{(3)}$ & $\frac{\text { Quartic }}{(4)}$ & $\frac{}{(5)}$ \\
\hline
\end{tabular}

Panel A. Low prop. to be formal

$\begin{array}{llllll}\text { Elegible(post application) } & -0.013 & 0.027 & -0.002 & -0.025 & 55,933 \\ & (0.030) & (0.045) & (0.057) & (0.070) & \\ \text { Elegible(pre application) } & -0.003 & -0.004 & -0.009 & -0.010 & 44,992 \\ & (0.005) & (0.007) & (0.008) & (0.009) & \end{array}$

Panel B. Medium prop. to be formal

$\begin{array}{lccccc}\text { Elegible(post application) } & -0.151^{* * *} & -0.158^{* *} & -0.244^{* * *} & -0.182 & 55,950 \\ & (0.045) & (0.068) & (0.091) & (0.118) & \\ \text { Elegible(pre application) } & -0.003 & 0.019 & 0.030 & 0.072^{*} & 44,955 \\ & (0.017) & (0.025) & (0.033) & (0.041) & \end{array}$

Panel C. High prop. to be formal

\begin{tabular}{lccccc} 
Elegible(post application) & -0.043 & -0.043 & -0.036 & -0.093 & 55,202 \\
& $(0.038)$ & $(0.057)$ & $(0.078)$ & $(0.095)$ & \\
Elegible(pre application) & 0.001 & 0.040 & 0.016 & 0.012 & 45,695 \\
& $(0.023)$ & $(0.035)$ & $(0.047)$ & $(0.058)$ & \\
\hline
\end{tabular}

Notes: The sample corresponds to heads of households and spouses of heads of households aged 18 to 57 at the time of the AFAM application during the period January 2008 to September 2010, from households within a range of $[-0.02 ;+0.02]$ of the eligibility score. The dataset corresponds to the AFAM baseline application records (January 2008 to September 2010) matched with the registered employment work histories for the period January 2005 to December 2012 from the Social Security Administration's administrative records (see Section 4.4 for a detailed description of the data). Each row presents the regression estimates from the basic model in Equation (2) with covariates at time of application to the program as in the notes to Table 3. The regressions are estimated as linear probability models. In columns (1) and (2), the dependent variable is registered employment, measured as an indicator variable equal to one if the SSA records indicate that there are social security contributions from employment for the individual in a given calendar month, and zero otherwise. The coefficients correspond to the "Eligible" variable, an indicator equal to one if the individual belongs to a household eligible for the program according to the AFAM eligibility rules (i.e., if score $_{i}>0$ ), and zero otherwise. Panels A, B and C present the regression estimates for the subgroups of individuals with Low, Medium and High predicted propensity to work as a registered employee, respectively. See Section 7 for a detailed explanation of the procedure to determine these predicted probabilities. The first row in each of the Panels presents results for registered employment during the post-application period, whereas the second row presents results for registered employment during the pre-application period. Column (1) presents results based on a quadratic RD polynomial estimated separately on either side of the eligibility threshold. Column (2) presents results from a linear RD polynomial estimated separately on either side of cutoff. Column (3) reports the mean for each dependent variable for ineligible individuals (the control group). Column (4) reports program's effect from the quadratic RD polynomial model (Column 1) as a percentage of the mean of the dependent variable for ineligible individuals (Column 3). Column (5) reports the total number of observations, which correspond to 24,563 individuals for up to 54 post-application months and 37 pre-application months. Standard errors clustered at the individual level in parentheses. ${ }^{*}$ significant at $10 \%$; $*$ significant at $5 \%$; *** significant at $1 \%$. 
Table A.13: Effect of AFAM on Registered Employment Change by Propensity to be a Registered Employee - Range of [-0.05; 0.05] of the Eligibility Score

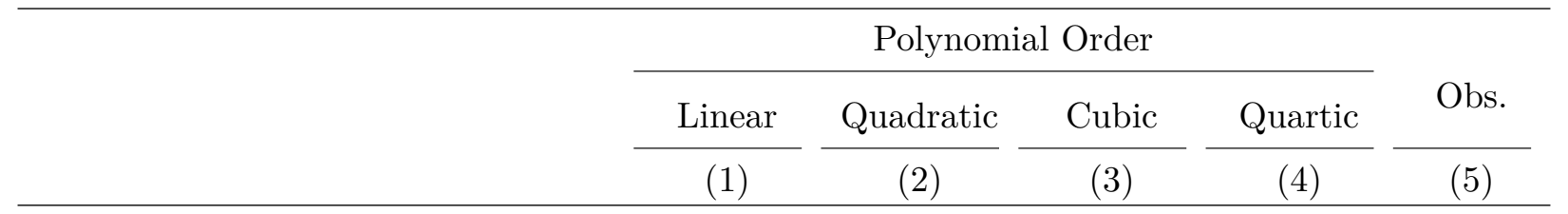

Panel A. Low prop. to be formal

$\begin{array}{lccccc}\text { Elegible(post application) } & -0.038^{*} & 0.016 & -0.017 & -0.041 & 143,983 \\ & (0.021) & (0.031) & (0.041) & (0.053) & \\ \text { Elegible(pre application) } & -0.006^{* *} & -0.008^{*} & -0.016^{* *} & -0.017^{* *} & 116,069 \\ & (0.003) & (0.005) & (0.007) & (0.009) & \end{array}$

Panel B. Medium prop. to be formal

$\begin{array}{lccccc}\text { Elegible(post application) } & -0.092^{* * *} & -0.092^{* *} & -0.195^{* * *} & -0.189^{* * *} & 143,597 \\ \text { Elegible(pre application) } & (0.028) & (0.043) & (0.058) & (0.072) & \\ & -0.007 & 0.001 & -0.007 & 0.013 & 116,439 \\ & (0.010) & (0.015) & (0.020) & (0.025) & \end{array}$

Panel C. High prop. to be formal

\begin{tabular}{lccccc} 
Elegible(post application) & $-0.046^{* *}$ & -0.050 & -0.038 & -0.013 & 141,985 \\
& $(0.022)$ & $(0.035)$ & $(0.048)$ & $(0.060)$ & \\
Elegible(pre application) & -0.004 & 0.004 & 0.010 & 0.043 & 117,993 \\
& $(0.014)$ & $(0.022)$ & $(0.029)$ & $(0.037)$ & \\
\hline
\end{tabular}

Notes: The sample corresponds to heads of households and spouses of heads of households aged 18 to 57 at the time of the AFAM application during the period January 2008 to September 2010, from households within a range of $[-0.05 ;+0.05]$ of the eligibility score. The dataset corresponds to the AFAM baseline application records (January 2008 to September 2010) matched with the registered employment work histories for the period January 2005 to December 2012 from the Social Security Administration's administrative records (see Section 4.4 for a detailed description of the data). Each row presents the regression estimates from the basic model in Equation (2) with covariates at time of application to the program as in the notes to Table 3. The regressions are estimated as linear probability models. In columns (1) and (2), the dependent variable is registered employment, measured as an indicator variable equal to one if the SSA records indicate that there are social security contributions from employment for the individual in a given calendar month, and zero otherwise. The coefficients correspond to the "Eligible" variable, an indicator equal to one if the individual belongs to a household eligible for the program according to the AFAM eligibility rules (i.e., if score $_{i}>0$ ), and zero otherwise. Panels A, B and C present the regression estimates for the subgroups of individuals with Low, Medium and High predicted propensity to work as a registered employee, respectively. See Section 7 for a detailed explanation of the procedure to determine these predicted probabilities. The first row in each of the Panels presents results for registered employment during the post-application period, whereas the second row presents results for registered employment during the pre-application period. Column (1) presents results based on a quadratic RD polynomial estimated separately on either side of the eligibility threshold. Column (2) presents results from a linear RD polynomial estimated separately on either side of cutoff. Column (3) reports the mean for each dependent variable for ineligible individuals (the control group). Column (4) reports program's effect from the quadratic RD polynomial model (Column 1) as a percentage of the mean of the dependent variable for ineligible individuals (Column 3). Column (5) reports the total number of observations, which correspond to 24,563 individuals for up to 54 post-application months and 37 pre-application months. Standard errors clustered at the individual level in parentheses. ${ }^{*}$ significant at $10 \%$; ${ }^{*}$ significant at $5 \% ; * * *$ significant at $1 \%$. 
Table A.14: Effect of AFAM on Registered Employment Change by Propensity to be a Registered Employee - Range of [-0.15; 0.15] of the Eligibility Score

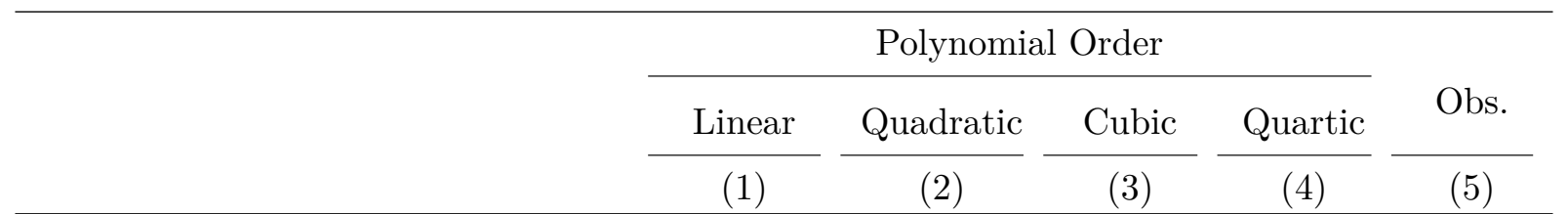

Panel A. Low prop. to be formal

$\begin{array}{lccccc}\text { Elegible(post application) } & -0.050^{* * *} & -0.058^{* * *} & -0.029 & 0.001 & 655,844 \\ & (0.013) & (0.019) & (0.025) & (0.030) & \\ \text { Elegible(pre application) } & -0.002 & -0.005^{*} & -0.007^{*} & -0.006 & 510,156 \\ & (0.002) & (0.003) & (0.004) & (0.005) & \end{array}$

Panel B. Medium prop. to be formal

$\begin{array}{lccccc}\text { Elegible(post application) } & -0.072^{* * *} & -0.066^{* * *} & -0.074^{* *} & -0.091^{* *} & 654,160 \\ & (0.016) & (0.024) & (0.033) & (0.041) & \\ \text { Elegible(pre application) } & -0.003 & -0.000 & -0.001 & -0.008 & 511,821 \\ & (0.005) & (0.007) & (0.010) & (0.012) & \end{array}$

Panel C. High prop. to be formal

\begin{tabular}{lccccc} 
Elegible(post application) & $-0.077^{* * *}$ & $-0.085^{* * *}$ & -0.032 & -0.038 & 644,459 \\
& $(0.012)$ & $(0.019)$ & $(0.025)$ & $(0.033)$ & \\
Elegible(pre application) & $-0.023^{* * *}$ & -0.018 & 0.008 & 0.007 & 521,515 \\
& $(0.009)$ & $(0.013)$ & $(0.018)$ & $(0.022)$ & \\
\hline
\end{tabular}

Notes: The sample corresponds to heads of households and spouses of heads of households aged 18 to 57 at the time of the AFAM application during the period January 2008 to September 2010, from households within a range of $[-0.15 ;+0.15]$ of the eligibility score. The dataset corresponds to the AFAM baseline application records (January 2008 to September 2010) matched with the registered employment work histories for the period January 2005 to December 2012 from the Social Security Administration's administrative records (see Section 4.4 for a detailed description of the data). Each row presents the regression estimates from the basic model in Equation (2) with covariates at time of application to the program as in the notes to Table 3. The regressions are estimated as linear probability models. In columns (1) and (2), the dependent variable is registered employment, measured as an indicator variable equal to one if the SSA records indicate that there are social security contributions from employment for the individual in a given calendar month, and zero otherwise. The coefficients correspond to the "Eligible" variable, an indicator equal to one if the individual belongs to a household eligible for the program according to the AFAM eligibility rules (i.e., if score $_{i}>0$ ), and zero otherwise. Panels A, B and C present the regression estimates for the subgroups of individuals with Low, Medium and High predicted propensity to work as a registered employee, respectively. See Section 7 for a detailed explanation of the procedure to determine these predicted probabilities. The first row in each of the Panels presents results for registered employment during the post-application period, whereas the second row presents results for registered employment during the pre-application period. Column (1) presents results based on a quadratic RD polynomial estimated separately on either side of the eligibility threshold. Column (2) presents results from a linear RD polynomial estimated separately on either side of cutoff. Column (3) reports the mean for each dependent variable for ineligible individuals (the control group). Column (4) reports program's effect from the quadratic RD polynomial model (Column 1) as a percentage of the mean of the dependent variable for ineligible individuals (Column 3). Column (5) reports the total number of observations, which correspond to 24,563 individuals for up to 54 post-application months and 37 pre-application months. Standard errors clustered at the individual level in parentheses. ${ }^{*}$ significant at $10 \%$; $*$ significant at $5 \%$; *** significant at $1 \%$. 
Table A.15: Effect of AFAM on Registered Employment Change by Propensity to be a Registered Employee - Range of [-0.2; 0.2] of the Eligibility Score

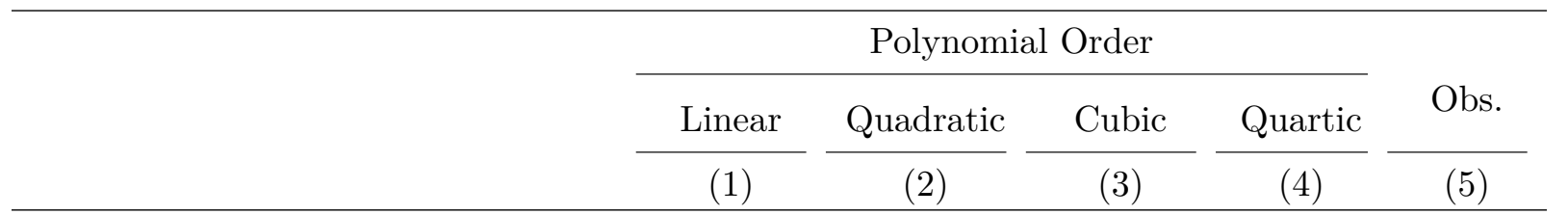

Panel A. Low prop. to be formal

$\begin{array}{lccccc}\text { Elegible(post application) } & -0.057^{* * *} & -0.045^{* * *} & -0.056^{* *} & -0.014 & 963,173 \\ \text { Elegible(pre application) } & (0.012) & (0.017) & (0.022) & (0.027) & \\ & -0.003^{*} & -0.003 & -0.007^{* *} & -0.009^{* *} & 743,589 \\ & (0.002) & (0.003) & (0.003) & (0.004) & \end{array}$

Panel B. Medium prop. to be formal

$\begin{array}{lccccc}\text { Elegible(post application) } & -0.069^{* * *} & -0.060^{* * *} & -0.064^{* *} & -0.075^{* *} & 961,117 \\ & (0.014) & (0.021) & (0.029) & (0.036) & \\ \text { Elegible(pre application) } & 0.003 & 0.003 & 0.002 & 0.006 & 745,624 \\ & (0.004) & (0.006) & (0.008) & (0.010) & \end{array}$

Panel C. High prop. to be formal

$\begin{array}{lccccc}\text { Elegible(post application) } & -0.076^{* * *} & -0.083^{* * *} & -0.071^{* * *} & -0.033 & 946,306 \\ & (0.010) & (0.016) & (0.022) & (0.028) & \\ \text { Elegible(pre application) } & -0.017^{* *} & -0.022^{*} & -0.004 & 0.006 & 760,424 \\ & (0.008) & (0.011) & (0.015) & (0.019) & \end{array}$

Notes: The sample corresponds to heads of households and spouses of heads of households aged 18 to 57 at the time of the AFAM application during the period January 2008 to September 2010, from households within a range of $[-0.2 ;+0.2]$ of the eligibility score. The dataset corresponds to the AFAM baseline application records (January 2008 to September 2010) matched with the registered employment work histories for the period January 2005 to December 2012 from the Social Security Administration's administrative records (see Section 4.4 for a detailed description of the data). Each row presents the regression estimates from the basic model in Equation (2) with covariates at time of application to the program as in the notes to Table 3. The regressions are estimated as linear probability models. In columns (1) and (2), the dependent variable is registered employment, measured as an indicator variable equal to one if the SSA records indicate that there are social security contributions from employment for the individual in a given calendar month, and zero otherwise. The coefficients correspond to the "Eligible" variable, an indicator equal to one if the individual belongs to a household eligible for the program according to the AFAM eligibility rules (i.e., if score $_{i}>0$ ), and zero otherwise. Panels A, B and C present the regression estimates for the subgroups of individuals with Low, Medium and High predicted propensity to work as a registered employee, respectively. See Section 7 for a detailed explanation of the procedure to determine these predicted probabilities. The first row in each of the Panels presents results for registered employment during the post-application period, whereas the second row presents results for registered employment during the pre-application period. Column (1) presents results based on a quadratic RD polynomial estimated separately on either side of the eligibility threshold. Column (2) presents results from a linear RD polynomial estimated separately on either side of cutoff. Column (3) reports the mean for each dependent variable for ineligible individuals (the control group). Column (4) reports program's effect from the quadratic RD polynomial model (Column 1) as a percentage of the mean of the dependent variable for ineligible individuals (Column 3). Column (5) reports the total number of observations, which correspond to 24,563 individuals for up to 54 post-application months and 37 pre-application months. Standard errors clustered at the individual level in parentheses. ${ }^{*}$ significant at $10 \% ;{ }^{* *}$ significant at $5 \% ; * * *$ significant at $1 \%$. 
Table A.16: Effect of AFAM on Registered Employment Change by Propensity to be a Registered Employee - Range of [-0.073; 0.073] of the Eligibility Score (Optimal Bandwidth)

\begin{tabular}{cccccc}
\hline & \multicolumn{3}{c}{ Polynomial Order } & \\
\cline { 2 - 3 } & $\frac{\text { Linear }}{(1)}$ & $\frac{\text { Quadratic }}{(2)}$ & $\frac{\text { Cubic }}{(3)}$ & $\frac{\text { Quartic }}{(4)}$ & Obs. \\
\hline
\end{tabular}

Panel A. Low prop. to be formal

$\begin{array}{lccccc}\text { Elegible(post application) } & -0.059^{* * *} & -0.018 & 0.023 & 0.003 & 249,250 \\ & (0.018) & (0.026) & (0.034) & (0.042) & \\ \text { Elegible(pre application) } & -0.005^{*} & -0.005 & -0.004 & -0.012^{*} & 197,062 \\ & (0.003) & (0.004) & (0.006) & (0.007) & \end{array}$

Panel B. Medium prop. to be formal

$\begin{array}{lccccc}\text { Elegible(post application) } & -0.076^{* * *} & -0.075^{* *} & -0.105^{* *} & -0.158^{* * *} & 248,009 \\ & (0.023) & (0.035) & (0.047) & (0.060) & \\ \text { Elegible(pre application) } & 0.002 & 0.000 & 0.001 & 0.008 & 198,283 \\ & (0.008) & (0.012) & (0.016) & (0.020) & \end{array}$

Panel C. High prop. to be formal

\begin{tabular}{lccccc} 
Elegible(post application) & $-0.063^{* * *}$ & -0.041 & -0.036 & -0.074 & 244,860 \\
& $(0.018)$ & $(0.028)$ & $(0.039)$ & $(0.049)$ & \\
Elegible(pre application) & 0.003 & -0.002 & 0.005 & 0.015 & 201,428 \\
& $(0.011)$ & $(0.018)$ & $(0.024)$ & $(0.031)$ & \\
\hline
\end{tabular}

Notes: The sample corresponds to heads of households and spouses of heads of households aged 18 to 57 at the time of the AFAM application during the period January 2008 to September 2010, from households within a range of $[-0.073 ;+0.073]$ of the eligibility score. The dataset corresponds to the AFAM baseline application records (January 2008 to September 2010) matched with the registered employment work histories for the period January 2005 to December 2012 from the Social Security Administration's administrative records (see Section 4.4 for a detailed description of the data). Each row presents the regression estimates from the basic model in Equation (2) with covariates at time of application to the program as in the notes to Table 3. The regressions are estimated as linear probability models. In columns (1) and (2), the dependent variable is registered employment, measured as an indicator variable equal to one if the SSA records indicate that there are social security contributions from employment for the individual in a given calendar month, and zero otherwise. The coefficients correspond to the "Eligible" variable, an indicator equal to one if the individual belongs to a household eligible for the program according to the AFAM eligibility rules (i.e., if score $_{i}>0$ ), and zero otherwise. Panels A, B and C present the regression estimates for the subgroups of individuals with Low, Medium and High predicted propensity to work as a registered employee, respectively. See Section 7 for a detailed explanation of the procedure to determine these predicted probabilities. The first row in each of the Panels presents results for registered employment during the post-application period, whereas the second row presents results for registered employment during the pre-application period. Column (1) presents results based on a quadratic RD polynomial estimated separately on either side of the eligibility threshold. Column (2) presents results from a linear RD polynomial estimated separately on either side of cutoff. Column (3) reports the mean for each dependent variable for ineligible individuals (the control group). Column (4) reports program's effect from the quadratic RD polynomial model (Column 1) as a percentage of the mean of the dependent variable for ineligible individuals (Column 3). Column (5) reports the total number of observations, which correspond to 24,563 individuals for up to 54 post-application months and 37 pre-application months. Standard errors clustered at the individual level in parentheses. ${ }^{*}$ significant at $10 \% ; *$ significant at $5 \% ; * * *$ significant at $1 \%$. 


\section{A.3.6 Robustness of the Effects of AFAM on Different Margins of Participation}

Table A.17: The Effect of AFAM on Different Margins of Participation - Alternative Polynomial Models

\begin{tabular}{|c|c|c|c|c|c|}
\hline & \multicolumn{4}{|c|}{ Polynomial Order } & \multirow{2}{*}{ Obs. } \\
\hline & Linear & Quadratic & Cubic & Quartic & \\
\hline & $(1)$ & $(2)$ & $(3)$ & $(4)$ & $(5)$ \\
\hline Registered Employment & $\begin{array}{c}-0.130^{* * *} \\
(0.039)\end{array}$ & $\begin{array}{c}-0.137^{* *} \\
(0.054)\end{array}$ & $\begin{array}{c}-0.172^{* *} \\
(0.072)\end{array}$ & $\begin{array}{c}-0.258^{* * *} \\
(0.091)\end{array}$ & 2,410 \\
\hline Non-Employment & $\begin{array}{c}0.044 \\
(0.035)\end{array}$ & $\begin{array}{c}0.046 \\
(0.049)\end{array}$ & $\begin{array}{c}0.093 \\
(0.067)\end{array}$ & $\begin{array}{c}0.115 \\
(0.086)\end{array}$ & 2,410 \\
\hline Informal Employment & $\begin{array}{c}0.086^{* *} \\
(0.039)\end{array}$ & $\begin{array}{c}0.091 \\
(0.056)\end{array}$ & $\begin{array}{c}0.080 \\
(0.075)\end{array}$ & $\begin{array}{c}0.143 \\
(0.094)\end{array}$ & 2,410 \\
\hline Joint p-value $(2 \& 3=0)$ & 0.004 & 0.052 & 0.070 & 0.028 & \\
\hline
\end{tabular}

Notes: The results in this table are based on the "Follow-Up Sample," which includes heads of households and spouses of heads of households aged 18 to 57 at the time of the AFAM application during the period January 2008 to September 2010. This sample corresponds to the subset of individuals who were interviewed for the program's follow-up survey during the period September 201-February 2013. The survey's sample was drawn from households within a range of $[-0.0426 ;+0.0727]$ of the eligibility score (see Section 4.3 for more details). The dataset corresponds to the AFAM baseline application records (January 2008 to September 2010) matched with information from the program's follow-up survey data (see Section 4.4 for a detailed description of the data). Each row presents the regression estimates from the basic model in Equation (2) with covariates at time of application to the program as in the notes to Table 3. The regressions are estimated as linear probability models. In the first row, the dependent variable is the registered employment status as reported by the individual lat the time of the interview (one if she is working as a registered employee, zero otherwise). In the second row, the dependent variable is non-employment again as reported by the individual at the time of the interview, which is equal to one if the individual is not working, and equal to zero if she is working (as a registered or as a non-registered employee). In the third row, the dependent variable is informal employment at the time of the interview, which is equal to one if the individual is working as an informal (or non-registered) employee, and zero otherwise (i.e., working as a registered employee or not working). Each of these rows presents the regression estimates from the basic model in Equation (2) with covariates at time of application to the program as in the notes to Table 3. The coefficients correspond to the "Eligible" variable, an indicator equal to one if the individual belongs to a household eligible for the program according to the AFAM eligibility rules (i.e., if score $_{i}>0$ ), and zero otherwise. The fourth row presents the p-value of the test that the coefficients for the "Non-Employment" and "Informal Employment" regressions are jointly equal to zero. Columns (1) through (4) present results based on linear, quadratic, cubic, and quartic RD polynomial estimated separately on either side of the eligibility threshold. Column (5) reports the total number of observations. Huber-White robust standard errors in parentheses. * significant at $10 \% ; * *$ significant at $5 \%$; ** significant at $1 \%$. 


\section{A.3.7 Robustness of Heterogeneous Effects by Socio-Economic Groups}

Table A.18: Heterogeneous Effects of AFAM Eligibility by Socio-Demographic Sub-Groups - Range of $[-0.02 ; 0.02]$ of the Eligibility Score

\begin{tabular}{|c|c|c|c|c|c|}
\hline \multirow{3}{*}{ Subgroups } & \multicolumn{4}{|c|}{ Polynomial Order } & \multirow[b]{2}{*}{ Obs. } \\
\hline & Linear & Quadratic & Cubic & Quartic & \\
\hline & (1) & $(2)$ & $(3)$ & $(4)$ & $(5)$ \\
\hline Household head & $\begin{array}{c}-0.100^{* * *} \\
(0.030)\end{array}$ & $\begin{array}{c}-0.070 \\
(0.045)\end{array}$ & $\begin{array}{l}-0.089 \\
(0.061)\end{array}$ & $\begin{array}{c}-0.136^{*} \\
(0.077)\end{array}$ & 129,505 \\
\hline Other HH. member & $\begin{array}{l}-0.068 \\
(0.058)\end{array}$ & $\begin{array}{l}-0.142 \\
(0.091)\end{array}$ & $\begin{array}{c}-0.244^{*} \\
(0.132)\end{array}$ & $\begin{array}{l}-0.275 \\
(0.181)\end{array}$ & 37,580 \\
\hline Female applicants & $\begin{array}{c}-0.109 * * * \\
(0.030)\end{array}$ & $\begin{array}{c}-0.097^{* *} \\
(0.046)\end{array}$ & $\begin{array}{c}-0.118^{*} \\
(0.063)\end{array}$ & $\begin{array}{c}-0.090 \\
(0.081)\end{array}$ & 117,703 \\
\hline Male applicants & $\begin{array}{l}-0.054 \\
(0.053)\end{array}$ & $\begin{array}{c}-0.072 \\
(0.083)\end{array}$ & $\begin{array}{l}-0.139 \\
(0.115)\end{array}$ & $\begin{array}{c}-0.371^{* *} \\
(0.144)\end{array}$ & 49,382 \\
\hline Two parent HH & $\begin{array}{c}-0.029 \\
(0.042)\end{array}$ & $\begin{array}{l}-0.031 \\
(0.065)\end{array}$ & $\begin{array}{l}-0.084 \\
(0.092)\end{array}$ & $\begin{array}{c}-0.199 \\
(0.123)\end{array}$ & 73,246 \\
\hline Single parent HH & $\begin{array}{c}-0.145^{* * *} \\
(0.035)\end{array}$ & $\begin{array}{c}-0.133^{* *} \\
(0.052)\end{array}$ & $\begin{array}{c}-0.132^{*} \\
(0.070)\end{array}$ & $\begin{array}{c}-0.156^{*} \\
(0.088)\end{array}$ & 85,902 \\
\hline Female heads & $\begin{array}{c}-0.171^{* * *} \\
(0.036)\end{array}$ & $\begin{array}{c}-0.174^{* * *} \\
(0.055)\end{array}$ & $\begin{array}{c}-0.174^{* *} \\
(0.074)\end{array}$ & $\begin{array}{c}-0.159^{*} \\
(0.094)\end{array}$ & 75,247 \\
\hline Male heads & $\begin{array}{c}0.053 \\
(0.117)\end{array}$ & $\begin{array}{c}0.210 \\
(0.185)\end{array}$ & $\begin{array}{c}0.218 \\
(0.229)\end{array}$ & $\begin{array}{c}-0.047 \\
(0.268)\end{array}$ & 10,655 \\
\hline Low education & $\begin{array}{c}-0.036 \\
(0.042)\end{array}$ & $\begin{array}{c}-0.094 \\
(0.064)\end{array}$ & $\begin{array}{c}-0.162^{*} \\
(0.085)\end{array}$ & $\begin{array}{c}-0.252^{* *} \\
(0.103)\end{array}$ & 71,626 \\
\hline Medium-high education & $\begin{array}{c}-0.129 * * * \\
(0.034)\end{array}$ & $\begin{array}{l}-0.079 \\
(0.052)\end{array}$ & $\begin{array}{c}-0.072 \\
(0.072)\end{array}$ & $\begin{array}{l}-0.092 \\
(0.095)\end{array}$ & 95,459 \\
\hline Aged below 30 & $\begin{array}{c}-0.174^{* * *} \\
(0.052)\end{array}$ & $\begin{array}{l}-0.120 \\
(0.077)\end{array}$ & $\begin{array}{c}-0.042 \\
(0.104)\end{array}$ & $\begin{array}{c}-0.005 \\
(0.129)\end{array}$ & 34,049 \\
\hline Aged 30 or more & $\begin{array}{c}-0.073^{* *} \\
(0.030)\end{array}$ & $\begin{array}{c}-0.079^{*} \\
(0.047)\end{array}$ & $\begin{array}{c}-0.138^{* *} \\
(0.064)\end{array}$ & $\begin{array}{c}-0.202^{* *} \\
(0.083)\end{array}$ & 133,036 \\
\hline
\end{tabular}

Notes: The sample corresponds to heads of households and spouses of heads of households aged 18 to 57 at the time of the AFAM

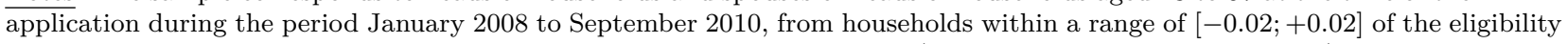
score. The dataset corresponds to the AFAM baseline application records (January 2008 to September 2010) matched with the registered employment work histories for the period January 2005 to December 2012 from the Social Security Administration's administrative records (see Section 4.4 for a detailed description of the data). Each row presents the regression estimates from the basic model in Equation (2) with covariates at time of application to the program as in the notes to Table 3. The regressions are estimated as linear probability models. In columns (1) and (2), the dependent variable is registered employment, measured as an indicator variable equal to one if the SSA records indicate that there are social security contributions from employment for the individual in a given calendar month, and zero otherwise. The coefficients correspond to the "Eligible" variable, an indicator equal to one if the individual belongs to a household eligible for the program according to the AFAM eligibility rules (i.e., if score $_{i}>0$ ), and zero otherwise. Each row presents results for registered employment during the post-application period for the corresponding subgroup. Column (1) presents results based on a quadratic RD polynomial estimated separately on either side of the eligibility threshold. Column (2) presents results from a linear RD polynomial estimated separately on either side of cutoff. Column (3) reports the mean for each dependent variable for ineligible individuals (the control group). Column (4) reports the program's effect from the quadratic RD polynomial model (Column 1) as a percentage of the mean of the dependent variable for ineligible individuals (Column 3). Column (5) reports the total number of observations, which correspond to 24,563 individuals for up to 54 post-application months. Standard errors clustered at the individual level in parentheses. ${ }^{*}$ significant at $10 \%$; $* *$ significant at $5 \%$; ** significant at $1 \%$. xxiv 
Table A.19: Heterogeneous Effects of AFAM Eligibility by Socio-Demographic Sub-Groups - Range of $[-0.05 ; 0.05]$ of the Eligibility Score

\begin{tabular}{|c|c|c|c|c|c|}
\hline \multirow{3}{*}{ Subgroups } & \multicolumn{4}{|c|}{ Polynomial Order } & \multirow{2}{*}{ Obs. } \\
\hline & Linear & Quadratic & Cubic & Quartic & \\
\hline & (1) & $(2)$ & $(3)$ & $(4)$ & $(5)$ \\
\hline Household head & $\begin{array}{c}-0.082^{* * *} \\
(0.018)\end{array}$ & $\begin{array}{c}-0.068^{* *} \\
(0.028)\end{array}$ & $\begin{array}{c}-0.112^{* * *} \\
(0.038)\end{array}$ & $\begin{array}{c}-0.085^{*} \\
(0.048)\end{array}$ & 333,002 \\
\hline Other HH. member & $\begin{array}{l}-0.050 \\
(0.036)\end{array}$ & $\begin{array}{l}-0.027 \\
(0.054)\end{array}$ & $\begin{array}{c}-0.109 \\
(0.074)\end{array}$ & $\begin{array}{c}-0.147 \\
(0.095)\end{array}$ & 96,563 \\
\hline Female applicants & $\begin{array}{c}-0.103^{* * *} \\
(0.019)\end{array}$ & $\begin{array}{c}-0.068^{* *} \\
(0.028)\end{array}$ & $\begin{array}{c}-0.128^{* * *} \\
(0.038)\end{array}$ & $\begin{array}{c}-0.116^{* *} \\
(0.049)\end{array}$ & 301,081 \\
\hline Male applicants & $\begin{array}{c}-0.012 \\
(0.032)\end{array}$ & $\begin{array}{c}-0.043 \\
(0.050)\end{array}$ & $\begin{array}{c}-0.070 \\
(0.069)\end{array}$ & $\begin{array}{c}-0.054 \\
(0.088)\end{array}$ & 128,484 \\
\hline Two parent $\mathrm{HH}$ & $\begin{array}{c}-0.054^{* *} \\
(0.026)\end{array}$ & $\begin{array}{l}-0.009 \\
(0.039)\end{array}$ & $\begin{array}{c}-0.051 \\
(0.053)\end{array}$ & $\begin{array}{c}-0.010 \\
(0.069)\end{array}$ & 190,088 \\
\hline Single parent HH & $\begin{array}{c}-0.090 * * * \\
(0.022)\end{array}$ & $\begin{array}{c}-0.100^{* * *} \\
(0.033)\end{array}$ & $\begin{array}{c}-0.165^{* * *} \\
(0.044)\end{array}$ & $\begin{array}{c}-0.160^{* * *} \\
(0.055)\end{array}$ & 218,704 \\
\hline Female heads & $\begin{array}{c}-0.112^{* * *} \\
(0.023)\end{array}$ & $\begin{array}{c}-0.112^{* * *} \\
(0.035)\end{array}$ & $\begin{array}{c}-0.203^{* * *} \\
(0.046)\end{array}$ & $\begin{array}{c}-0.205^{* * *} \\
(0.058)\end{array}$ & 191,495 \\
\hline Male heads & $\begin{array}{c}0.059 \\
(0.069)\end{array}$ & $\begin{array}{c}-0.011 \\
(0.110)\end{array}$ & $\begin{array}{c}0.143 \\
(0.151)\end{array}$ & $\begin{array}{c}0.209 \\
(0.191)\end{array}$ & 27,209 \\
\hline Low education & $\begin{array}{c}-0.060^{* *} \\
(0.026)\end{array}$ & $\begin{array}{l}-0.006 \\
(0.040)\end{array}$ & $\begin{array}{c}-0.085 \\
(0.054)\end{array}$ & $\begin{array}{c}-0.082 \\
(0.068)\end{array}$ & 184,047 \\
\hline Medium-high education & $\begin{array}{c}-0.086^{* * *} \\
(0.021)\end{array}$ & $\begin{array}{c}-0.095^{* * *} \\
(0.032)\end{array}$ & $\begin{array}{c}-0.126^{* * *} \\
(0.043)\end{array}$ & $\begin{array}{c}-0.107^{*} \\
(0.055)\end{array}$ & 245,518 \\
\hline Aged below 30 & $\begin{array}{c}-0.132^{* * *} \\
(0.034)\end{array}$ & $\begin{array}{c}-0.118^{* *} \\
(0.050)\end{array}$ & $\begin{array}{c}-0.160^{* *} \\
(0.066)\end{array}$ & $\begin{array}{c}-0.135^{*} \\
(0.082)\end{array}$ & 88,091 \\
\hline Aged 30 or more & $\begin{array}{c}-0.061^{* * *} \\
(0.019)\end{array}$ & $\begin{array}{c}-0.046 \\
(0.029)\end{array}$ & $\begin{array}{c}-0.099 * * \\
(0.039)\end{array}$ & $\begin{array}{c}-0.089^{*} \\
(0.050)\end{array}$ & 341,474 \\
\hline
\end{tabular}

Notes: The sample corresponds to heads of households and spouses of heads of households aged 18 to 57 at the time of the AFAM application during the period January 2008 to September 2010, from households within a range of $[-0.05 ;+0.05]$ of the eligibility score. The dataset corresponds to the AFAM baseline application records (January 2008 to September 2010) matched with the registered employment work histories for the period January 2005 to December 2012 from the Social Security Administration's administrative records (see Section 4.4 for a detailed description of the data). Each row presents the regression estimates from the basic model in Equation (2) with covariates at time of application to the program as in the notes to Table 3. The regressions are estimated as linear probability models. In columns (1) and (2), the dependent variable is registered employment, measured as an indicator variable equal to one if the SSA records indicate that there are social security contributions from employment for the individual in a given calendar month, and zero otherwise. The coefficients correspond to the "Eligible" variable, an indicator equal to one if the individual belongs to a household eligible for the program according to the AFAM eligibility rules (i.e., if score $_{i}>0$ ), and zero otherwise. Each row presents results for registered employment during the post-application period for the corresponding subgroup. Column (1) presents results based on a quadratic RD polynomial estimated separately on either side of the eligibility threshold. Column (2) presents results from a linear RD polynomial estimated separately on either side of cutoff. Column (3) reports the mean for each dependent variable for ineligible individuals (the control group). Column (4) reports the program's effect from the quadratic RD polynomial model (Column 1) as a percentage of the mean of the dependent variable for ineligible individuals (Column 3). Column (5) reports the total number of observations, which correspond to 24,563 individuals for up to 54 post-application months. Standard errors clustered at the individual level in parentheses. ${ }^{*}$ significant at $10 \%$; $* *$ significant at $5 \%$; *** significant at $1 \%$. 
Table A.20: Heterogeneous Effects of AFAM Eligibility by Socio-Demographic Sub-Groups - Range of $[-0.15 ; 0.15]$ of the Eligibility Score

\begin{tabular}{|c|c|c|c|c|c|}
\hline \multirow{3}{*}{ Subgroups } & \multicolumn{4}{|c|}{ Polynomial Order } & \multirow[b]{2}{*}{ Obs. } \\
\hline & Linear & Quadratic & Cubic & Quartic & \\
\hline & $(1)$ & $(2)$ & $(3)$ & $(4)$ & $(5)$ \\
\hline Household head & $\begin{array}{c}-0.081^{* * *} \\
(0.011)\end{array}$ & $\begin{array}{c}-0.086 * * * \\
(0.016)\end{array}$ & $\begin{array}{c}-0.076^{* * *} \\
(0.021)\end{array}$ & $\begin{array}{c}-0.077^{* * *} \\
(0.027)\end{array}$ & $1,527,489$ \\
\hline Other HH. member & $\begin{array}{c}-0.075^{* * *} \\
(0.020)\end{array}$ & $\begin{array}{c}-0.081^{* * *} \\
(0.031)\end{array}$ & $\begin{array}{l}-0.017 \\
(0.042)\end{array}$ & $\begin{array}{l}-0.041 \\
(0.052)\end{array}$ & 426,974 \\
\hline Female applicants & $\begin{array}{c}-0.091^{* * *} \\
(0.011)\end{array}$ & $\begin{array}{c}-0.103^{* * *} \\
(0.016)\end{array}$ & $\begin{array}{c}-0.099 * * * \\
(0.022)\end{array}$ & $\begin{array}{c}-0.085^{* * *} \\
(0.027)\end{array}$ & $1,384,818$ \\
\hline Male applicants & $\begin{array}{c}-0.053^{* * *} \\
(0.018)\end{array}$ & $\begin{array}{l}-0.040 \\
(0.028)\end{array}$ & $\begin{array}{c}0.025 \\
(0.037)\end{array}$ & $\begin{array}{l}-0.028 \\
(0.048)\end{array}$ & 569,645 \\
\hline Two parent HH & $\begin{array}{c}-0.062^{* * *} \\
(0.014)\end{array}$ & $\begin{array}{c}-0.072^{* * *} \\
(0.022)\end{array}$ & $\begin{array}{l}-0.029 \\
(0.029)\end{array}$ & $\begin{array}{l}-0.035 \\
(0.037)\end{array}$ & 840,066 \\
\hline Single parent $\mathrm{HH}$ & $\begin{array}{c}-0.092^{* * *} \\
(0.013)\end{array}$ & $\begin{array}{c}-0.093^{* * *} \\
(0.019)\end{array}$ & $\begin{array}{c}-0.091^{* * *} \\
(0.026)\end{array}$ & $\begin{array}{c}-0.095^{* * *} \\
(0.032)\end{array}$ & $1,024,492$ \\
\hline Female heads & $\begin{array}{c}-0.097^{* * *} \\
(0.014)\end{array}$ & $\begin{array}{c}-0.111^{* * *} \\
(0.020)\end{array}$ & $\begin{array}{c}-0.118^{* * *} \\
(0.027)\end{array}$ & $\begin{array}{c}-0.115^{* * *} \\
(0.033)\end{array}$ & 897,481 \\
\hline Male heads & $\begin{array}{c}-0.054 \\
(0.039)\end{array}$ & $\begin{array}{c}0.027 \\
(0.059)\end{array}$ & $\begin{array}{c}0.097 \\
(0.080)\end{array}$ & $\begin{array}{c}0.050 \\
(0.104)\end{array}$ & 127,011 \\
\hline Low education & $\begin{array}{c}-0.064^{* * *} \\
(0.015)\end{array}$ & $\begin{array}{c}-0.071^{* * *} \\
(0.023)\end{array}$ & $\begin{array}{c}-0.057^{*} \\
(0.030)\end{array}$ & $\begin{array}{l}-0.015 \\
(0.039)\end{array}$ & 870,608 \\
\hline Medium-high education & $\begin{array}{c}-0.091^{* * *} \\
(0.012)\end{array}$ & $\begin{array}{c}-0.096 * * * \\
(0.018)\end{array}$ & $\begin{array}{c}-0.070 * * * \\
(0.024)\end{array}$ & $\begin{array}{c}-0.103^{* * *} \\
(0.030)\end{array}$ & $1,083,855$ \\
\hline Aged below 30 & $\begin{array}{c}-0.104^{* * *} \\
(0.020)\end{array}$ & $\begin{array}{c}-0.113^{* * *} \\
(0.029)\end{array}$ & $\begin{array}{c}-0.127^{* * *} \\
(0.039)\end{array}$ & $\begin{array}{c}-0.139 * * * \\
(0.048)\end{array}$ & 457,835 \\
\hline Aged 30 or more & $\begin{array}{c}-0.073^{* * *} \\
(0.011)\end{array}$ & $\begin{array}{c}-0.078^{* * *} \\
(0.016)\end{array}$ & $\begin{array}{c}-0.049^{* *} \\
(0.021)\end{array}$ & $\begin{array}{c}-0.054^{* *} \\
(0.027)\end{array}$ & $1,496,628$ \\
\hline
\end{tabular}

Notes: The sample corresponds to heads of households and spouses of heads of households aged 18 to 57 at the time of the AFAM application during the period January 2008 to September 2010, from households within a range of $[-0.15 ;+0.15]$ of the eligibility score. The dataset corresponds to the AFAM baseline application records (January 2008 to September 2010) matched with the registered employment work histories for the period January 2005 to December 2012 from the Social Security Administration's administrative records (see Section 4.4 for a detailed description of the data). Each row presents the regression estimates from the basic model in Equation (2) with covariates at time of application to the program as in the notes to Table 3. The regressions are estimated as linear probability models. In columns (1) and (2), the dependent variable is registered employment, measured as an indicator variable equal to one if the SSA records indicate that there are social security contributions from employment for the individual in a given calendar month, and zero otherwise. The coefficients correspond to the "Eligible" variable, an indicator equal to one if the individual belongs to a household eligible for the program according to the AFAM eligibility rules (i.e., if score $_{i}>0$ ), and zero otherwise. Each row presents results for registered employment during the post-application period for the corresponding subgroup. Column (1) presents results based on a quadratic RD polynomial estimated separately on either side of the eligibility threshold. Column (2) presents results from a linear RD polynomial estimated separately on either side of cutoff. Column (3) reports the mean for each dependent variable for ineligible individuals (the control group). Column (4) reports the program's effect from the quadratic RD polynomial model (Column 1) as a percentage of the mean of the dependent variable for ineligible individuals (Column 3). Column (5) reports the total number of observations, which correspond to 24,563 individuals for up to 54 post-application months. Standard errors clustered at the individual level in parentheses. ${ }^{*}$ significant at $10 \%$; $* *$ significant at $5 \%$; *** significant at $1 \%$. 
Table A.21: Heterogeneous Effects of AFAM Eligibility by Socio-Demographic Sub-Groups - Range of $[-0.2 ; 0.2]$ of the Eligibility Score

\begin{tabular}{|c|c|c|c|c|c|}
\hline \multirow{3}{*}{ Subgroups } & \multicolumn{4}{|c|}{ Polynomial Order } & \multirow[b]{2}{*}{ Obs. } \\
\hline & Linear & Quadratic & Cubic & Quartic & \\
\hline & $(1)$ & $(2)$ & $(3)$ & $(4)$ & $(5)$ \\
\hline Household head & $\begin{array}{c}-0.078^{* * *} \\
(0.009)\end{array}$ & $\begin{array}{c}-0.084^{* * *} \\
(0.014)\end{array}$ & $\begin{array}{c}-0.081^{* * *} \\
(0.019)\end{array}$ & $\begin{array}{c}-0.074^{* * *} \\
(0.023)\end{array}$ & $2,243,124$ \\
\hline Other HH. member & $\begin{array}{c}-0.080^{* * *} \\
(0.018)\end{array}$ & $\begin{array}{c}-0.066^{* *} \\
(0.027)\end{array}$ & $\begin{array}{c}-0.073^{* *} \\
(0.036)\end{array}$ & $\begin{array}{l}-0.019 \\
(0.045)\end{array}$ & 627,472 \\
\hline Female applicants & $\begin{array}{c}-0.085^{* * *} \\
(0.010)\end{array}$ & $\begin{array}{c}-0.098^{* * *} \\
(0.014)\end{array}$ & $\begin{array}{c}-0.103^{* * *} \\
(0.019)\end{array}$ & $\begin{array}{c}-0.093^{* * *} \\
(0.024)\end{array}$ & $2,031,387$ \\
\hline Male applicants & $\begin{array}{c}-0.064^{* * *} \\
(0.016)\end{array}$ & $\begin{array}{l}-0.036 \\
(0.024)\end{array}$ & $\begin{array}{c}-0.023 \\
(0.033)\end{array}$ & $\begin{array}{c}0.014 \\
(0.041)\end{array}$ & 839,209 \\
\hline Two parent HH & $\begin{array}{c}-0.069^{* * *} \\
(0.012)\end{array}$ & $\begin{array}{c}-0.058^{* * *} \\
(0.019)\end{array}$ & $\begin{array}{c}-0.066^{* * *} \\
(0.026)\end{array}$ & $\begin{array}{l}-0.026 \\
(0.032)\end{array}$ & $1,235,262$ \\
\hline Single parent $\mathrm{HH}$ & $\begin{array}{c}-0.080 * * * \\
(0.011)\end{array}$ & $\begin{array}{c}-0.096 * * * \\
(0.017)\end{array}$ & $\begin{array}{c}-0.091^{* * *} \\
(0.022)\end{array}$ & $\begin{array}{c}-0.086^{* * *} \\
(0.028)\end{array}$ & $1,502,249$ \\
\hline Female heads & $\begin{array}{c}-0.085^{* * *} \\
(0.012)\end{array}$ & $\begin{array}{c}-0.107 * * * \\
(0.018)\end{array}$ & $\begin{array}{c}-0.114^{* * *} \\
(0.023)\end{array}$ & $\begin{array}{c}-0.110^{* * *} \\
(0.029)\end{array}$ & $1,315,170$ \\
\hline Male heads & $\begin{array}{c}-0.041 \\
(0.034)\end{array}$ & $\begin{array}{c}-0.016 \\
(0.051)\end{array}$ & $\begin{array}{c}0.067 \\
(0.069)\end{array}$ & $\begin{array}{c}0.089 \\
(0.089)\end{array}$ & 187,079 \\
\hline Low education & $\begin{array}{c}-0.068^{* * *} \\
(0.013)\end{array}$ & $\begin{array}{c}-0.061^{* * *} \\
(0.020)\end{array}$ & $\begin{array}{c}-0.071^{* * *} \\
(0.027)\end{array}$ & $\begin{array}{c}-0.044 \\
(0.033)\end{array}$ & $1,324,719$ \\
\hline Medium-high education & $\begin{array}{c}-0.085^{* * *} \\
(0.011)\end{array}$ & $\begin{array}{c}-0.095^{* * *} \\
(0.016)\end{array}$ & $\begin{array}{c}-0.088^{* * *} \\
(0.021)\end{array}$ & $\begin{array}{c}-0.074^{* * *} \\
(0.026)\end{array}$ & $1,545,877$ \\
\hline Aged below 30 & $\begin{array}{c}-0.094^{* * *} \\
(0.017)\end{array}$ & $\begin{array}{c}-0.115^{* * *} \\
(0.026)\end{array}$ & $\begin{array}{c}-0.127^{* * *} \\
(0.034)\end{array}$ & $\begin{array}{c}-0.122^{* * *} \\
(0.042)\end{array}$ & 709,202 \\
\hline Aged 30 or more & $\begin{array}{c}-0.074^{* * *} \\
(0.009)\end{array}$ & $\begin{array}{c}-0.072^{* * *} \\
(0.014)\end{array}$ & $\begin{array}{c}-0.070 * * * \\
(0.019)\end{array}$ & $\begin{array}{c}-0.048^{* *} \\
(0.023)\end{array}$ & $2,161,394$ \\
\hline
\end{tabular}

Notes: The sample corresponds to heads of households and spouses of heads of households aged 18 to 57 at the time of the AFAM application during the period January 2008 to September 2010, from households within a range of $[-0.2 ;+0.2]$ of the eligibility score. The dataset corresponds to the AFAM baseline application records (January 2008 to September 2010) matched with the registered employment work histories for the period January 2005 to December 2012 from the Social Security Administration's administrative records (see Section 4.4 for a detailed description of the data). Each row presents the regression estimates from the basic model in Equation (2) with covariates at time of application to the program as in the notes to Table 3. The regressions are estimated as linear probability models. In columns (1) and (2), the dependent variable is registered employment, measured as an indicator variable equal to one if the SSA records indicate that there are social security contributions from employment for the individual in a given calendar month, and zero otherwise. The coefficients correspond to the "Eligible" variable, an indicator equal to one if the individual belongs to a household eligible for the program according to the AFAM eligibility rules (i.e., if score $_{i}>0$ ), and zero otherwise. Each row presents results for registered employment during the post-application period for the corresponding subgroup. Column (1) presents results based on a quadratic RD polynomial estimated separately on either side of the eligibility threshold. Column (2) presents results from a linear RD polynomial estimated separately on either side of cutoff. Column (3) reports the mean for each dependent variable for ineligible individuals (the control group). Column (4) reports the program's effect from the quadratic RD polynomial model (Column 1) as a percentage of the mean of the dependent variable for ineligible individuals (Column 3). Column (5) reports the total number of observations, which correspond to 24,563 individuals for up to 54 post-application months. Standard errors clustered at the individual level in parentheses. ${ }^{*}$ significant at $10 \%$; $* *$ significant at $5 \%$; *** significant at $1 \%$. 
Table A.22: Heterogeneous Effects of AFAM Eligibility by Socio-Demographic Sub-Groups - Range of $[-0.073 ; 0.073]$ of the Eligibility Score (Optimal Bandwidth)

\begin{tabular}{|c|c|c|c|c|c|}
\hline \multirow{3}{*}{ Subgroups } & \multicolumn{4}{|c|}{ Polynomial Order } & \multirow[b]{2}{*}{ Obs. } \\
\hline & Linear & Quadratic & Cubic & Quartic & \\
\hline & $(1)$ & $(2)$ & $(3)$ & $(4)$ & $(5)$ \\
\hline Household head & $\begin{array}{c}-0.090^{* * *} \\
(0.015)\end{array}$ & $\begin{array}{c}-0.071^{* * *} \\
(0.023)\end{array}$ & $\begin{array}{c}-0.071^{* *} \\
(0.031)\end{array}$ & $\begin{array}{c}-0.102^{* * *} \\
(0.039)\end{array}$ & 576,828 \\
\hline Other HH. member & $\begin{array}{c}-0.057^{*} \\
(0.030)\end{array}$ & $\begin{array}{l}-0.040 \\
(0.045)\end{array}$ & $\begin{array}{l}-0.055 \\
(0.060)\end{array}$ & $\begin{array}{l}-0.086 \\
(0.076)\end{array}$ & 165,291 \\
\hline Female applicants & $\begin{array}{c}-0.109^{* * *} \\
(0.016)\end{array}$ & $\begin{array}{c}-0.090^{* * *} \\
(0.023)\end{array}$ & $\begin{array}{c}-0.073^{* *} \\
(0.031)\end{array}$ & $\begin{array}{c}-0.109^{* * *} \\
(0.040)\end{array}$ & 521,760 \\
\hline Male applicants & $\begin{array}{l}-0.021 \\
(0.026)\end{array}$ & $\begin{array}{l}-0.003 \\
(0.040)\end{array}$ & $\begin{array}{l}-0.055 \\
(0.056)\end{array}$ & $\begin{array}{c}-0.068 \\
(0.071)\end{array}$ & 220,359 \\
\hline Two parent $\mathrm{HH}$ & $\begin{array}{c}-0.061^{* * *} \\
(0.021)\end{array}$ & $\begin{array}{l}-0.037 \\
(0.032)\end{array}$ & $\begin{array}{l}-0.016 \\
(0.043)\end{array}$ & $\begin{array}{l}-0.033 \\
(0.055)\end{array}$ & 324,561 \\
\hline Single parent $\mathrm{HH}$ & $\begin{array}{c}-0.098^{* * *} \\
(0.018)\end{array}$ & $\begin{array}{c}-0.086^{* * *} \\
(0.027)\end{array}$ & $\begin{array}{c}-0.111^{* * *} \\
(0.037)\end{array}$ & $\begin{array}{c}-0.154^{* * *} \\
(0.046)\end{array}$ & 381,836 \\
\hline Female heads & $\begin{array}{c}-0.117^{* * *} \\
(0.019)\end{array}$ & $\begin{array}{c}-0.108^{* * *} \\
(0.029)\end{array}$ & $\begin{array}{c}-0.128^{* * *} \\
(0.038)\end{array}$ & $\begin{array}{c}-0.182^{* * *} \\
(0.048)\end{array}$ & 333,301 \\
\hline Male heads & $\begin{array}{c}0.033 \\
(0.056)\end{array}$ & $\begin{array}{c}0.076 \\
(0.087)\end{array}$ & $\begin{array}{c}0.024 \\
(0.120)\end{array}$ & $\begin{array}{c}0.070 \\
(0.154)\end{array}$ & 48,535 \\
\hline Low education & $\begin{array}{c}-0.078^{* * *} \\
(0.022)\end{array}$ & $\begin{array}{l}-0.025 \\
(0.033)\end{array}$ & $\begin{array}{l}-0.024 \\
(0.044)\end{array}$ & $\begin{array}{l}-0.059 \\
(0.056)\end{array}$ & 316,240 \\
\hline Medium-high education & $\begin{array}{c}-0.089^{* * *} \\
(0.017)\end{array}$ & $\begin{array}{c}-0.090^{* * *} \\
(0.026)\end{array}$ & $\begin{array}{c}-0.094^{* * *} \\
(0.035)\end{array}$ & $\begin{array}{c}-0.124^{* * *} \\
(0.045)\end{array}$ & 425,879 \\
\hline Aged below 30 & $\begin{array}{c}-0.106^{* * *} \\
(0.028)\end{array}$ & $\begin{array}{c}-0.148^{* * *} \\
(0.042)\end{array}$ & $\begin{array}{c}-0.124^{* *} \\
(0.055)\end{array}$ & $\begin{array}{c}-0.146^{* *} \\
(0.068)\end{array}$ & 160,578 \\
\hline Aged 30 or more & $\begin{array}{c}-0.076^{* * *} \\
(0.015)\end{array}$ & $\begin{array}{c}-0.045^{*} \\
(0.023)\end{array}$ & $\begin{array}{c}-0.054^{*} \\
(0.031)\end{array}$ & $\begin{array}{c}-0.086^{* *} \\
(0.040)\end{array}$ & 581,541 \\
\hline
\end{tabular}

Notes: The sample corresponds to heads of households and spouses of heads of households aged 18 to 57 at the time of the AFAM application during the period January 2008 to September 2010, from households within a range of $[-0.073 ;+0.073]$ of the eligibility score. The dataset corresponds to the AFAM baseline application records (January 2008 to September 2010) matched with the registered employment work histories for the period January 2005 to December 2012 from the Social Security Administration's administrative records (see Section 4.4 for a detailed description of the data). Each row presents the regression estimates from the basic model in Equation (2) with covariates at time of application to the program as in the notes to Table 3. The regressions are estimated as linear probability models. In columns (1) and (2), the dependent variable is registered employment, measured as an indicator variable equal to one if the SSA records indicate that there are social security contributions from employment for the individual in a given calendar month, and zero otherwise. The coefficients correspond to the "Eligible" variable, an indicator equal to one if the individual belongs to a household eligible for the program according to the AFAM eligibility rules (i.e., if score $\left._{i}>0\right)$, and zero otherwise. Each row presents results for registered employment during the post-application period for the corresponding subgroup. Column (1) presents results based on a quadratic RD polynomial estimated separately on either side of the eligibility threshold. Column (2) presents results from a linear RD polynomial estimated separately on either side of cutoff. Column (3) reports the mean for each dependent variable for ineligible individuals (the control group). Column (4) reports the program's effect from the quadratic RD polynomial model (Column 1) as a percentage of the mean of the dependent variable for ineligible individuals (Column 3). Column (5) reports the total number of observations, which correspond to 24,563 individuals for up to 54 post-application months. Standard errors clustered at the individual level in parentheses. ${ }^{*}$ significant at $10 \% ; * *$ significant at $5 \%$; ** significant at $1 \%$. 


\section{A.4 Additional Results: Figures}

\section{A.4.1 Timing of Application to AFAM}

Figure A.1: Distribution of Households by AFAM Application Date, January 2008 to December 2009

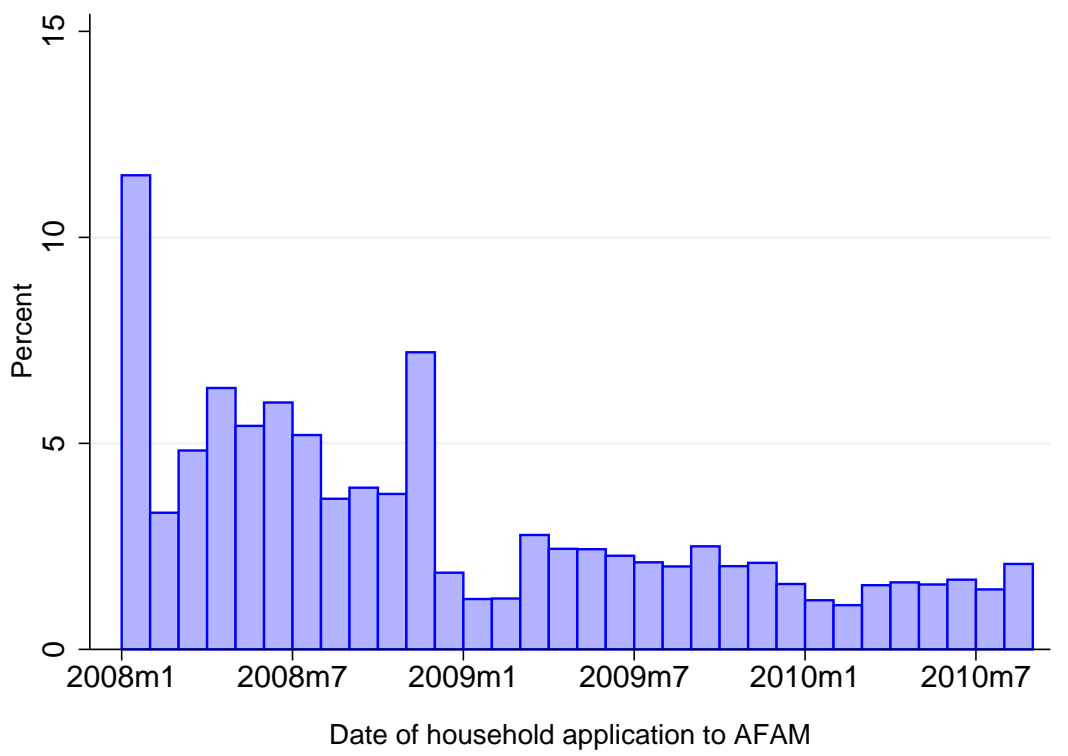

Notes: The sample corresponds to the entire population of applicant households with adults aged 18 to 57 at the time of the AFAM application during the period January 2008 to September 2010. The dataset corresponds to the AFAM baseline application records (January 2008 to September 2010). The outcome variable is date of application to AFAM defined as the month and year of household application date. 


\title{
A.4.2 Balance Figures for Baseline Characteristics
}

\author{
Figure A.2: Covariates RD Plots
}

a) Female applicant (\%)

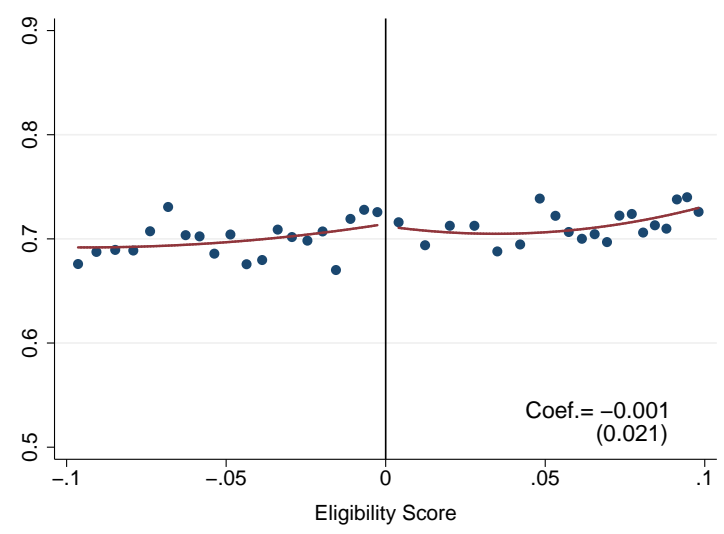

c) Female head (within heads) (\%)

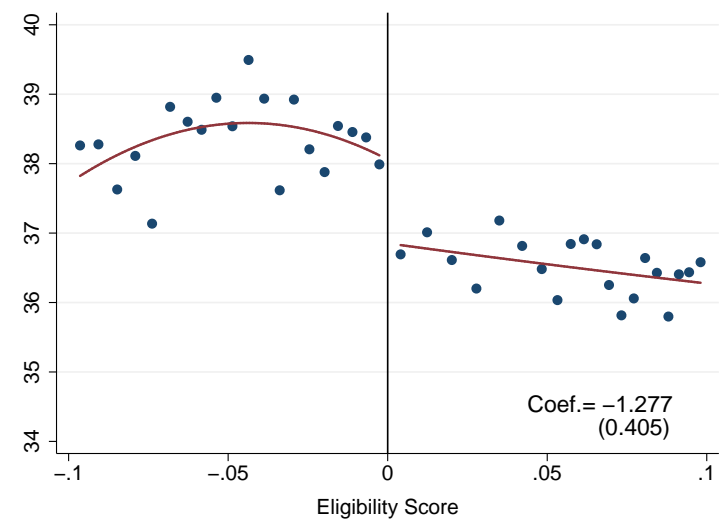

e) Married/in couple (\%)

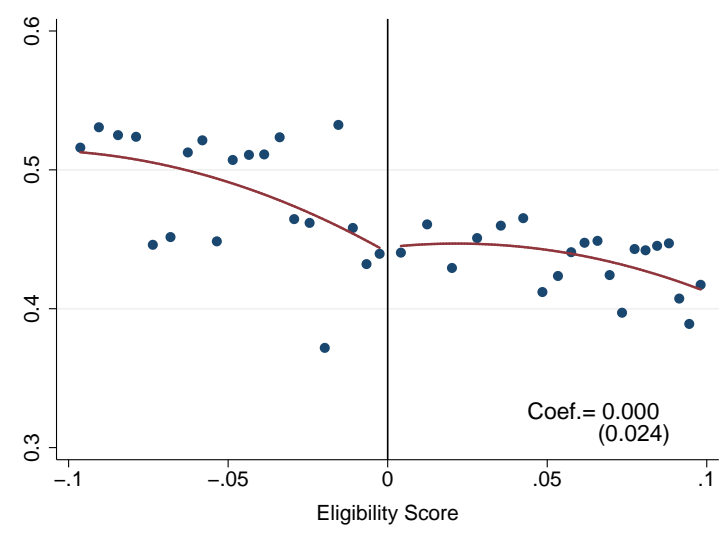

b) Household head (\%)

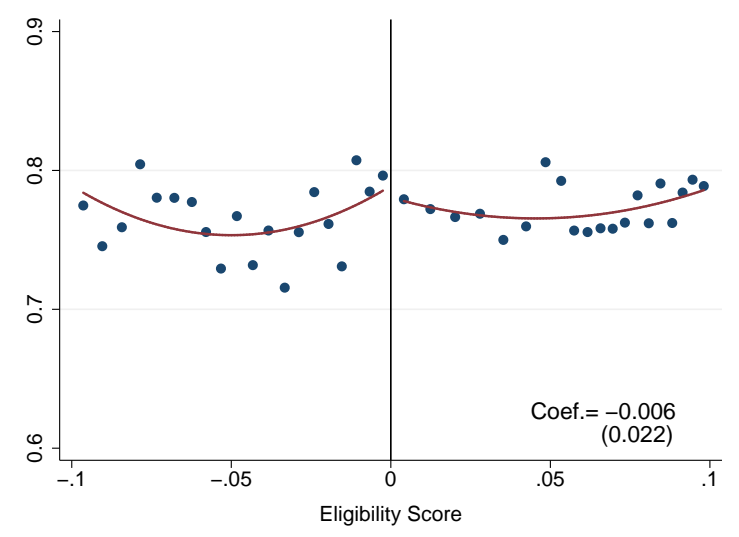

d) Age at AFAM application

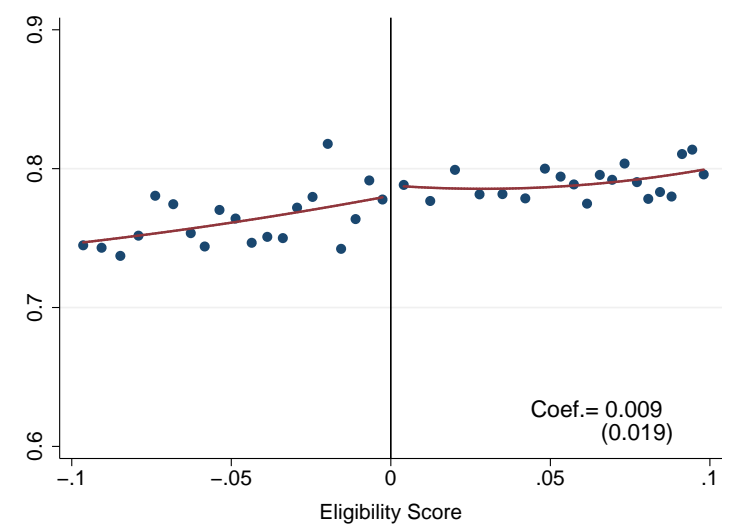

f) Missing married/in couple: (\%)

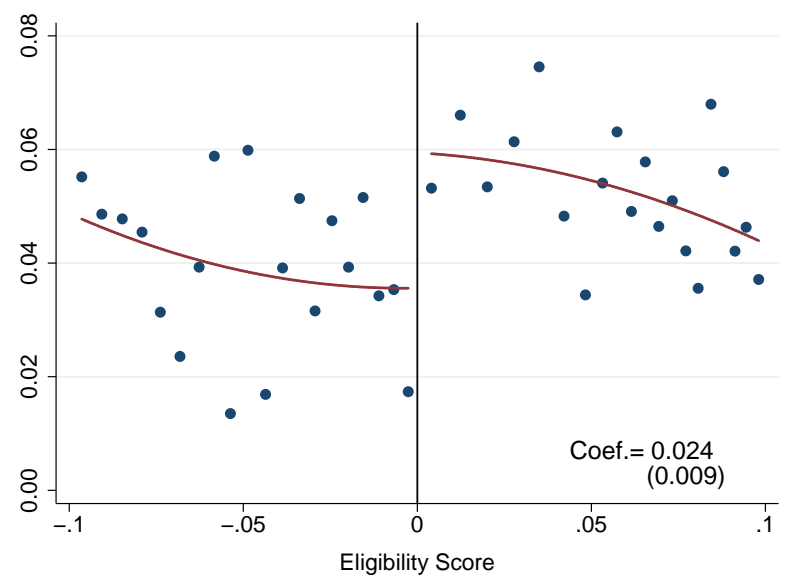

Notes: These figures plot pre-application characteristics against the eligibility score. The sample corresponds to heads of households and spouses of heads of households aged 18 to 57 at the time of application to AFAM during the period January 2008 to September 2010, from households within a range of $[-0.1 ;+0.1]$ of the eligibility score. The dataset corresponds to the AFAM baseline application records (January 2008 to September 2010). The eligibility score is standardized so that the eligibility threshold is zero, with positive scores indicating individuals in eligible households and negative scores indicating individuals in ineligible households. Each point (blue circle) in the plot represents the average value of the outcome variable in eligibility score bins with a width one half of a percentage point. The red solid line plots predicted values from a second degree polynomial model estimated at each side of the eligibility threshold. "Coef." reports the estimated coefficient (and its corresponding standard error in parenthesis) from a quadratic polynomial RD regression without additional covariates. 
a) Single mother (within singles) $(\%)$

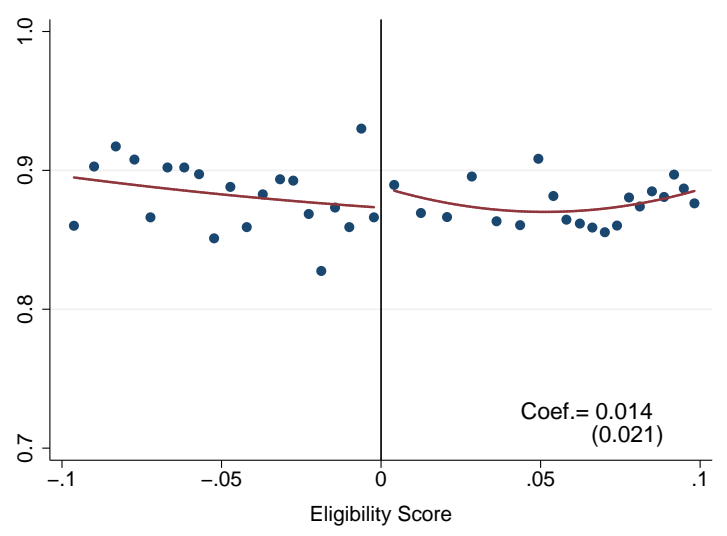

c) Less than primary $(\%)$

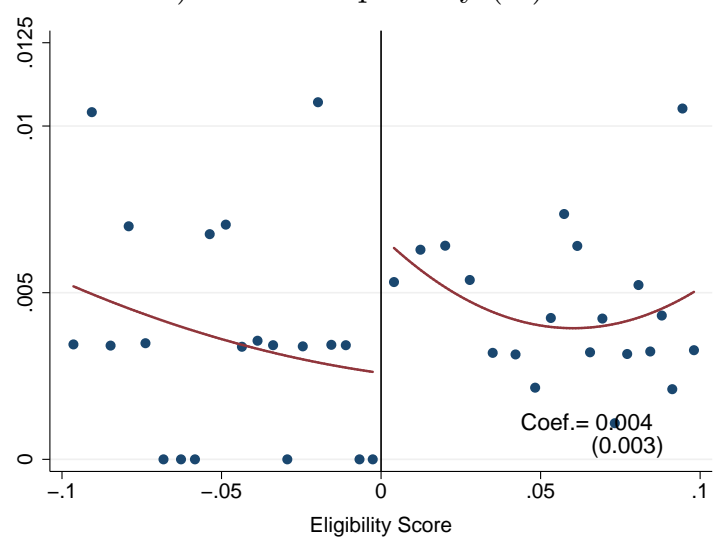

e) Secondary or more $(\%)$

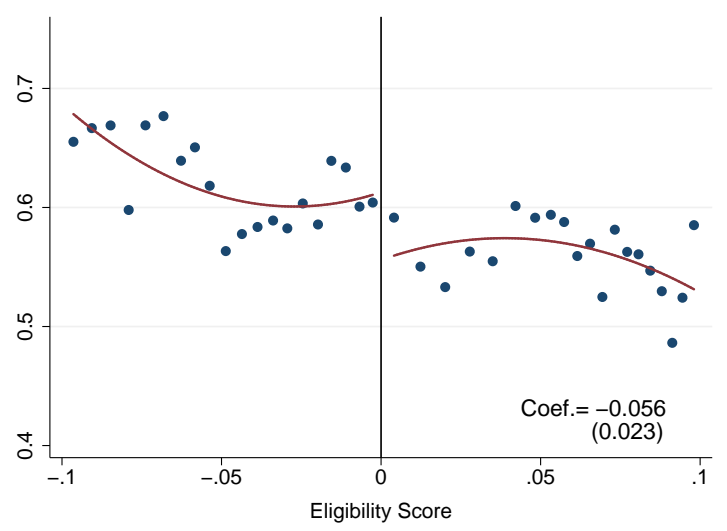

b) Numb. of children

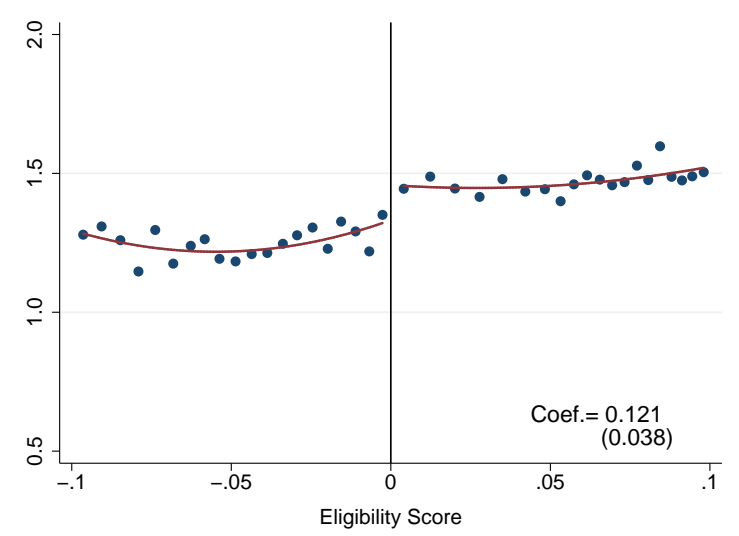

d) Complete primary $(\%)$

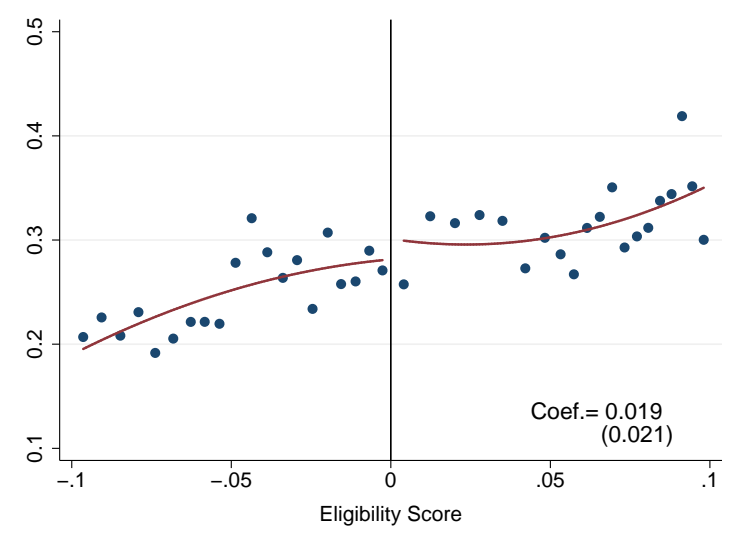

f) Missing education (\%)

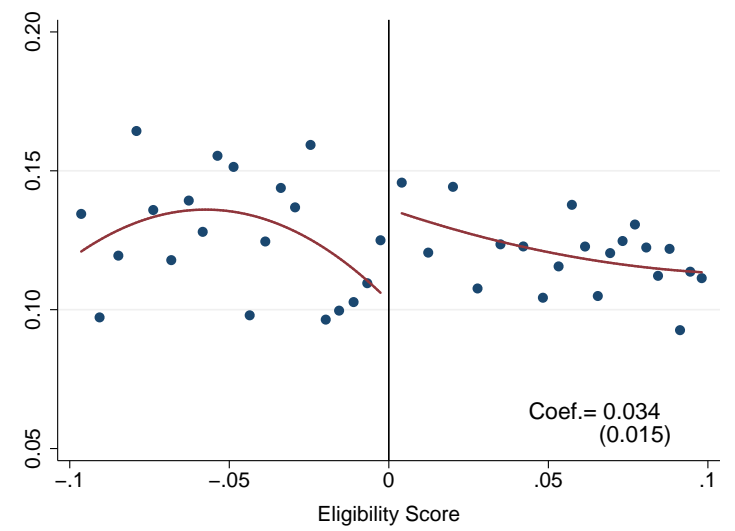

Notes: These figures plot pre-application characteristics against the eligibility score. The sample corresponds to heads of house$\overline{\text { holds }}$ and spouses of heads of households aged 18 to 57 at the time of application to AFAM during the period January 2008 to September 2010, from households within a range of $[-0.1 ;+0.1]$ of the eligibility score. The dataset corresponds to the AFAM baseline application records (January 2008 to September 2010). The eligibility score is standardized so that the eligibility threshold is zero, with positive scores indicating individuals in eligible households and negative scores indicating individuals in ineligible households. Each point (blue circle) in the plot represents the average value of the outcome variable in eligibility score bins with a width one half of a percentage point. The red solid line plots predicted values from a second degree polynomial model estimated at each side of the eligibility threshold. "Coef." reports the estimated coefficient (and its corresponding standard error in parenthesis) from a quadratic polynomial RD regression without additional covariates. 
Figure A.4: Covariates RD Plots

a) Enrolled in PANES (\%)

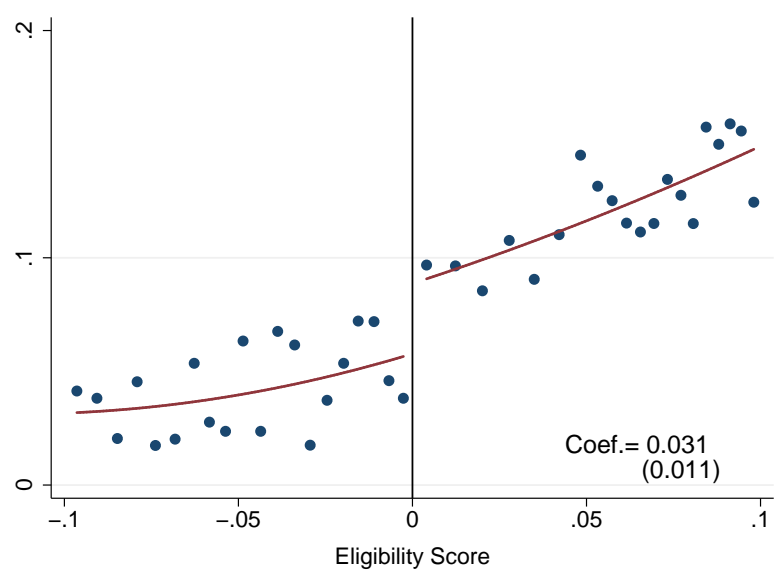

b) Montevideo (capital city) (\%)

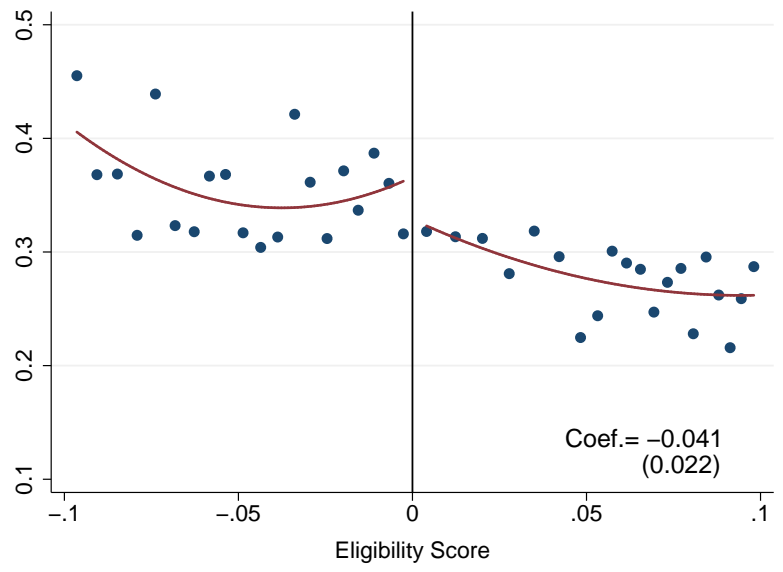

c) Employed before application (\%)

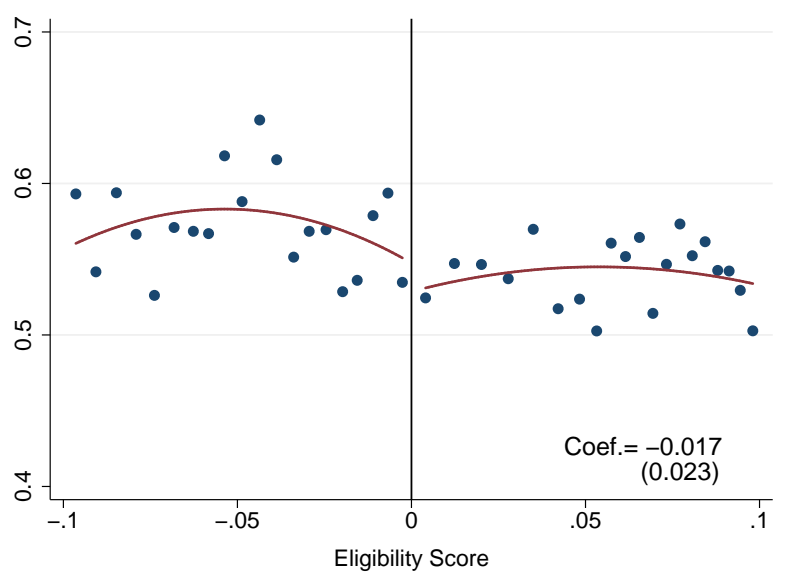

Notes: These figures plot pre-application characteristics against the eligibility score. The sample corresponds to heads of households and spouses of heads of households aged 18 to 57 at the time of application to AFAM during the period January 2008 to September 2010, from households within a range of $[-0.1 ;+0.1]$ of the eligibility score. The dataset corresponds to the AFAM baseline application records (January 2008 to September 2010). The eligibility score is standardized so that the eligibility threshold is zero, with positive scores indicating individuals in eligible households and negative scores indicating individuals in ineligible households. Each point (blue circle) in the plot represents the average value of the outcome variable in eligibility score bins with a width one half of a percentage point. The red solid line plots predicted values from a second degree polynomial model estimated at each side of the eligibility threshold. "Coef." reports the estimated coefficient (and its corresponding standard error in parenthesis) from a quadratic polynomial RD regression without additional covariates. 


\section{A.4.3 Balance Figure for the Predicted Registered Employment Rate}

Figure A.5: RD Plot for Predicted Registered Employment

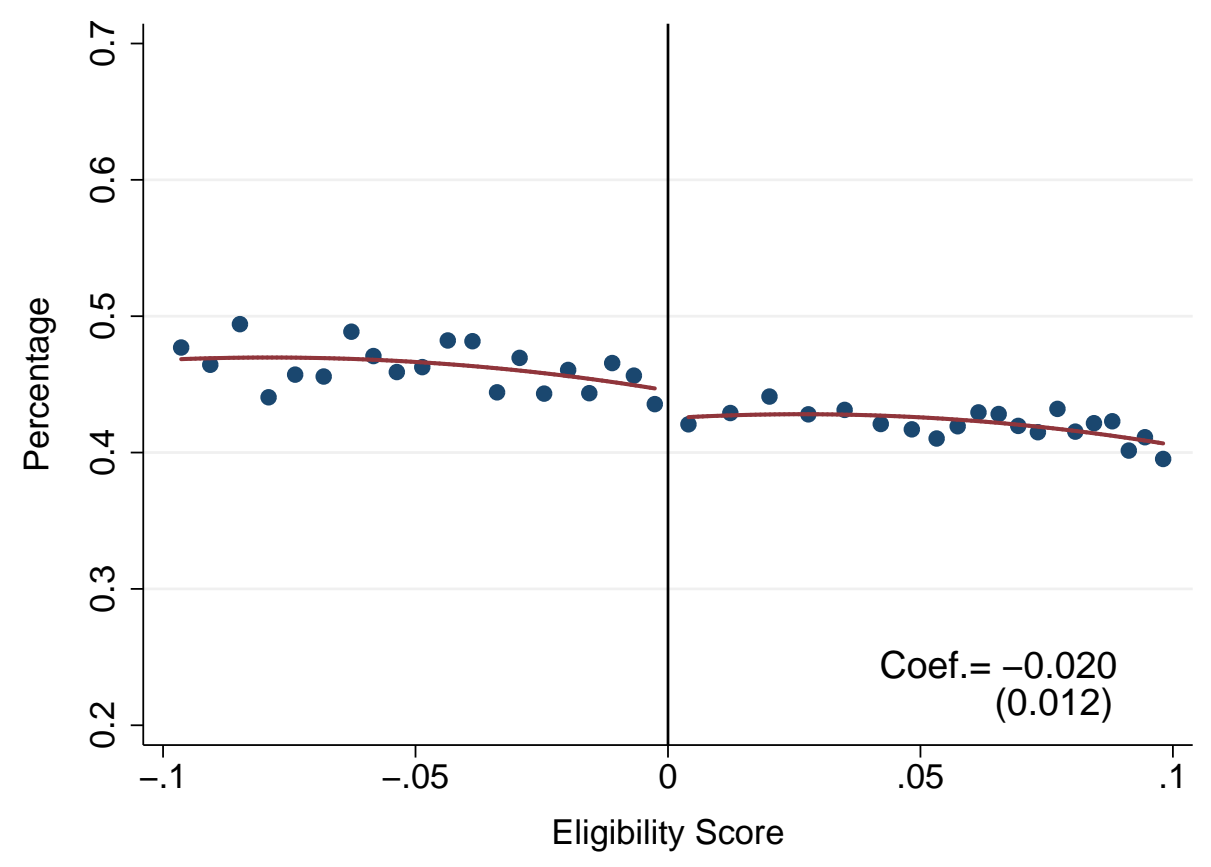

Notes: This figure plots predicted registered employment against the eligibility score. The sample corresponds to heads of households and spouses of heads of households aged 18 to 57 at the time of application to AFAM during the period January 2008 to September 2010, from households within a range of $[-0.1 ;+0.1]$ of the eligibility score. The dataset corresponds to the AFAM baseline application records (January 2008 to September 2010) matched with the registered employment work histories for the period January 2005 to December 2012 from the Social Security Administration's administrative records. The registered employment measure is predicted using the characteristics in Table 2 and pre-period registered employment data. The eligibility score is standardized so that the eligibility threshold is zero, with positive scores indicating individuals in eligible households and negative scores indicating individuals in ineligible households. Each point (blue circle) in the plot represents the average value of the outcome variable in eligibility score bins with a width one half of a percentage point. The red solid line plots predicted values from a second degree polynomial model estimated at each side of the eligibility threshold. "Coef." reports the estimated coefficient (and its corresponding standard error in parenthesis) from a quadratic polynomial RD regression without additional covariates. 


\section{A.4.4 McCrary Test}

Figure A.6: Distribution of the Assignment Variable and the McCrary Test

a) Eligibility Score (Assignment Variable)

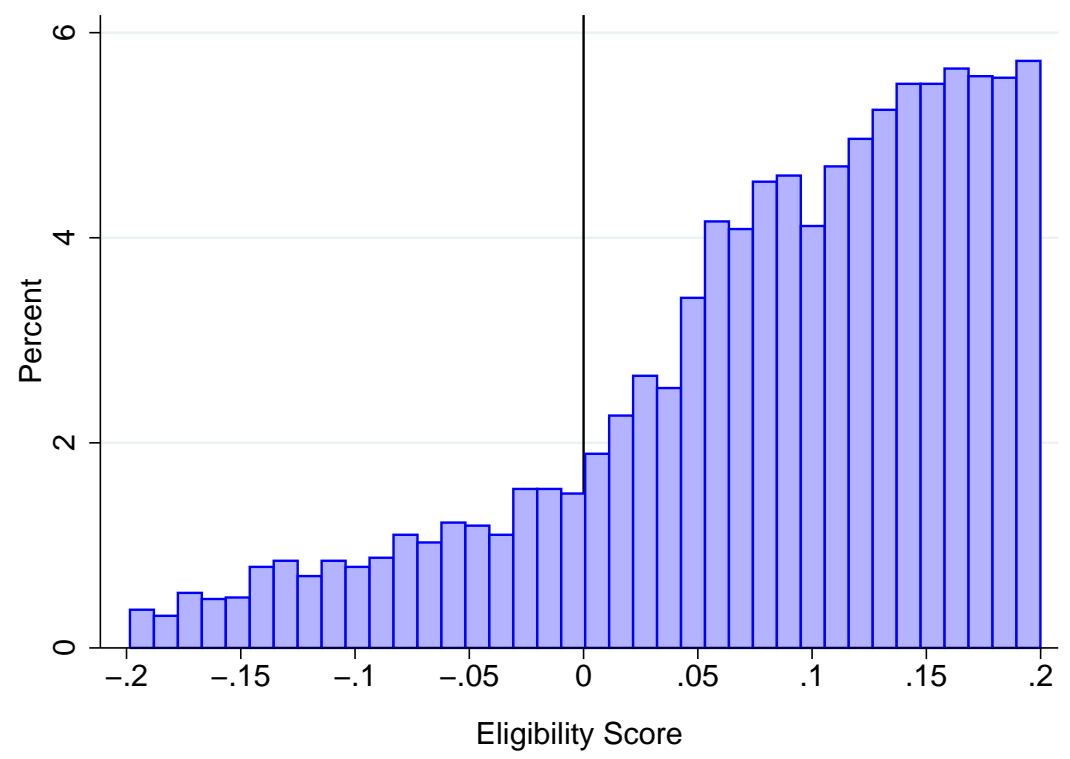

b) McCrary's Density Test

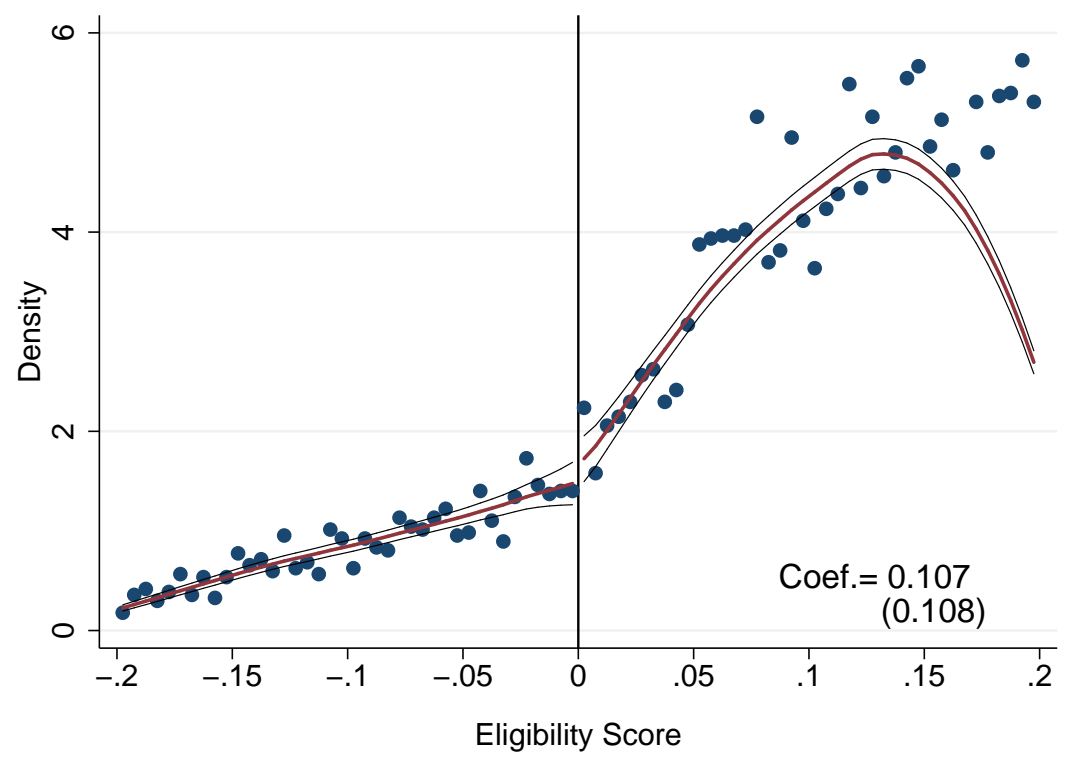

Notes: The sample corresponds to the entire population of applicant households with adults aged 18 to 57 at the time of the AFAM application during the period January 2008 to September 2010. The dataset corresponds to the AFAM baseline application records (January 2008 to September 2010). Figure a shows the histogram of the eligibility score distribution in bins with a width one percentage point. Figure b plots the eligibility score density in bins with a width one half of a percentage point. The solid red line plots predicted values from a local linear regression (with a width one half of a percentage point) with separate score trends estimated either side of the eligibility threshold. The dashed lines show $95 \%$ confidence intervals. The bandwidth is chosen using the Imbens-Kalyanaraman bandwidth selection rule (2012), and we use a rectangular kernel. 